\title{
STUDIES \\ in \\ in
}

AFRIGAN LINGUISTICS

\section{JULY 1970 Volume 1, Number 2}


Published by the Department of Linguistics and the African Studies Center

The University of California, Los Angeles

Editorial Board

Karen Courtenay

Victoria Fromkin

Larry M. Hyman

Peter Ladefoged

Frederick Longan

Charles Kraft

Thomas Penchoen

Paul Schachter

Erhard Voeltz

William E. Welmers
Copy Editor

Leon Jacobson

Editorial Assistance

Theodora Graham

Alice McGaughey

Editor

Talmy Givón

Subscription: U.S. and Canada: $\$ 6.00$ per volume (three issues)

$$
\begin{array}{ll}
\text { Overseas: } & \$ 7.00 \text { per volume (air mail) } \\
\text { Single issue: } & \$ 2.50
\end{array}
$$

Make checks payable to: African Studies Center

Studies in African Linguistics is published three times a year.

For subscription and editorial information please write:

The Editor, Studies in African Linguistics

c/o Department of Linguistics

University of California

Los Angeles, California 90024

$$
\text { Volume 1, Number 2, July } 1970
$$

Copyright 1970

by The Regents of The University of California 


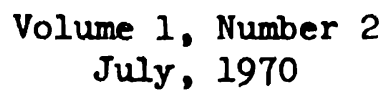

TABLE OF CONTENTS

Page

James D. McCawley, A NOTE ON TONE IN TIV CONJUNCTION ........... 123

Benji Wald, RELATIVIZATION IN UMBUNDU . . . . 131

Livingstone Walusimbi and Talmy Givón, CONJOINED AND STACKED RESTRICTIVE CLAUSES: DEEP AND NOT-SO-DEEP CONSTRAINTS IN LIGHT OF LUGANDA DATA • • . . . . . . • • 157

Larry M. Hyman, Erhard F. K. Voeltz and Georges Tchokokam, NOUN CLASS LEVELLING IN BAMILEKE •. . . . . . . . 185

Tim Shopen and Mamadou Konaré, SONRAI CAUSATIVES AND PASSIVES: TRANSFORMATIONAL VERSUS LEXICAL DERIVATIONS FOR PROPOSITIONAL HEADS • • • • • • • • • • • • • 211 



\title{
A NOTE ON TONE IN TIV CONJUGATION
}

\author{
James D. McCawley \\ Department of Linguistics \\ University of Chicago
}

It is well established that many cases of downstep must be derived syachronically from an underlying high-low-high sequence as follows:

a. Specific tone levels are assigned to high and low tones by means of rules whereby consecutive highs are on the same pitch, consecutive lows are on the same pitch, and the interval down from a high to a following low exceeds the interval up from a low to a following high (i.e. highs are 'lowered' after a low), b. Certain low tones are then either removed or assimilated to the level of a following high or (less commonly) a preceding high.

For example, 1

Twi :

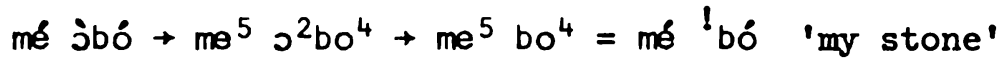
[Schachter and Fromkin 1968:110]

Tonga: $\quad$ bàlíbàlángì dè $\rightarrow \mathrm{ba}^{2} \mathrm{li} \mathrm{i}^{5} \mathrm{ba}^{1} \mathrm{la} \mathrm{a}^{4} \mathrm{ngi}{ }^{0} \mathrm{de} \mathrm{e}^{0} \rightarrow$

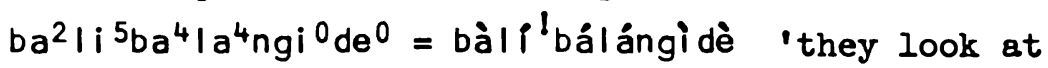
them' [Meeussen 1963:73]

Shambala: mivi mihyá $\rightarrow \mathrm{mi}^{2} v i^{5} \mathrm{mi}^{1} h y a^{4} \rightarrow \mathrm{mi}^{2} v i^{5} \mathrm{mi}^{5} \mathrm{hya} \mathrm{a}^{4}=$ mivi mi' hyá 'new arrows' [Spaandonck 1967:47]. The example of deletion in Twi involved deletion of the syllable that bore the low tone responsible for the lowering of the subsequent highs. A hypothetical example where a tone rather than its bearer was deleted would be bâmá $\rightarrow \mathrm{ba}^{5-2} \mathrm{ma}^{4} \rightarrow \mathrm{ba}^{5} \mathrm{ma}^{4}$, in which one of a sequence of tones on the same syllable is lost but the syllable otherwise remains unchanged. In this note I will explore the consequences of analysing

${ }^{1}$ The underlying forms are quoted directly from the respective authors, though not (except in the Twi example) the intermediate stages. The superscript numerals indicate relative pitch levels, higher numbers corresponding to higher pitches. I follow the standard practise of using for high tone, for low, l for downstep, "for a high-low fall, and for a low-high rise. 
downstep in Tiv as arising from deleted low tones which in underlying structure are parts of tone sequences on single syllables. My source of data and of many features of the analysis will be Arnott's important paper of 1964.

Arnott presents examples both of downstep contributed by the item following the downstep and of downstep contributed by the item preceding the downstep, e.g.
(1) i lú kwá
gá 'It was not a ring of huts'
it was ring of huts not
i lú 'kwá gá
'It was not a leaf'
it was leaf not
(2) $\uparrow$ lú tóhó gá 'It was not grass' it was grass not
ká 'tóhó gá 'It is not grass'
it is grass not

To derive these forms, Arnott set up underlying forms with preposed and postposed downsteps, which I propose to reinterpret as follows:

$\begin{array}{ccl}\text { Arnott } & \text { reinterpretation } & \\ \text { kwá } & \text { kwá } & \text { 'ring of huts' } \\ \text { ! kwá } & \text { kwă } & \text { 'leaf' } \\ \text { lú } & \text { lú } & \text { recent past copula } \\ k a ́ ! & \text { kâ } & \text { 'it is' }\end{array}$

The reinterpretation makes it necessary to have rules which eliminate the low part of a rising or falling tone sequence on a single syllable. Since the only rising tones in Tiv are on syllables ending in a sonorant or a voiced spirant (e.g. běr 'pond' [Abraham 1940:3] and since the formulation of tonal rules for conjugation will provide reason for treating such final sonorants and voiced spirants as if they were separate syllables with their own tone (e.g. bĕr = bèr), Tiv must be analysed as having no surface rising-toned syllables. Thus, a rule which deleted the low part of underlying rising-toned syllables such as I propose for / kwă/ 'leaf' would not affect anything other than what $I$ want it to affect. 
There do exist true falling-toned syllables in Tiv, so that there can not simply be a rule which deletes the low part of every high-low sequence on a single syllable. However, Arnott points out that precisely the words which contribute a following downstep when followed by a high pitch are pronounced with a final falling pitch when at the end of a phrase, ${ }^{2}$ e.g.

\section{mbá 'kásév 'there are women' \\ kásév mbâ 'there are women'}

Thus, the rule deleting the low part of a high-low sequence on a single syllable is only applicable non-finally, and my underlying form for items contributing a following downstep is identical with their phrasefinal alternant.

The proposal to use combinations of high and low to represent downstep allows appreciable simplification in the rules which assign tone to the various forms of the verb. I have reproduced in Table 1, with slight differences in notation and layout, the tabulation of tones given by Arnott for high-toned and low-toned verbs of one, two, and three syllables. I have ignored the distinction between the large H's and L's which Arnott used to represent the tones on full syllables and the small H's and L's which he used to represent tones on the tone-bearing final voiced consonants which occur in four of the tenses, e.g. Yévésén 'used to run away'. I have also treated the geminate vowels of the Habitual 3, Habitual 4, and Past Habitual of monosyllabic verbs as units. Thus, I treat váán 'comes (Habitual 3)' as exemplifying the formula HH rather than Arnott's $\mathrm{HH}$.

Consider first the General Past. The downstep plus high of the first syllable of high-toned verbs will be represented as a low-high sequence on that syllable. Since the low tone on the first syllable of low-toned verbs can equally well be represented as a sequence of two low tones on that syllable, the following generalization can be made

${ }^{2}$ Except, of course, that for syntactic reasons certain items such as /kâ/ 'it is' can never occur in phrase-final position. 


\begin{tabular}{|c|c|c|c|c|c|c|}
\hline & 1-sy] & able & 2-syllal & ble & 3-syllable & \\
\hline & High & Low & High & Low & High & Low \\
\hline General Past & $!_{H}$ & $\mathrm{I}$ & $!_{\mathrm{H}} \mathrm{L}$ & L L & $!_{\mathrm{H}} \mathrm{L} \mathrm{L}$ & L L L \\
\hline Recent Past A & $t_{\mathrm{H}}$ & $\mathfrak{l}_{\mathrm{H}}$ & $\mathfrak{l}_{\mathrm{H} \mathrm{H}}$ & L $\mathrm{H}$ & $!_{\mathrm{H} \mathrm{H} \mathrm{L}}$ & L H L \\
\hline Recent Past B & $\mathrm{H}$ & $\mathrm{H}$ & $\mathrm{H} \mathrm{H}$ & $\mathrm{H}{ }^{\prime}{ }_{\mathrm{H}}$ & $\mathrm{H} \mathrm{H} \mathrm{L}$ & $\mathrm{H} \mathrm{H} \mathrm{L}$ \\
\hline Subjunctive & & & same as & Recent & Past $B$ & \\
\hline Habitual 1 & & & $!_{\mathrm{H}} \mathrm{H}$ & L $\mathrm{H}$ & $\mathrm{H} \mathrm{H} \mathrm{L}$ & $\mathrm{L} \mathrm{H} \mathrm{I}$ \\
\hline Habitual 2 & $!_{\mathrm{H}} !$ & $!_{H} !$ & $!_{\mathrm{H} \mathrm{H}} !^{!}$ & $\mathrm{L} \mathrm{H}^{!}$ & $!_{\mathrm{H} \mathrm{H} \mathrm{H}}$ & nexistant \\
\hline Habitual 3 & $\mathrm{l}_{\mathrm{H} \mathrm{H}}$ & $!_{\mathrm{H} \mathrm{H}}$ & $!_{\mathrm{H} \mathrm{H} \mathrm{H}}$ & $\mathrm{L} \mathrm{H} \mathrm{H}$ & $!_{\mathrm{H} H ~ H}(\mathrm{H})$ & $\mathrm{L} \mathrm{H} \mathrm{H}(\mathrm{H})$ \\
\hline Habitual 4 & $\mathrm{H} \mathrm{L}$ & $\mathrm{H} \mathrm{L}$ & $\mathrm{H} \mathrm{H} \mathrm{L}$ & $\mathrm{H} \mathrm{H} \mathrm{L}$ & $\mathrm{H} \mathrm{H} \mathrm{H} \mathrm{L}$ & $\mathrm{H} \mathrm{H} \mathrm{L}$ \\
\hline Past Habitual & ${ }^{\prime} \mathrm{H} \mathrm{L}$ & ${ }^{d} \mathrm{H} \mathrm{L}$ & ${ }^{!} \mathrm{H} \mathrm{H} \mathrm{L}$ & $\mathrm{L} \mathrm{H} \mathrm{L}$ & ${ }^{l_{\mathrm{H} \mathrm{H} \mathrm{H} \mathrm{I}}}$ & $\mathrm{L} \mathrm{H} \mathrm{H} \mathrm{L}$ \\
\hline Continuous & $\mathrm{H} \mathrm{L}$ & $\mathrm{H} \mathrm{L}$ & $\mathrm{H} \mathrm{L} \mathrm{L}$ & $\mathrm{H} \mathrm{L} \mathrm{L}$ & $\mathrm{H} \mathrm{L} \mathrm{L}$ & $\mathrm{H} \mathrm{L} \mathrm{L}$ \\
\hline Imperative & $\mathrm{H}$ & $\mathrm{H}$ & $\mathrm{H} \mathrm{L}$ & $\mathrm{L} \mathrm{H}$ & $\mathrm{H} \mathrm{H} \mathrm{L}$ & $\mathrm{L} \mathrm{H} \mathrm{L}$ \\
\hline Future & ${ }^{\prime} \mathrm{H}$ & $\mathrm{L}$ & $\mathrm{H} \mathrm{L}$ & L L & $\mathrm{H} \mathrm{L} \mathrm{L}$ & L L L \\
\hline
\end{tabular}

\section{Table 1}

about General Pasts: the first syllable has a low tone plus the basic tone of the verb (i.e. high in the case of a high-toned verb and low in the case of a low-toned verb), and any subsequent syllables are on a low tone. I summarize this generalization with the formula $\hat{\mathrm{LB}} \mathrm{L}_{\mathrm{O}}$. In this formula, the tie indicates being in the same syllable, and the subscript 0 , to be read 'zero or more', means that if there are any subsequent syllables, lows are to be put on all of them.

Consider now the Recent Past A. Disyllabic verbs obviously fit the formula $\widehat{L B} \mathrm{H}$ and trisyllabic verbs the formula $\widehat{\mathrm{LB}} \mathrm{H} \mathrm{L}$. A single formula which covers both of these cases and also the monosyllabic case can be set up by regarding the $\hat{H B}$ and $H$ of the last two formulas as obligatorily present in the Recent Past A but the $L$ of the trisyllabic case as merely filling up leftover syllables. If $\widehat{L B}$ and $H$ were combined on a single syllable, ' $\mathrm{H}$ would result regardless of whether $B$ were $H$ or $L$ : both LHH and LLH would bring about lowering of the H('s), and the rule about deleting the low part of a rising tonal sequence would leave the equivalent results ${ }^{\prime} \mathrm{HH}$ and ${ }^{H}$. Thus, the following formula covers all 
Recent Past $A^{\prime} s$, regardless of number of syllables: $\hat{\mathrm{LB}} \mathrm{H} \mathrm{L} \mathrm{L}_{\mathrm{O}}$. The proper interpretation of these formulas requires the convention that when $a$ formula containing two syllables worth of obligatory tonal material is applied to a monosyllabic form, these tones are stuck together on that single syllable (NB: tones with the subscript 0 are not involved in this convention: they are only assigned to whatever syllables are left over after the obligatory material has been assigned).

A single formula is also possible for the Habitual 3. Since the first syllable of disyllabic and trisyllabic verbs can be interpreted as $\widehat{L B}$ and the subsequent syllables are all high, the formula $\widehat{L B} H_{0}$ suggests itself. That formula will not do for the monosyllabic case, since it would incorrectly predict * $\mathrm{L} \mathrm{H}$ for a monosyllabic low-toned verb. To get a formula that covers this case too, it is necessary to regard two $H^{\prime}$ 's as obligatorily present in this tense and only the final $H$ of trisyllabic verbs as 'filler' material. The formula is thus $\widehat{\mathrm{IB}} \mathrm{HH} \mathrm{H}_{0}$ ' The convention about combining tones on a single syllable if there are not enough separate syllables to accomodate them will have to be refined slightly in order to insure correct application of this formula to monosyllabic verbs (NB: a monosyllabic verb has a disyllabic Habitual 3): when three syllables worth of obligatory material is distributed over two syllables, it is necessary to combine the tone in the middle with the preceding tone rather than the following tone, since otherwise ${ }^{*} \mathrm{~L} H$ would result as the Habitual 3 of a monosyllabic low-toned verb.

In six of the twelve tenses, a single formula covers all cases, and in three of the remaining tenses a formula covering two of the three verb lengths is possible. As in the formulas given on page 49 of Arnott, it is nowhere necessary to give separate formulas for high-toned and lowtoned verbs, and in only one instance (the imperative of disyllabic verbs) is it necessary to resort to an at all ad-hoc notational device to avoid treating high-toned and low-toned verbs by different formulas. The formulas are: 
General Past $\quad \widehat{\mathrm{LB}} \mathrm{L}_{\mathrm{O}}$

Recent Past $\mathrm{A} \quad \widehat{\mathrm{LB}} \mathrm{H} \mathrm{L}_{\mathrm{O}}$

Recent Past B H (1-syll), H $\widehat{B H}$ (2-syll), H H L (3-syll)

Subjunctive

(same as Recent Past B)

Habitual 1

$\widehat{\mathrm{IB}} \mathrm{H}$, except $\mathrm{BH} \mathrm{L}$ (3-syll)

Habitual 2

$\widehat{\mathrm{LB}} \widehat{\mathrm{HL}}$, except $\widehat{\mathrm{LB}} \mathrm{HH}$ (3-syll)

Habi tual 3

$\mathrm{LB} H \mathrm{HH}_{0}$

Habitual 4

$\mathrm{H}_{\mathrm{O}} \mathrm{L}$

Past Habitual $\widehat{\mathrm{LB} H ~ H} \mathrm{H}$

Continuous

H L

Imperative

H (1-syll), B $\bar{B}$ (2-syll; $\bar{B}=$ opposite of basic tone), B H L (3-syll)

Future

$B L_{O}$, except $\widehat{L B}$ (l-syll).

The treatment of downstep in Tiv as arising from the lowering effect of underlying low tones that are eventually deleted partially explains one striking feature of the Tiv verb paradigms, namely that there are several tenses in which the contrast between high-toned and low-toned verbs is neutralized only in monosyllabic verbs, but there are no tenses in which it is neutralized only in disyllabic verbs or only in trisyllabic verbs. The above discussion shows that in a tense which is covered by a single formula, tonal contrasts which are manifested in verbs of two or more syllables are neutralized in monosyllabic verbs if the combining of two syllables worth of tones on a single syllable sandwiches the basic tone between $a \mathrm{~L}$ and $a \mathrm{H}$. 


\section{REFERENCES}

Abraham, R. C. 1940. The principles of Tiv. London: Crown Agents for the Colonies.

Arnott, David W. 1964. "Downstep in the Tiv verbal system." African Language Studies 5:34-51.

Meeussen, A. E. 1963. "Morphotonology of the Tonga verb." Journal of African Languages 2:72-92.

Schachter, Paul, and Victoria Fromkin. 1968. "A phonology of Akan: Akuapem, Asante, and Fante." Working Papers in Phonetics 9. University of California at Los Angeles.

Spaandonck, Marcel van. 1967. Morfotonologische analyse in Bantutalen. Leiden: E. J. Brill. 


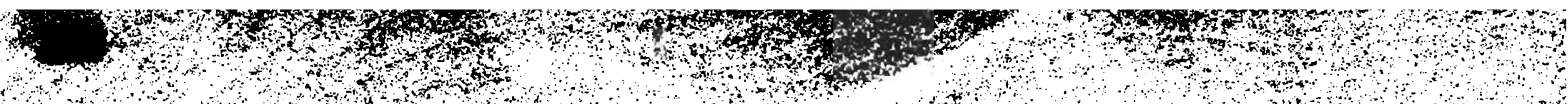

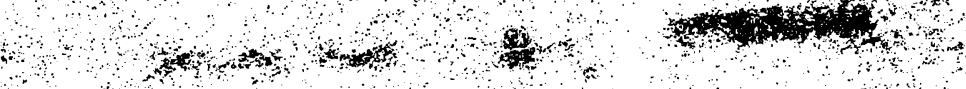

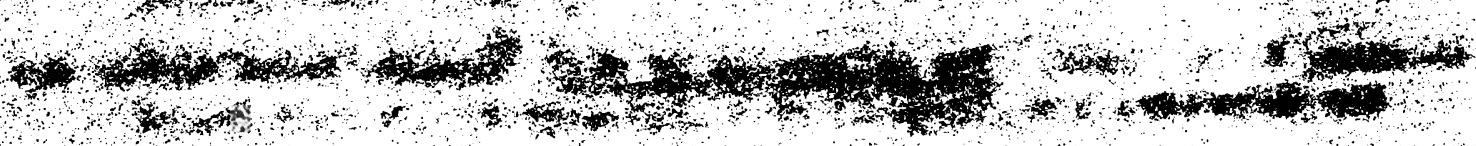

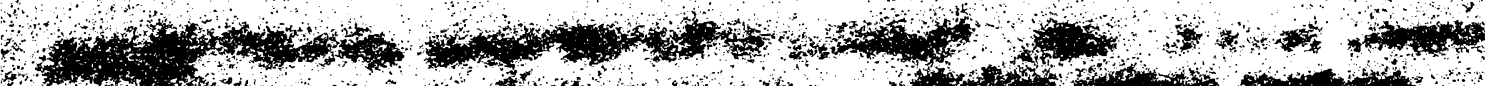

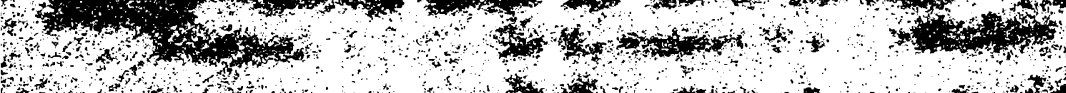

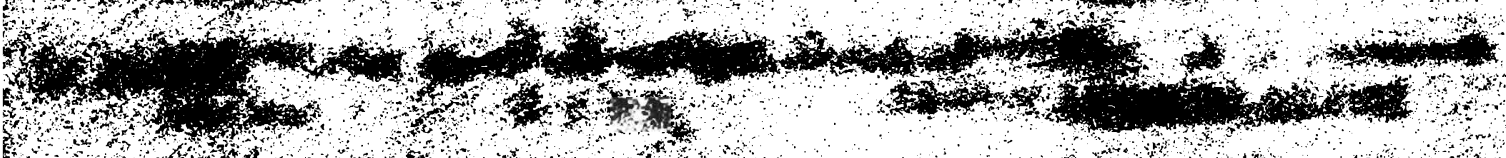

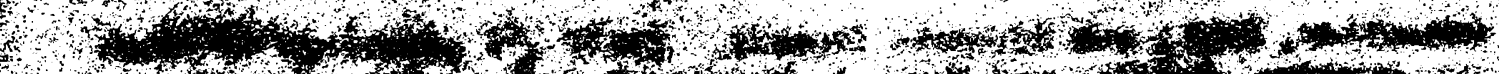

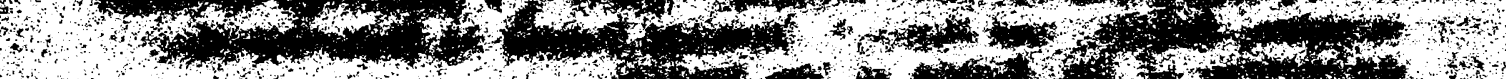

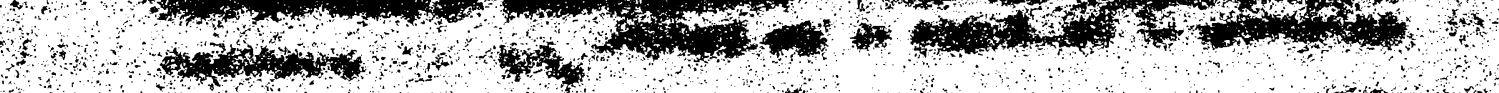

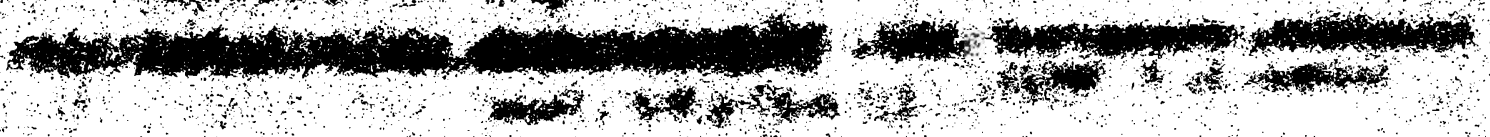

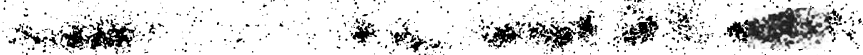

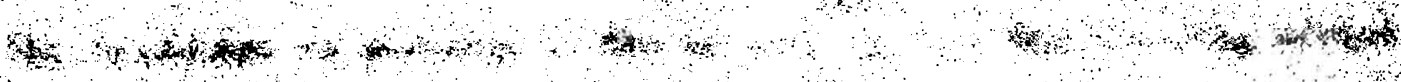

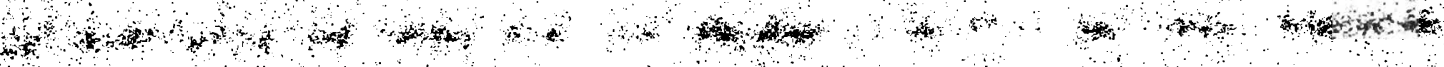

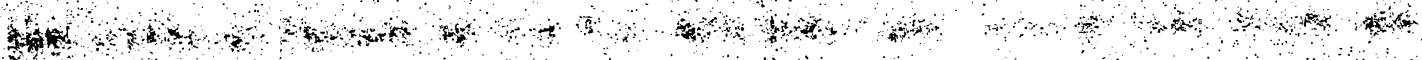

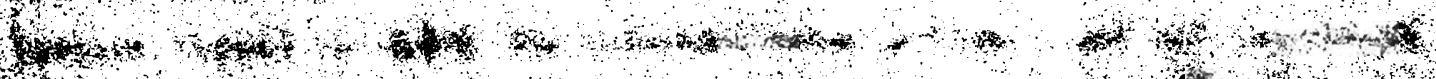
W

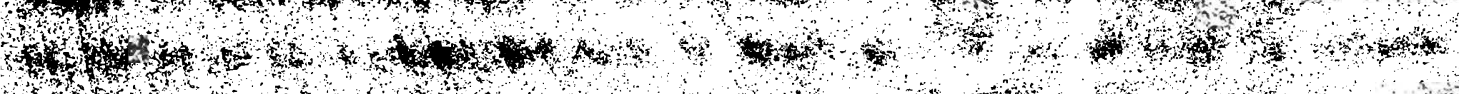

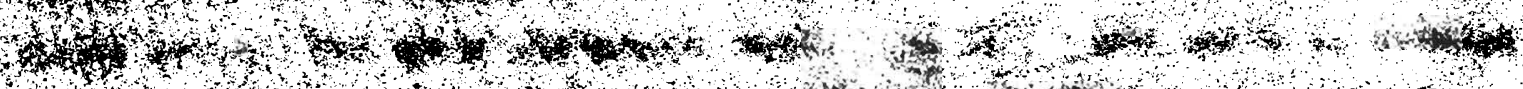
w

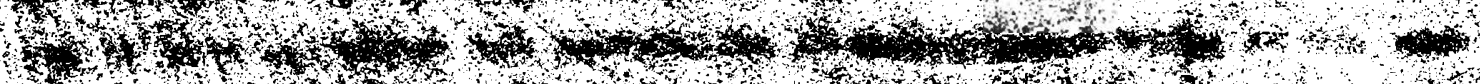
1

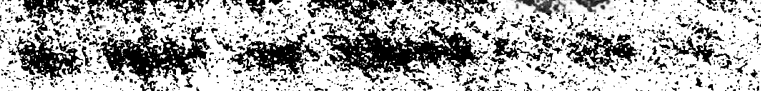

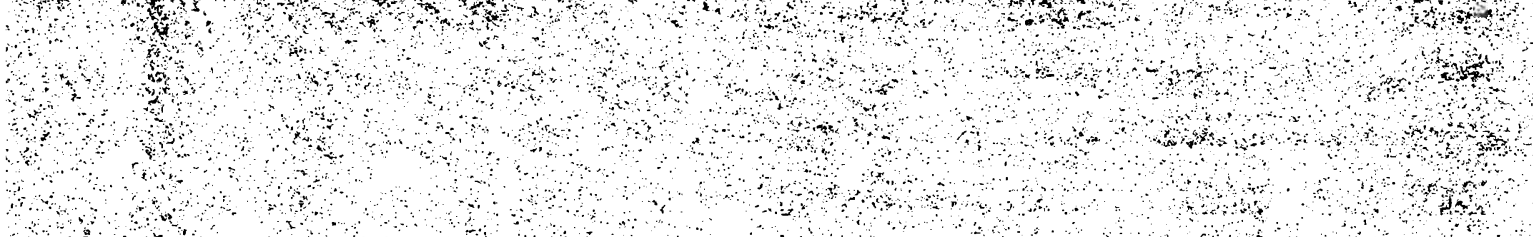




\section{RELATIVIZATION IN UMBUNDU}

\section{Benji Wald}

Department of Linguistics

Columbia University

I.

One of the transformations which lays claim to universal status is that of relativization. Current conventions in generative grammar build the conditions for the application of the relativization transformation into the phrase structure by means of the recursive rule:

(1) $\quad \mathrm{NP} \rightarrow \mathrm{N}(\mathrm{S})$

This convention, established by the time of Chomsky [1965:107(vii)] has remained basically unchanged up to the present. The convention, in my opinion, is not completely satisfactory, in that there is no control over rewriting the embedded sentence in such a way that a $\mathrm{N}$ identical to the $\mathbb{N}$ expressed in ( 1 ) appears in it, although this is a necessary condition for the operation of the relativization transformation. Currently, it appears that the resolution of this problem is achieved by assuming a set of filters which will rule out as ungramatical or unacceptable (the distinction is not clear) sentences with embedded sentences which do not contain the identical noun but are generated through (1). To my knowledge this has not been an issue of much concern, although there has been some discussion of the phrase structure rules which create the conditions for relativization, and is not dealt with in any detail in the literature on the subject. Actually, as (1) stands, it is not as inadequate a rule for English as it may be for many other languages when we consider such perfectly natural (non)standard sentences as:

(2a) He $\left\{\begin{array}{l}\text { wanted me to } \\ \text { suggested that } 1\end{array}\right\}$ pay in advance which I didn't want to
do $(i t)$.

(2b) I lived in the mountains which it was cold there at night. 
One can observe that some condition of identity is still preserved in such sentences but it is not identity of noun or noun phrase in any conventional sense. Furthermore the relative clauses in these sentences and others of this type are nonrestrictive. For the purposes of this paper I will restrict the discussion of relativization to the more well-known and discussed version, that of identical nouns. Any more general version such as that which would account for the sentences in (2), I suspect, would be less likely to be of universal validity.

One important aspect of relativization is that it is one of the strong arguments for the necessity of a grammar to contain recursive rules and to be able to produce infinitely long sentences (one way of having an infinite set of sentences). This is claimed to be a property of natural language and underlies the necessity for a distinction between competence (the grammar determining the ability to produce and understand the sentences of a language) and performance (not a well-defined notion, but apparently non-linguistic factors interfering with competence). Thus, it is claimed that a sentence with, say, five or ten embedded relative clauses is grammatical although it will never occur in natural discourse. In general, I think that the distinction between competence and performance has been somewhat arbitrarily made in actual analytic practice, and that the actual design of language must be determined by factors that also determine performance, to some extent, since language is a human creation for use by humans, but I do not think that recursion is relevant to this issue. The most current challenge to recursion (of certain types) on the grounds of performance is that of Reich [1969]. He objects to the grammatical status of multiple eentral embedding and would like to rule it out of the grammar by means of a set of conventions opposed to (1) above which allows it to exist. He challenges the grammaticality of sentences such as:

(3) The ship which the man that my father paid built sank.

In point of fact, one must account for the awkwardness and/or nonoccurrence of sentences of this magnitude of complexity. However, if we accept the relatedness of active and passive sentences, expressed by means 
of the passive transformation, we cannot accept Relch's alternative model which, in effect, makes the discussion no longer one of grammatical structure. Relch's paper implies that he himself would accept the gram maticality and even potential infiniteness of such sentences as:

(4) The ship which was built by the man who was paid by my father sank.

It seems then that the difference in intelligibility between (3) and (4) are matters of surface structure or perhaps intermediate structure but certainly not of deep structure. I will explore this issue of the difference between (3) and (4) which entails a difference between active and passive and their use according to discourse conventions elsewhere. My only aim here has been to establish the basic importance of relativization to current issues in linguistic theory.

II.

The claim that all languages have a phrase structure rule which has been represented as ( 1 ) is not directly verifiable since there are no languages known to linguists that have the surface form which ( 1 ) by itself would generate. In other words, (1) always produces structures which are subject to certain transformations. If this is the case, what does (1) mean? Leaving aside questions of simplicity in the description of specific languages, for this is by no means a settled issue, I would interpret ( 1 ) as a claim that all languages have a device for incorporating certain information into a single sentence, information that could also be expressed in more than one sentence without changing lexical items of high information content. Thus,

(5) The man whom you met yesterday has arrived. contains the same semantic information as (6) The man has arrived. You met $\left\{\begin{array}{l}\text { him } \\ \text { that man }\end{array}\right\}$ yesterday.

The differences between (5) and (6) involve sentences within a discourse and the appropriate way of organizing information in a discourse. In 
terms of sentence gramar, however, (5) contains the same information as (6). The function of relativization appears to be the identification of the antecedent noun, in contrast to other objects that could be referred to by the same noun when it remains without further specification. Thus we should no more expect a language to be without relativization than without demonstratives (this, that, etc.) and it would be even more surprising to find a language without a relativization device than to find one without demonstratives. In fact, some of the Bantu languages present morphological evidence that relative embedded sentences and demonstratives should be dominated by the same category symbol, that which is generally called Det(erminer). Syntactic evidence can probably be found in any language.

In Umbundu, the major Bantu language of Angola, 1 there are three demonstratives. They are morphologically complex and are as follows:
'this'
a + Vowel of Class Prefix + Class Prefix
'that' (near you)
$0+$ Class Prefix +0
'that' (unspecified)
Class Prefix + na

For example,

(8)

$$
\begin{aligned}
& u \text {-l ume }\left\{\begin{array}{l}
a-u-u>u u^{2} \\
o-u-0>0 o \\
u-n a>u n a
\end{array}\right\} \quad\left\{\begin{array}{l}
\text { 'this } \\
\text { 'that } \\
\text { that }
\end{array}\right\} \quad \operatorname{man}^{\prime}
\end{aligned}
$$

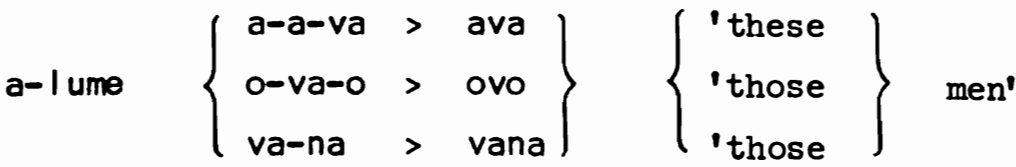

${ }^{1}$ Although Umbundu is the major Bantu language of Angola, Portuguese colonial policy does not grant it any recognition, not to mention official status. Many Ovimbundu, as a result, have lost pride in the language. It is not clear what the general status of the language among its speakers is, but I would like to express my anger at this attempt to discredit and destroy the African cultural heritage in Angola.

2 or $\infty$, irregular morphophonemically. 


$$
0-m-b w a^{3}\left\{\begin{array}{ll}
a-i-y i^{4} & >\text { eyi } \\
o-y i-o & >\text { oyo } \\
y i-n a & >\text { yina }
\end{array}\right\} \quad\left\{\begin{array}{l}
\text { 'this } \\
\text { that } \\
\text { those }
\end{array}\right\} \quad \operatorname{dog}
$$

These forms are used as relative markers and, as a result, location of the antecedent is obligatorily marked. However, location need not be spatial in the concrete sense. As one would expect, since specification of location is unavoidable, the least semantically marked demonstrative is most commonly used if location is unimportant or unknown. Elicitation of sentences with relatives in them, out of any locative context, brings the -na form as a response. ${ }^{5}$

One is not justified in separating the two uses of these demonstratives into two different sets of morphemes. That is, one cannot claim that there are two (u-)na's for example, one a demonstrative and the other a relative marker, since:

$$
\begin{aligned}
& \text { ulume una ndamoĩa heĩa wayongola okulya } \\
& \text { man that (one) I saw yesterday wanted to eat } \\
& \text { 'the/that man whom I saw yesterday wanted to eat' }
\end{aligned}
$$

but not,

(10) *ulume una una ndamoĩa heĩa wayongola okulya

purportedly, 'that man that I saw yesterday wanted to eat'. Similar arguments exist for all other forms of the demonstratives.

A sentence such as:

(11) ulume uu ndamoĩa heĨa wayongola okulya man this (one) whom I saw yesterday wanted to eat

'this man whom I saw yesterday wanted to eat'

${ }^{3} \mathrm{O}$ is an automatic preprefix.

"With typical Bantu vowel coalescence.

${ }^{5}$ Class Prefix + na demonstrative is optionally deleted under certain conditions, but if the speaker responded with a sentence with no overt relative marker, the paraphrase with - na was the most acceptable. There are other conditions under which -na cannot be deleted for syntactic reasons, not because location is an issue. This indicates that - na is the unmarked demonstrative. 
raises the question of the distinction between restrictive and nonrestrictive relative clauses. (II) is perfectly acceptable but if it is taken to be a nonrestrictive, its source, according to current generative thought on the subject, is different from that of restrictive relative clauses and is not from a deep structure generated by ( 1 ). In accord with the above discussion, the restrictive relative clause appears to "filter out" objects from the set of possible objects referred to by the noun, while the nonrestrictive simply presents additional information about the object referred to by the noun. Having both a demonstrative and a restrictive clause then appears to unnecessarily doubly identify the nown; this makes the nonrestrictive interpretation of the relative clause more probable. However, the Umbundu usage is such that (II) can be either restrictive or nonrestrictive like the equivalent English translation where a restrictive interpretation can be obtained, at least colloquially, with an unstressed this. (10) is rejected under any interpretation. I shall restrict the rest of my paper to the restrictive relative clause intended in the recursive rule ( 1 ).

So far we have not justified a node dominating both Dem(onstrative) and the embedded $S$, but simply a rule of the type:

(12) $\mathrm{NP} \rightarrow \mathrm{N}(\operatorname{Dem}(\mathrm{S}))$

This simply leads to a tripartite division if all options are taken:

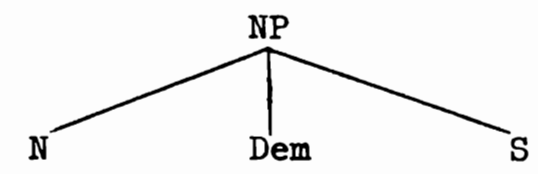

(12) is strange in that it implicitly allows a dependency relation to exist in the choice of $S$ on Dem, i.e. the choice of $S$ depends on Dem being selected. The seemingly innocuous convention allowing (12) to be represented, is a rather strong claim about the possible structure of language, i.e. that there can be unmotivated dependency relations. It would seem, however, rather arbitrary to break (12) into two rules simply to form a node to avold this problem without any empirical motivation. That is, to insist that (12) is nonconventional and must be converted into 
(14a) NP $\rightarrow$ N (Det)

(14b) Det $\rightarrow$ Dem $(s)$

Fortunately for the conventions, there is further motivation for the two rules in (14), as against (12). This has to do with the extraposition of relative clauses from the NP. Thus, we may convert (9) into

(15) ulume wayongola okulya una ndamoía heĩa

'the man wanted to eat, whom I saw yesterday'

but not,

(16) *ulume una wayongola okulya ndamoĩa heĩa.

(16) is not gramatical and does not even mean

(17) 'the man who wanted to eat I saw yesterday'.

(17) is an example of Topicalization (Ross) or Y-Movement (Postal) and has an Umbundu analog, but it is not (16). It is:

(18) Ulume una wayongola okulya ndoo ${ }^{6}$ mol̃a hel̃a

'the man who wanted to eat - I saw him yesterday'

This transformation, I call it Preposing, converts structures such as

(19) ndamoĩa ulume

'I saw the man'

into

(20) ulume ndoomoĩa

'the man, I saw him'

and will be discussed later. (15) and (16) suggest that [una] ${ }_{\text {Dem }}$ [ndamoía heila] $]_{S}$ moves as a unit and therefore the two constituents are dominated by a node which unites them. This supports the structural analysis predicted by (14) rather than by (12).

It appears that many languages of the Congo share this overt morphological property with Umbundu and some varieties of Congo Swahili use the

${ }^{6}$ From nda-u where $u$ is the object marker referring to ulume. 
Swahili demonstrative as a relative marker e.g. $m(u n)$ tu yule nilimwona jana alitaka kula which is unacceptable in Coastal Swahili. In Standard Swahili ambaye would be used instead of yule here or mtu niliyemwona jana alitaka kula with the referential marker ye, indicating relativization, appended to the tense particle.

III.

If there are universal aspects to relativization as Bach [1965] suggests, is there a single rule relative transformation? Or are there, alternatively, several rules in a specific language, one or more being universal, the others being language specific (since surface relativization is not identical in all languages)?

Essentially, the recurrent or universal aspect of relativization rules has been indicated as the pronominalization of the noun referring to the antecedent and its movement to the head of the embedded $S$ and its deletion or conversion into a relative marker, or alternately the creation of a relative marker introducing the embedded sentence and the attraction of the relativized noun to it in a pronominalized form.

For example, if we take (9) again, presumably the underlying structure at the stage of the derivation that relativization begins to operate is :

(21)

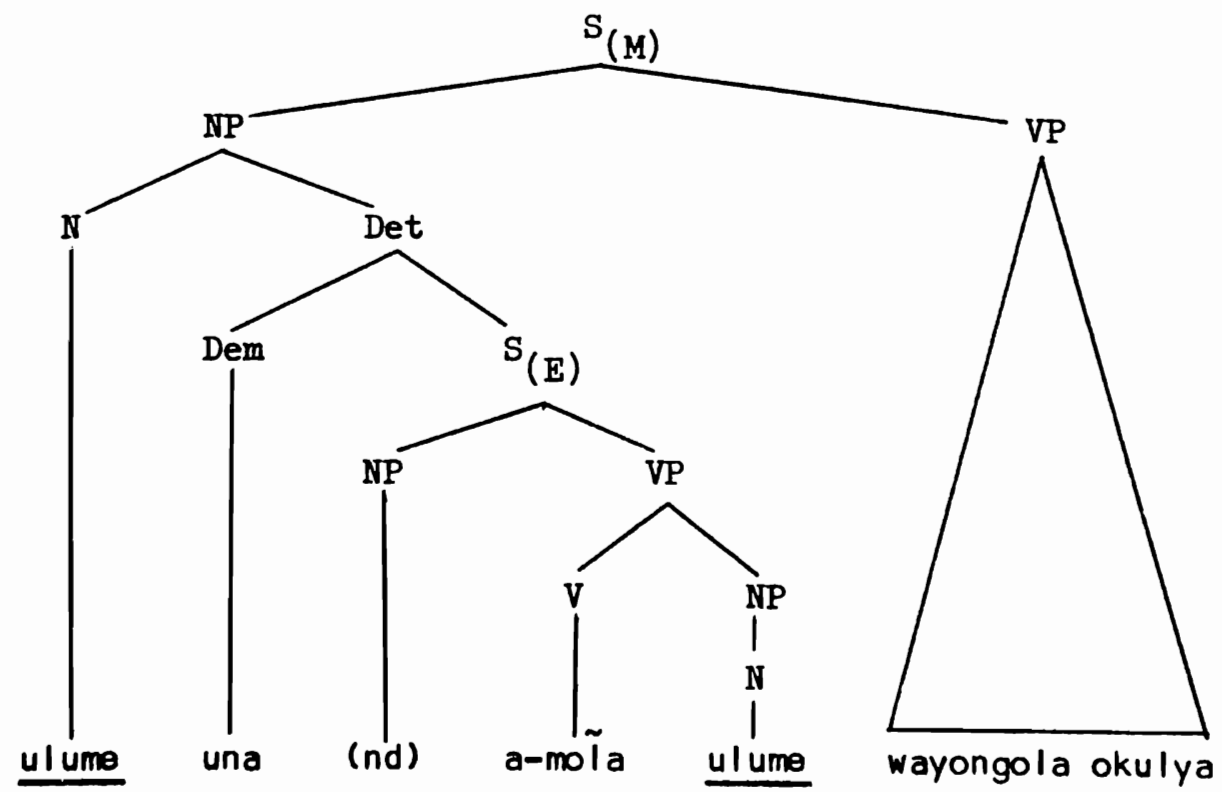


The underlined $N$ in the embedded $S$ is to be relativized and is identical to the underlined $N$ in the matrix sentence. According to the universal rule ulumo in $S_{E}$ should be moved to the front of $S_{E}$ and then deleted.

Now, several objections may be raised at this point. The first objection has to do with the representation of (2l) and, in fact, is part of my previously mentioned dissatisfaction with (1) or its revised form (14). That is, that the implication of (21) is that the underlined noun in $\mathrm{S}_{\mathrm{E}}$ has already been lexically inserted. I believe that this is an error and probably has its roots in the earlier generative distinction between local and generalized transformations. Before Chomsky [1965], the practice was to describe relativization as a generalized transformation, i.e. as the combining of two independent sentences. (See Chomsky [1957:113], for example.) While Chomsky [1965] established recursion in the phrase structure by means of rules such as (1) the theory, as a whole, for a variety of reasons, left the convention that lexical insertion into terminal symbols precede all transformations. This means that the underlined $N$ in $S_{E}$ must undergo lexical insertion before any rules of relativization apply. The relativization transformation then specified that the relativized noun (phrase) be identical morphologically as well as referentially to the noun of the matrix $S$. This was because of the principle of recoverability. Since the NP was to be deleted after having been previously (lexically) inserted, it would only be recoverable if it was identical to the antecedent NP. In effect, the notation of the transformation made it look like morphological identity was a necessary although insufficient condition for relativization. In essence, this is the same problem that leads to the Bach-Peters paradox in pronominalization, viz. morphological identity of coreferents. I contend that the NP which is to be deleted or pronominalized should not have been lexically inserted in the first place, but rather that coreference alone is a sufficient condition. At present, the representation for a terminal symbol which is not lexically filled is the dumy symbol $\Delta$. Thus, a more accurate representation of (2l) would be 


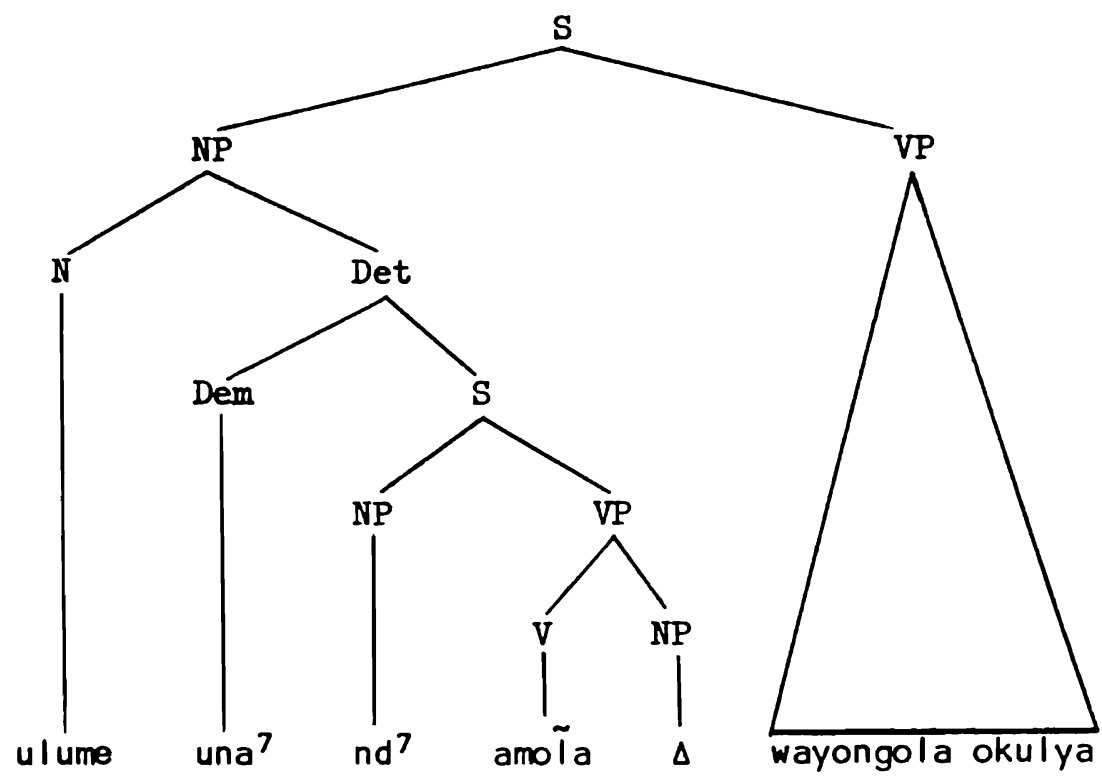

Such a convention in all coreference situations (of which relativization is one) avoids the Bach-Peters paradox, and also the problem with quantifiers exposed and discussed by McCawley and Lakoff in various papers and lectures, viz. how to distinguish the underlying structures of all men want to be rich and all men want all men to be rich. These problems of pronominalization naturally affect relativization as well. The problem still remains as to how to express coreference, but that was a problem before as well. If we could in some way establish the convention that when the embedded $S$ in $(14)$ is expanded, there must be a $\Delta$ where coreference is intended, then original objection to $(1)$ and (14) would lose its force. While this may seem to be merely a matter of alternative notations, $\Delta$ versus lexically filled symbols, the Bach-Peters paradox and the quantifier problem illustrate the extent to which notation can become a linguistic issue.

A major problem with the proposed $\Delta$ is that it has no semantic-syntactic leatures, some of which are necessary in most languages to produce

7We will pass over other problems in the accuracy of (22). For example, nd- should actually be a feature of $V$ and is a concord for an underlying NP meaning ' $I$ ' and una should not necessarily have been lexically inserted at this point. I am trying to avold irrelevant complications in the diagram. 
grammatical sentences. In fact, the basis of lexical insertion preceding transformations was to express coocurrence restrictions through selectional rules. It follows then that there must be rules which map necessary features onto $\Delta$ from the coreferent noun, a copying rule. In order to insure correct coocurrence restrictions, the number of features and which features should be copied has to be investigated. It is not likely that all features should be copied. In any case the $\Delta$ remains a $\Delta$ no matter how many features are copied onto it and it will not appear in the surface structure although its effects will. Swahili offers some evidence for this position, where concord has the following effects:

(23a) mtoto wangu ni mkubwa 'my child is big'

(23b) mtoto mkubwa ni wangu

'the big child is mine'

where mtoto is one of a class of nouns which takes mu- concord, wwith the possessive;

(24a) nyumba yangu ni kubwa 'my house is big'

(24b) nyumba kubwa ni yangu

'the big house is mine'

where nyumba is one of a class of nouns which takes ni- concord, ywith the possessive. Now, with kinship terms we get what appears to be mixed concord.

(25) baba yangu ni mkubwa 'my father is big' cf. (24a)

(26) baba mkubwa ni wangu 'the big father is mine' cf. (23b)

There is a general rule in Swahili that human nouns take mu- concord. We can see that (25) violates that rule. There is a finer rule that kinship terms in the possessive construction, which is where they 
most frequently occur, take $\mathrm{ni}$ - concord in the possessive. This rule is apparently acquired late in that speakers claim that baba wangu (cf. (25)) sounds 'childish'. At any rate, according to the lexical insertion theory the source of (26) should be

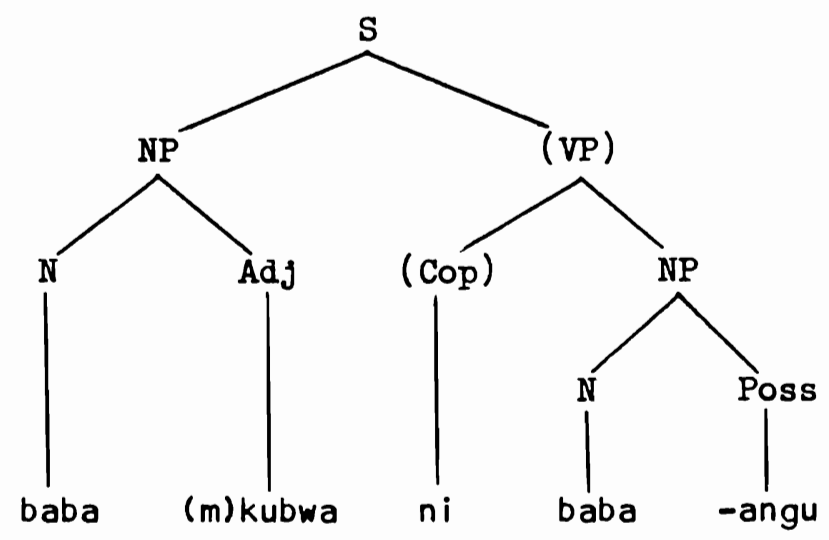

(Again, the diagram (27) is rough; Poss, for instance, could be further complicated.) If (27) is taken as the source of (26) there is no generalization that we can make about the fact that kinship terms being human take human concord in (26) but not in (25). (25) is the exception; (26) is not. But when concord is applied (25) and (26) are indistinguishable if both are represented as the NP dominated by (VP) is in (27). The proposal I have made, however, will take the source of (26) to be (28) with the feature human copied onto the $\Delta$ but not the feature(s) determining kinship.

(28)

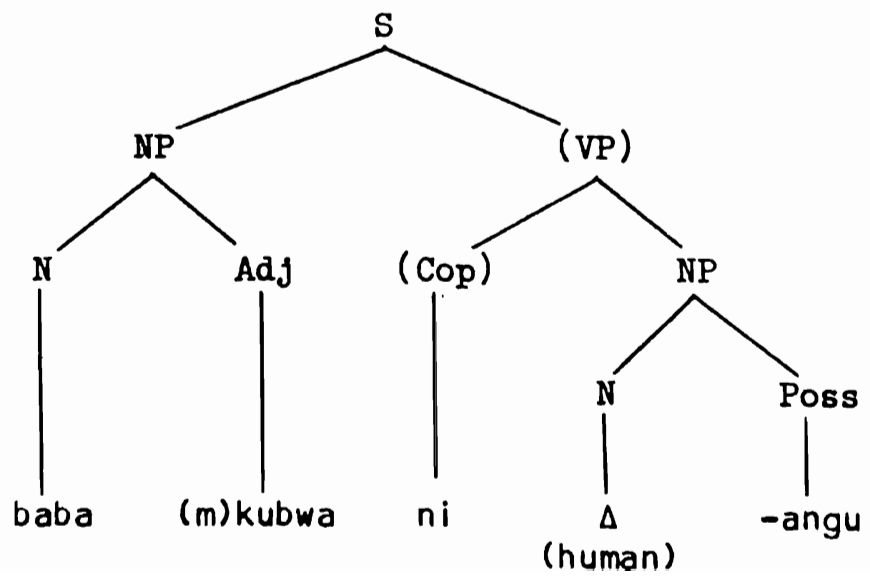


The evidence is not conclusive but $I$ think it is worthy of consideration.

Returning to (22), if we stick strictly to Umbundu, one might argue that on the basis of the evidence considered so far it is unnecessary to consider the coreferential noun to have moved but it could be deleted where it stands. In this case there is compelling evidence in terms of the generative model that there is a movement of the $N$ of the relative clause.

Compare the following:

(29)

ufeko w-alya

'the girl ate'

ul ume w-alya

'the man ate'

Both ufeko and ulume belong to the same concord class and produce a subject marker $w$ (underlying 0 ) by a concordial rule operating on the verb.

Now compare the following sentences:

(31) ulume una wamoila ufeko wayongola okulya

'the man who saw the girl wanted to eat'

(32) ulume una ufeko amoía wayongola okulya

'the man whom the girl saw wanted to eat'

The structure of the source of the relative clause in (31) is

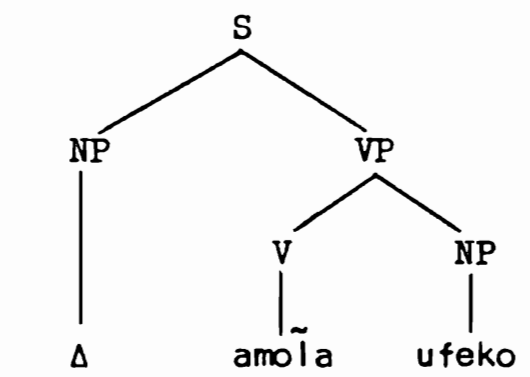

(ulume)

Before relativization subject marking operates on the verb causing a-moila (Past Tense + Verb Stem) to be realized as w-amoila. This means 
the appropriate noun class features have been copied on to the NP $\Delta$. Clearly, subject marking precedes relativization rules.

In (32) the source of the relative clause is

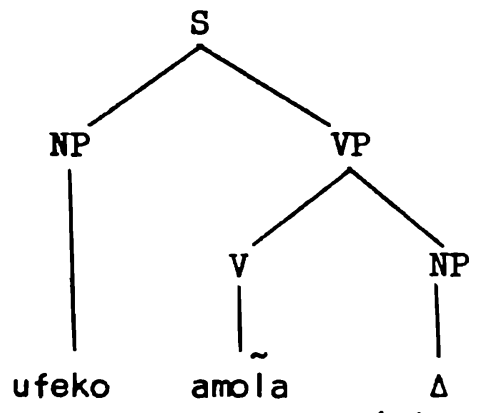

(ul ume)

Since subject marking precedes relativization, we expect amoía to be changed to wamoila as in (29), (30), (31), but in (32) we see the surface form has no $W$, although if we paraphrase (32) with a passive: (35) ulume una wamwiwa (lufeko) wayongola okulya 'the man who was seen (by the girl) wanted to eat'

the subject marker appears on the surface; and if we do the same with (31):

(36) ulume una ufeko amwiwa lahẽ wayongola okulya

'the man whom the girl was seen by wanted to eat'

the subject marker does not appear.

(32) and (36) have in common the absence of a subject marker and in both cases the relativized noun was not the subject, but behind the verb. The universal rule says that the relativized noun will move to the beginning of its sentence. We can then attribute the absence of the subject marker to the movement of the relativized noun, i.e. the coreferent $\Delta$, over the verb. It appears then that the subject marking rule applies and then if the $\Delta$ moves over the verb during relativization the subject marker is erased.

Actually, the subject marker $w$ is not erased but changed to a. This can be seen in other tenses. For example, in the present continuous : 
(37a) ulume una okasi okulya olusi unene

'the man who is eating the Ish is big'

(3To) olusi luna ulume akasi okulya lunene

'the fish which the man is eating is big'

The phonological rules of Umbundu require that o-a-lya > w-a-lya 'he ate' versus o-kasi okulya 'he is eating' and a-a-lya > a-lya 'he ate'.

Thus, the change is from 0 to $a$ and may be ascribed to the movement of the relativized NP over the verb. This change only occurs with the subject marker for the animate $((\mathrm{m}) \mathrm{u}$ - class) noun class in the singular and will be referred to as the o/a alternation for future reference.

Support for this analysis comes from another source. In interrogatives, the question word may either precede or follow the verb. Since the language, as all the examples above have shown (and note Preposing (19) and (20) in particular), is underlying svo we assume that a transformation moves the question word to the front of the sentence, i.e. over the verb. Thus, we have pairs of sentences of which the first is the source of the second (in a manner of speaking):

(38a) walinga nye

'what did he do?'

(38b) nye alinga

(39a) waenda pi

'where did he go?'

(39b) pi aenda

(40a) waveta el iye

'whom did he hit?'

(40b) heliye aveta (heliye and eliye 'who(m)' vary in just this way)

There are also sentences involving negative attraction:

(4la) kalingile cimwẽ

'he didn't do anything'

(4Ib) lacimwẽ alinga

'he did nothing'

In all cases we notice the o/a alternation and in all cases the question word or negated noun has been preposed to the verb. 
This all strongly suggests that when a noun moves over a verb in a transformation of a certain type $0>a$ is operant. It is thus not a transformation-specific rule but provides evidence that in relativization, the relativized NP is moved rather than deleted where it stands. I suggest that the structural description that relates the negative, interrogative, and relative transformations is a category symbol dominating the main $S$, which attracts a noun in that $S$ from behind the main verb of that S. Thus, the underlying structure of (38) is:

(42)

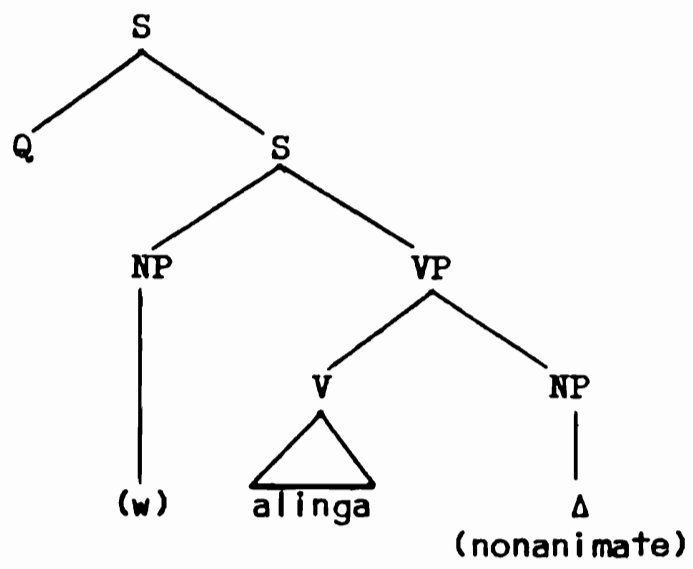

Underlying (4I) is the structure:

(43)

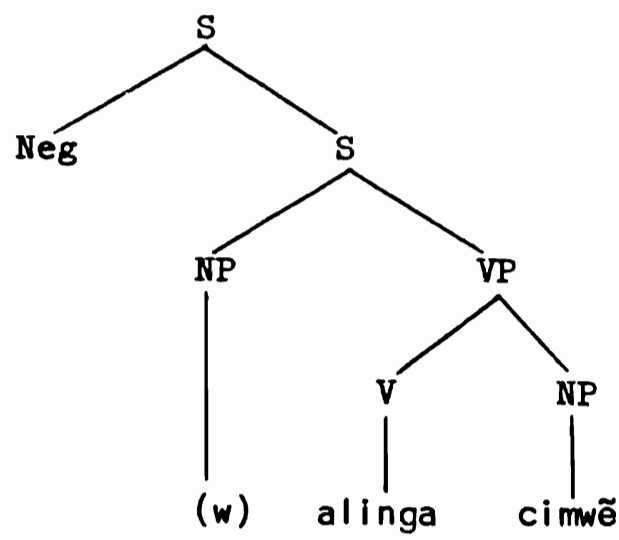

and the Dem symbol is the overt attracting element in the relative (as in (22) for example).

Because of other properties of Umbundu gramatical structure, surface minimal pairs are possible involving the $0 / a$ alternation. For example, 
(44) ulume una wamoîa walya

'the man who saw (something) ate'

(45) ulume una amoĩa walya

'the man whom he saw ate'

(44) is possible because no Umbundu transitive verb requires a surface direct object. The effect, however, is not the same as in English usage, and wamoila is more appropriately translated 'he did seeing' than 'he saw' in the sense that he wasn't blind (anymore). One might want to describe this phenomenon by a dumny-object deletion rule.

There is one final point which must be brought up to complete the picture. The data as presented so far is quite consistent and allows a description which relates several processes; the interrogative, the negative, and relativization in an insightful way. However, upon further investigation I elicited the following:

ulume una ufeko alya olusi Iwahẽ wasanjuka

(the) man that (the) girl ate his fish (is) happy

'the man whose fish the girl ate is happy'

The pronominal trace in this possessive sentence is typical of Bantu and presents no particular problem (cf. (36) with la-hẽ 'by him'). The $\circ>a$ has applied as expected in conformity to the rule since the relativized NP referring to ulume moved over the verb. But now,

(47) ulume una omol̃ahẽ $\left\{\begin{array}{c}a m w i w a \\ \text { wamwiwa }\end{array}\right\}$ lufeko wasanjuka

(the) man that his-son was-seen (by) (the) girl (is) happy

'the man whose son was seen by the girl is happy'

It appears then that movement over the verb is not the correct generalization since omolahẽ for omolla wa (ulume) always preceded the verb. Since all data was collected from one informant I do not know whether this construction, (47), is typical of any Umbundu speech community, i.e. whether it is variable, dialectal, or idiosyncratic. Judging by one informant if a grammatical change is involved in extending 
the $0 / a$ alternation to constructions like (47) it is complete. Given that most of the evidence points to the conditions for $0 / a$ as being the movement of a NP over a verb, the Umbundu generalization is that any movement of the relativized noun from its original position during the relativization transformation will register the change of 0 to $a$. This leaves only the subject relativized noun unaffected since this NP moves vacuously, i.e. not at all.

Having raised the question of gramatical change, I would like to explore the historical aspect of this change in the following section. IV.

The alternation $o / a$ is widespread among Bantu languages. In some languages it has a distinctive function as in Umbundu, demonstrated by (44) versus (45). In other languages it is determined by surface cooccurrence restrictions.

This alternation occurs, for example, in Swahili as the yu/a alternation. It serves no distinctive function in Swahili, the a being the animate singular subject marker and the $y u$ being the pronominal concord marker for the same class. Thus, in Swahili: a-li-cheka 'he laughed', watoto aliowaona mtu 'the children whom the sam saw', mtu aliyewaona watoto 'the man who saw the children', etc. and: mtu yule 'that man', mtu huyu 'this man', mtu huyo ( $\times$ hu-yu-o) 'the man just mentioned', mtu yu tayari 'the man is ready', etc. In the literature on Swahili dialects it is sometimes reported that $y u$ is used with the short present tense as a subject marker (e.g. Ashton [1944]), but it is still incapable of surface contrast with a.

It will not be possible in this paper to go into the origin of the contrast between the two forms of the concord, but the contrast exhibited by Umbundu also occurs in the Nguni group ( $\mathrm{Zulu}$, Xhosa, etc.) and gives us more insight into the development seen in Umbundu. Certain aspects of Zulu relativization support the notion that the Umbundu $0 / a$ alternation has been extended to positions like that in (47) and also help us understand one line of development of relativization in Bantu generally. 
Zulu has the alternation in the form of $u / a$ and works similarly to the Umbundu alternation in the relative construction. The following examples are adapted from Louw, Ziervogel, Ngidi [1967].

(48) umfazi omsizayo umfana ufundile

'the woman who helped the boy is learned'

(49) umfazi amsizayo umfana ufundile

'the woman whom the boy helped is learned'

(48) and (49) differ in the same way that (31) and (32) above in Umbundu differ, and represent equivalent underlying structures (cf. relative clause in (33) and (34)).

The morphological structure of omsizayo in (48) (a-u-mu-siza-o) is a (introducer of the relative clause), $u$ (third person animate subject marker in singular), $m(u)$ (animate singular object marker agreeing with umfana 'boy'), siza (verb stem 'help'), (y)o (unmarked for concord referential particle marking the relative clause along with the initial morpheme a). The morphological structure of amsizayo (< a-a-mu-siza-o) in (49) is the same as that in (48) except that $u$ is replaced by a. $(a+a>a$ and $a+u>0$ are regular phonological processes in $\mathrm{Zulu}$, as in most Bantu languages.)

There are, however, notable differences between the pairs Umbundu (31), (32) and Zulu (48), (49). The relativizers a and yo are absent in Umbundu, but there is evidence that a derives, at least historically, from an original demonstrative, e.g. Jordan [1967], and therefore is equivalent to Umbundu Class Prefix + na. The subject NP of the relative clause in (49) is postposed and there is an object marker prefixed to the verb stem in (48) and (49). Postposition of the subject NP cannot occur in Umbundu, but is optional in Zulu. Object marking is operant under different conditions in $\mathrm{Zulu}$ and Umbundu. In Umbundu, object marking occurs if the object NP is preposed to the verb as in (20) above. 8 In

8Note that this preposing rule in Umbundu is different from the one discussed for $(38)-(45)$ above where attraction is involved and the structural descriptions for the transformations are different. 
Zulu, object marking is optional in most contexts but preposing and postposing are contingent upon it. This indicates that Umbundu represents an older stage of Bantu in this respect where object marking is not well developed compared to $\mathrm{Zulu}$ (and Swahili) and 'scrambling' (preposing and postposing) is not possible in Umbundu. In $\mathrm{Zulu}$,

(50a) umfana upheka ukudya

(50b) umfana uyakupheka ukudya

(50c) umfana ukudya uyakupheka

(50d) ukudya uyakupheka umfana 'the boy cooks food'

\begin{tabular}{|c|c|c|c|c|c|c|}
\hline " & " & $"$ & " & (with & object & marker) \\
\hline " & " & $"$ & " & ( " & $"$ & $"$ \\
\hline & " & $"$ & $"$ & ( " & $n$ & $"$ \\
\hline
\end{tabular}

but not:

(50e) *umfana ukudya upheka

or

(50f) *ukudya upheka umfana

The $k u$, as in uyakupheka of $(50 \mathrm{~b})-(50 \mathrm{~d})$, is the object marker agreeing in concord with the object ukudya 'food'.9

These data suggest that in Zulu object marking must precede preposing and postposing, and postposition is optional; while in Umbundu, postposing is impossible, and preposing and object marking are concomitant (or object marking makes preposing obligatory); Umbundu therefore seems less highly developed in object marking, and represents an older stage of Bantu. Umbundu relativization when compared to Zulu exhibits an older and simpler system; that is:

(5la) Overtness of the demonstrative as a condition for relativization (5lb) Stricter constraints on object marking

The ya or 'long' form of the present is not relevant to the present discussion but indicates an interesting line of development for the object marker in Zulu and elsewhere outside the Nguni group. This will be discussed in the paper on Bantu coreference. In this paper we need only note that descriptively the 'Iong' form of the present, as opposed to the $\emptyset$ 'short' present occurs obligatorily when the object marker is present or the object noun is unrealized on the surface. 
(5lc) More reliance on (or weight carried by) the o/a contrast for indicating the grammatical function of NP's in a $\mathrm{S}$.

In this light we can see the Swahili development of subcategorizing nouns semantically (animate versus inanimate) for optionality or obligatoriness or object marking (animate objects must cause object marking), as an innovation and extention of the line of development seen in Umbundu and Zulu. The loss of the $O / a$ functional distinction and Swahili's form of relativization may also be seen as being influenced by the development of object marking. These grammatical changes intersect with other Bantu grammatical devices such as the pre-prefix and will be discussed in another paper on the development of coreference devices in Bantu languages.

Returning to $\mathrm{Zulu}$, we find the following situation in relative clauses where the possessive is involved:

(52a) umfana a(si)thenga isigqoko sakhe umfazi uhambe (the) boy (who) (the) woman bought his hat has gone

'the boy whose hat the woman bought has gone'

(52b) izinkomo ezimelusi wazo ulele zizofohla

(the) cattle (which) (the) herdboy of-them is asleep will escape 'the cattle whose herdboy is asleep will escape'

In (52a) a(si)thenga consists of the relative marker $a$, the subject marker a (not $u$ ) as expected (since the relativized NP is behind the verb), an optional object marker si agreeing with isigqoko 'hat', and the verb stem thenga 'buy'. (52a) is comparable to (46) in Umbundu. We expect the subject marker a since the relativized NP represented by khe in sakhe (si agreeing with isigqoko, a possessive, khe the trace agreeing with umfana) is behind the verb and thus the $\Delta$ NP moved over the verb leaving the pronominal trace khe behind. In $(52 b)$ we note that $u-l e l e$ has a subject marker $u$ agreeing with (u)melusi 'herdboy'. The antecedent of the relative clause is izinkomo and has left its trace in the possessive wazo ( $u+a+z i t o: ~ u u$ for umelusi, a possessive, $z i$ for izinkomo, and 0 referential). The $u$ is in 
contradistinction to (47) in Umbundu in the same type of construction. The $\Delta \mathbb{N P}$ in $(52 \mathrm{~b})$ did not move over the verb; but it did move, if one assumes that relativization moves the relativized NP to sentence initial position, as in Umbundu. This movement, not over the verb, has not been registered by a change of $u$ to $a$ in Zulu.

(53) umfazi ongane yakhe igulayo uyahlupheka

(the) woman (who) her child is sick is suffering

'the woman whose child is sick is suffering'

(53) is also to be compared with (47). The crucial word in (53) is the NP ongane which consists of a (relative marker), $u$ (concord with the antecedent umfazi 'woman'), ngane (noun 'child', with pre-prefix form is ingane). Note that $u$ is the form for the concord for the antecedent 'possessor' umfazi. This construction is not directly comparable to any Umbundu construction, but again the point is that the relativized NP does not move over the verb, and its concord is $u$, not a .

The data in (52) and (53) above, in particular, support the notion that the $0 / a$ alternation in Umbundu originally applied only to movement over the verb. The grammatical change in Umbundu is thus:

(54a) Originally the a concord marker denoted the movement of a NP over a verb. This is seen in Zulu and supported by the Umbundu interrogative and negative attraction movements.

(54b) Umbundu has generalized the rule in the relative so that any movement of the NP from its original position registers a concord rather than $u$. This has the effect that only a NP coreferent with the antecedent and which is the subject of the relative clause registers as $u$, since only here is movement to the front of the sentence vacuous. In the possessive, if the possessor of the subject is coreferent with the antecedent, it moves over the subject NP leaving a pronominal trace in the possessive, and this nonvacuous movement is a new environment for the $0>a$ rule. 
On the basis of our present knowledge of grammatical change, and due to insufficient data on closely related languages, it is difficult to say whether the o/a alternation in Umbundu negative and interrogative sentences is an innovation or more typical of an earlier stage of Bantu. Accurate comparative and dialect geographical data should enable this problem to be resolved and elucidate more of the principles of grammatical change.

The only further data I have to bear on the matter are anecdotal. It is not typical of Bantu to have a negative morpheme attached to a noun as far as I have been able to ascertain. Umbundu is almost unique in this respect. I had a conversation with someone passing through New York City who speaks Vambo, a Bantu dialect-cluster of South-West Africa. Vambo is closely related to Umbundu. With regard to the negative, I found that negation with indefinites is accomplished by means of the existential paraphrasis in standard Vambo, i.e. the most acceptable style of Vambo speech. So, to say I didn't see anyone one must say there wasn't anyone (a person) whom I saw. This is typical of a large variety of Bantu languages. However, the speaker admitted that in nonstandard, i.e. less acceptable speech, most frequently among younger people, Neg + someone was possible as an alternative for 'there-Tense-not-be-someone who ...' which is equivalent to Umbundu practice (this is observation; the speaker did not know Umbundu). This seems to indicate a spread of the Umbundu-type construction southward and that the construction involving a negative morpheme attached to a nominal form is of recent origin. It follows that the o/a alternation in the negative cannot be of ProtoBantu origin. It is my guess that the application of this alternation to Neg and $Q$ has its origin in the relative construction as a device for foregrounding; i.e. nothing (is what) he did (4I) and what (is it that) he did (38). Relativization is a well known gramatical device in Bantu languages and elsewhere for foregrounding of $Q$ and Neg words in connection with a particular NP. 
V.

I would like to discuss the implications of the body of this paper for aspects of generative linguistic theory, in conclusion.

(a) the relative $S$ should be represented as dominated by Determiner in the deep structure and commanded by Demonstrative.

(b) the demonstrative with relative clauses, the Q-marker, and the Negmarker share the property of commanding a S (see (22), (42), (43)). It is therefore not entirely fortuitous that morphologically the relative marker resembles the demonstrative in many languages, e.g. English that, and it is likely that the Q-marker and the relative marker are closely related, cf. most Indo-European languages.

(c) the NP coreferent to the antecedent of the relative $S$ should not be lexically filled. This eliminates counterintuitive filtering rules for blocking sentences with relative clauses without coreferent NP's.

(d) All $\Delta^{\prime}$ s should be deleted by a surface convention that lexically unfilled items obviously have no phonological representation. Deletion of apparently lexically filled items should be viewed with suspicion, especially when the level of abstraction is high. 10

(e) Certain rules such as Umbundu $0>$ a which operate under specified conditions at different points in the grammar are necessary without radical revision of the generative grammatical model. A rule such as this is similar to the ones Lakoff has called derivational or global constraints [e.g. December 1969, ISA meeting] or Ross [1967] would call constraints that need to be put in a conditions box:

... they are not universal, and to state them on each transformation which they affect is to miss a generalization. What is necessary is that the grammar of every natural natural language be provided with a conditions box [underlining is Ross's; BW] in which all such particular constraints are stated once for the whole language. By a

10 There are such problems as the deletion of that in relative clauses and complement sentences in English and - na in relative clauses in Umbundu which might be appropriately viewed as the deletion of lexical material. 
universal convention of interpretation, all conditions in the conditions box will be understood to be conditions on the operation of every rule in the grammar. ...

$$
\text { [Ross 1967:4.3.2] }
$$

The Umbundu example makes the following question more than academic. Obviously language-specific constraints, not being universal, must have evolved by some means and are subject to change. Addition of these constraints to the theory of grammar is serious, in that they reduce the power of the argument for ordered rules to account for syntactic facts in language. The expansion of a language specific constraint in a particular transformation throws into question the usefulness of these conventions in examining a language in the process of change. In purely descriptive terms, how do we maintain the generalization about $0 / a$ for the relative, negative, and interrogative, and at the same time indicate the generalization about the relative stated in (54b)? 


\section{REFERENCES}

Ashton, E. 0. 1944. Swahili grammar. London: Longmans.

Bach, Emmon. 1965. "On some recurrent types of transformations" Georgetown University Monograph Series on Languages and Linguistics 18:3-18.

Chomsky, Noam. 1957. Syntactic otructures. The Hague: Mouton.

Chomsky, Noam. 1965. Aspects of the theory of syntax. Cambridge: M.I.T. Press.

Jordan, A. C. 1967. "The adjective in the Nguni languages of southern Africa with special reference to Xhosa". Journal of African Languages $6: 132-45$.

Reich, Peter L. 1969. "The finiteness of natural language". Language $45: 831-43$.

Ross, John Robert. 1967. "Constraints on variables in syntax". Massachusetts Institute of Technology doctoral dissertation.

Ziervogel, Dirk, J. A. Louw, and J. Ngidi. 1967. A handbook of the Zulu lanquage. Pretoria: Van Schaik, 
CONJOINED AND STACKED RESTRICTIVE RELATIVE CLAUSES:

DEEP AND NOT-SO-DEEP CONSTRAINTS IN LIGHT OF LUGANDA DATA ${ }^{1}$

\author{
Livingstone Walusimbi and Talmy Givón \\ Department of Linguistics \\ The University of California, Los Angeles
}

\title{
1. Introduction
}

This paper deals with the type of recursive rules which make possible multiple recursion of modifiers within the noun phrase. It is primarily concerned with the rule specifying embedding of sentences as relative clauses, and more incidentally with the rule specifying sentence conjunction. We think we can demonstrate that both types of recursive rules are needed in order to account for facts of both English and Luganda. We would like to regard these recursive rules as constraint on the deep/ semantic structure. In addition, we would like to suggest that many other constraints that may operate in the grammar of restrictive relative clauses, and as a result of which several types of surface configurations may be blocked--either universally or in some specific language, are best construed as constraints on less-than-deep structure. Thus, while one must seek to understand deep-structure constraints at least in part on semantic grounds, one should not seek similar grounds to explain shallowstructure or surface-structure constraints.

Over the past few years, several formulations have been proposed to account for recursion of restrictive relative clauses (henceforth RRC) within the framework of generative grammar. Most of them have been based upon data derived almost exclusively from English. All of them were formulated in terms of constraints on deep structure--i.e., as base rules. of these formulations, we shall discuss briefly only three, since it seems to us that the rest are in one way or another variants of those.

${ }^{1}$ We would like to record our indebtedness to Andy Rogers, Sandra Annear Thompson, Paul Schachter and Benji Wald for very helpful comments on an earlier version of this paper. 
a. The ART-S solution. This solution may be found in Chomsky [1965]. For sentence (1) below, it offers the P-marker (2):

(1) The professor (whom) I like...

(2)

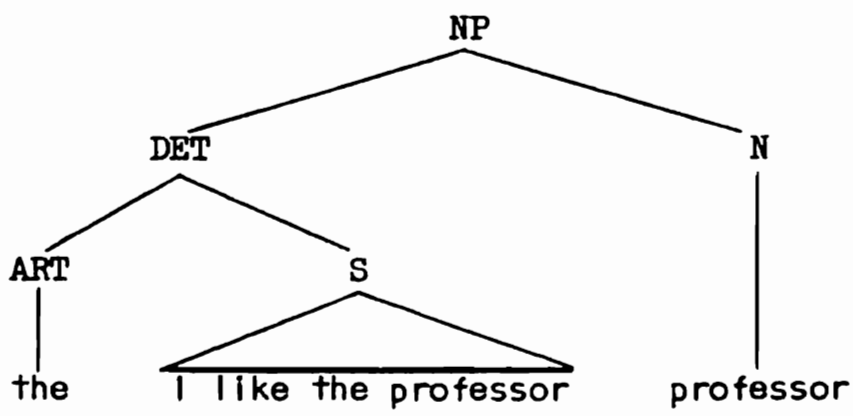

Proponents of this analysis claim that it captures the generality that, in some senses, a RRC acts just like a determiner or article in narrowing down the domain of the modified noun phrase, or restricting it. However, the solution is open to criticism on two fundamental grounds. First, it may very well be that articles and determiners are not deep-structure categories, but rather derive from conventions involving larger previous discourse, reference, and presuppositions. If this is indeed true, the node ART in (2) cannot be a deep-structure node, and the node DET then becomes superfluous, so that one may reduce the sub-rule responsible for structures such as (2) to:

(3) $\mathrm{NP} \rightarrow(\mathrm{S}) \mathrm{N}$

A more severe drawback, however, is the fact that a rule such as (3) (or its predecessor responsible for (2)) is not by itself a recursive rule, although it introduces the recursive category-symbol S. Given this symbol, one may obtain recursivity either through the S-conjunction sub-rule:

$$
S \rightarrow S \text { and } S \text { (and } S \text { )* }
$$

or through further expansion of $S$ to NP-VP etc. While rule (4) may account for conjoined RRC's, rule (3) cannot correctly characterize the recursivity involved in stacked $R R C^{\prime} s-i . e .$, that the first modifier modifies only the head noun, while the next one modifies the alreadymodified noun phrase. The necessity of assuming that stacked RRC's do 
indeed exist will be discussed later on. Given a rule such as (3), however, sentence (5) below can only be characterized by the P-marker (6):

(5) The man who was here whom I saw left

(6)

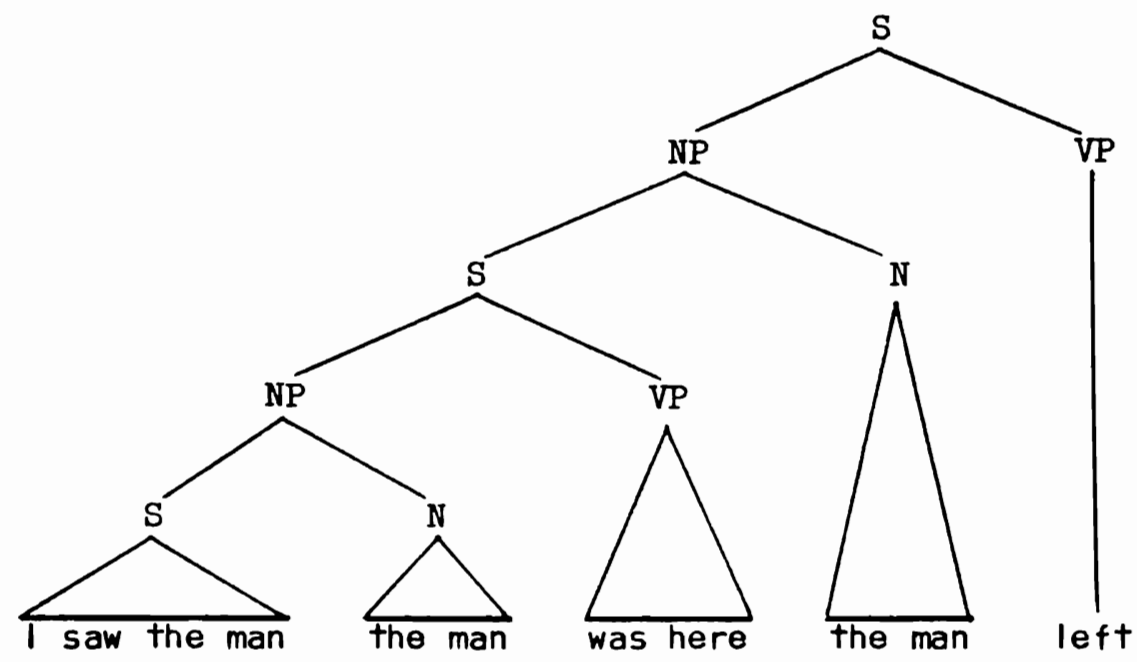

P-marker (6) portrays 1 saw the man as modifying the head noun of The man was here, not the already-modified noun phrase the man who was here. While it is true that an elaborate transformational machinery may permute (6) to yield the correct configuration, there exists a solution which would yield the correct configuration without recourse to that machinery.

b. The conjoined solution. Thompson [1971] has suggested that all relative clauses, including restrictive ones, arise from sentence coordination through a rule such as (4), not from embedding. She claims that (7) below is derived from the conjoined source in (8):

(7) I met a girl who speaks Basque.

(8) (l met girl).(girl speaks Basque)

Several explicit assumptions are associated with Thompson's analysis [1971:3-5]: (a) that definiteness is not a deep-structure category/ feature; or, in her words: ". . that the choice of the definite determiner will in general correlate with certain presuppositions which the speaker makes about the extent of his listener's knowledge ..." 
(b) ". . that the distinction between 'matrix' and 'constituent' sentences in relative clause structures can be seen to relate to nothing in the structural portion of the representation of such sentences . . ." (c) ". . . the 'restrictiveness' of a relative clause is also shown not to be a property best described in terms of an embedding underlying representation . . ."

Thompson further claims that sentences $(9)$ and (10) below are identical in meaning, as are also (11) and (12):

(9) I met a girl and she speaks Basque.

(10) There's a girl who speaks Basque and I met her.

(11) I met a girl who speaks Basque.

(12) A girl I met speaks Basque.

Implicit in her claims, however, is the assumption that structural features such as topic-comment and presuppositions are not part of the deep structure of utterances.

Thompson points out (in private conversation) that her solution can indeed characterize stacked RRC's, by the use of a transformational machinery that, given various presuppositions, would presumably convert a batch of conjoined sentences into the right stacked configuration. Presumably, the stacked interpretation will be then obtained by some surface structure interpretation rule.

The data from luganda presented in this paper indicate that in that language one must account for at least the following surface configurations of RRC's:

(a) Three types of conjoined RRC's, with the conjunction manifested on the surface; and,

(b) Stacked RRC's, with no conjunction manifested on the surface. Given Thompson's solution, the following machinery must be available for converting deep to surface structure in Luganda: 
(a) Transformational rules which will be able to decide which conjoined sentences are to be converted to conjoined RRC's, and which are to be converted into stacked RRC's;

(b) Transformational rules converting some conjoined sentences into the appropriate sequence of stacked RRC's;

(c) Rules of surface interpretation assigning the 'contrastive' meaning to stacked RRC's.

None of these rules is needed in order to account for the data of Luganda in the alternative solution given below.

c. The NP-S solution. Several current formulations of this, notably that of Ross [1967], generate RRC's through a recursive sub-rule such as (13):

(13) $\mathrm{NP} \rightarrow \mathrm{NP} \mathrm{S}$

For a sentence such as (14), this solution would assume the P-marker (15): (14) The boys I saw had beards

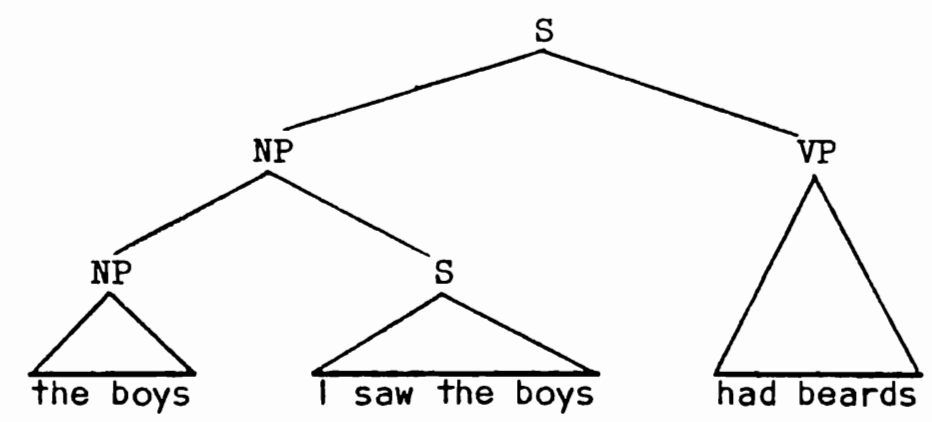

This analysis is probably closer to the surface facts of most languages in which relative clauses follow the head noun (notable exceptions to this are Basque, Amharic and Japanese), though this is not necessarily relevant to its merits. Further, as we shall see below, this is the only solution that characterizes structurally the stacked RRC's construction, without recourse to added transformational or interpretative machinery. Further, it characterizes properly the difference between stacked and conjoined RRC's, the first arising from reapplication of the recursive rule (13), the second from one application of rule (13) and then from the sentence-conjunction rule (4). 
2. Stacked restrictive modifiers in Luganda

Stockwell, Schachter and Partee [1969:471] have noted that for some native speakers of English a surface chain of RRC's can only be inter preted as conjoined, but never as stacked. That is, in terms of the NP-S model described above and given rules (4) and (13), a recursive chain of RRC's is assigned only the structural interpretation (16), but never (17):

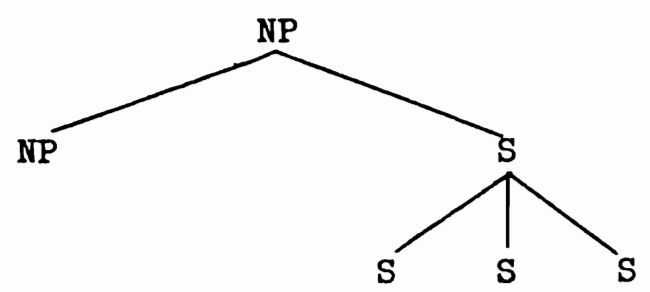

(17)

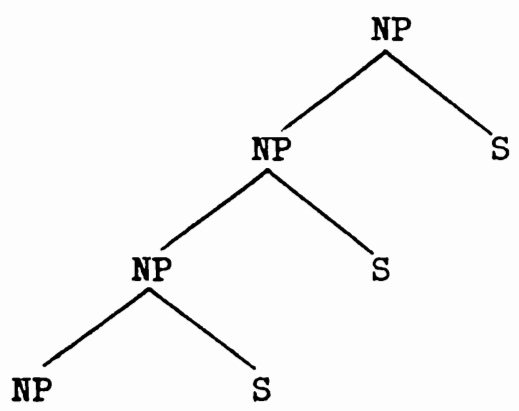

They further note,". - it appears that stacking of relative clauses may be a fairly deep kind of basis for dialect differentiation, such that some speakers have the ART-S deep structure (which is easily constrained against stacking), where others have some sort of $\mathrm{N}-\mathrm{S}$ structure (here the distinction between the NP-S and NOM-S is of no consequence . . ." In other words, the difference between these 'dialects' is assumed to involve the base rules, i.e., it is ascribed to constraints on deep structure.

In this section we shall illustrate the existence of stacked-interpreted relative clauses (and other modifiers) in Luganda. In a following section we will illustrate the existence of conjoined RRC's in Luganda. Eventually, by presenting evidence concerning various constraints on the distribution of stacked and conjoined restrictive modifiers in Luganda, we shall claim that constraints of the kind discussed by Stockwell, 
Schachter and Partee [1969] should be best viewed as constraints on lessthan-deep structure, but not on the base rules of the grammar.

One preliminary note must be given to modifying adjectives in Luganda. The rule of Relative Clause Reduction in Luganda, which pertains to embedded adjectives, and by which (18) below is embedded as a modifying adjective in (19):

$$
\begin{aligned}
& \text { (18) omusajja mu-lungi } \\
& \text { man good } \\
& \text { 'the man is good' } \\
& \text { (19) omusajja o-mu-lungi a-genze } \\
& \text { man good left } \\
& \text { 'the good man left' }
\end{aligned}
$$

is in many ways different from a similar rule operating in English. For one thing, the deletion of the copula and tense marker in the present tense is obligatory in Luganda, so that (20) is therefore ungramatical:

(20) *omusajja e ali (o)mulungi agenze man who is good left

'the man who is good left'

Further, there are strong reasons to believe that the initial vowel of the VCV-agreement prefix of the adjective (i.e., the 0 in o-mu-lungi), functions like a relative pronoun. This means that the Relative Clause Reduction rule deletes the copula but retains the relative pronoun. Since in Luganda the embedded adjective modifier follows the head noun much like relative clauses do, a formal distinction between embedded adjectives and relative clauses, as in English, is not as meaningful. This will be reflected at times in the English glosses given to Luganda adjectival modifiers, where we may use interchangeably adjectival (reduced) or relative clause (unreduced) translations.

Stacked restrictive modifiers in Luganda may obtain for relative clauses, adjectives and 'possessives' (we shall disregard other possibilities here). We will noi attempt to illustrate here all possible combinations. Now, consider the following: 
(21) omusajja omu-lungi omu-nene a-genze

$$
\text { man good big left }
$$

'the big good man left'

(but not the small good one)

Contrast it with (22) below, in which the order of the two modifiers has been changed:

$$
\begin{aligned}
& \text { omusajja omu-nene omu-lungi a-genze } \\
& \text { man big good left } \\
& \text { 'the good big man left' } \\
& \text { (but not the bad big one) }
\end{aligned}
$$

For speakers of Luganda a clear contrast in meaning exists, and the meaning change associated with the order change (and typical of all stacked chains of RRC's) can be rendered as with the following: while the modifier closer to the head noun modifies only the head noun itself, the one next to it modifies the entire modified NP preceding it. In other words, each added modifier in the chain further restricts the domain of the noun phrase.

The same contrast may be obtained with unreduced RRC's:

$$
\begin{aligned}
& \text { omusajja gwe o-labye (e) a-badde wano a-genze } \\
& \text { man whom you-saw who was here left } \\
& \text { 'the man whom you saw who was here left' } \\
& \text { (but not the one whom you saw who wasn't here) }
\end{aligned}
$$

(24) omusajja (e) a-badde wano gwe o-labye a-genze man who was here whom you-saw left

'the man who was here whom you saw left'

(but not the one who was here whom you didn't see )

Given the NP-S analysis, the difference between (23) and (24) above can be represented by the P-markers (25) and (26), respectively: 
(25)

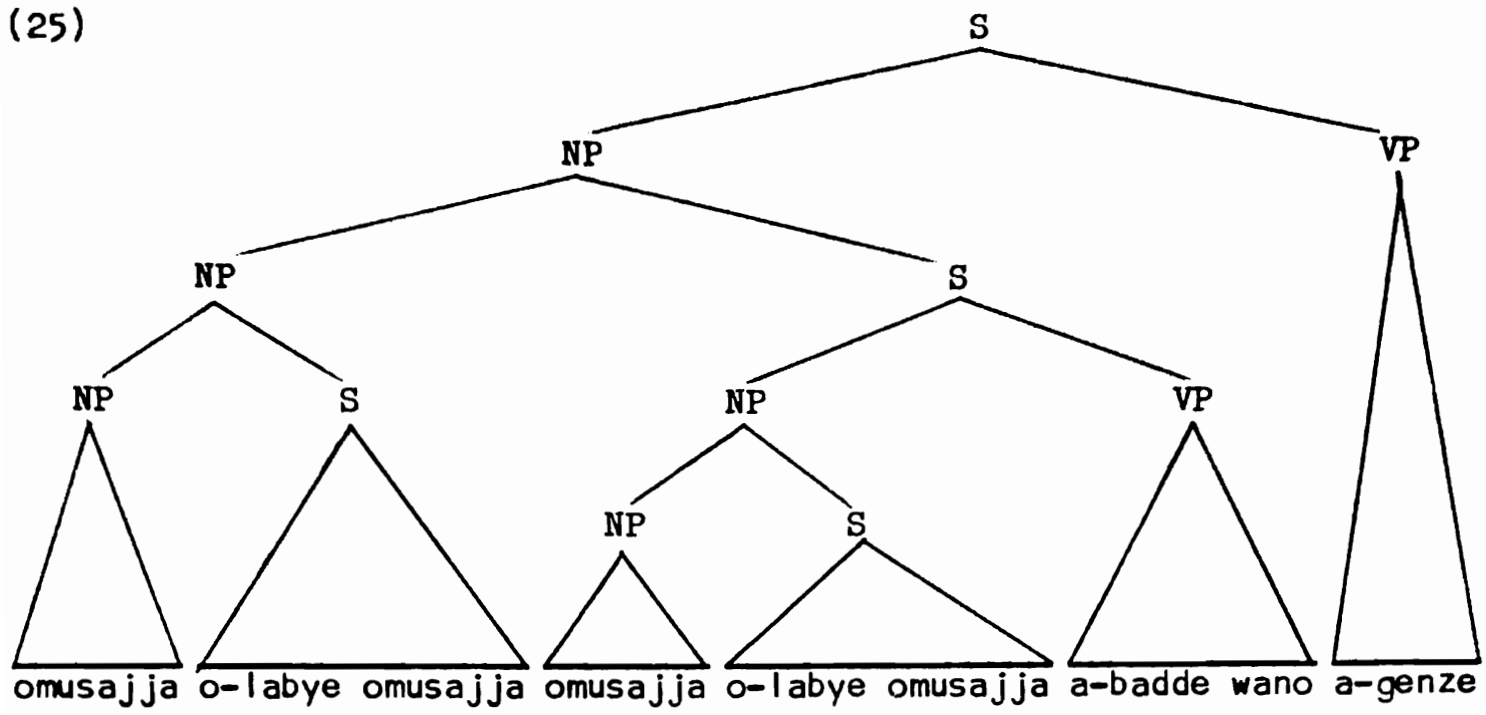

the man you saw the man the man you saw the man was here left

(26)

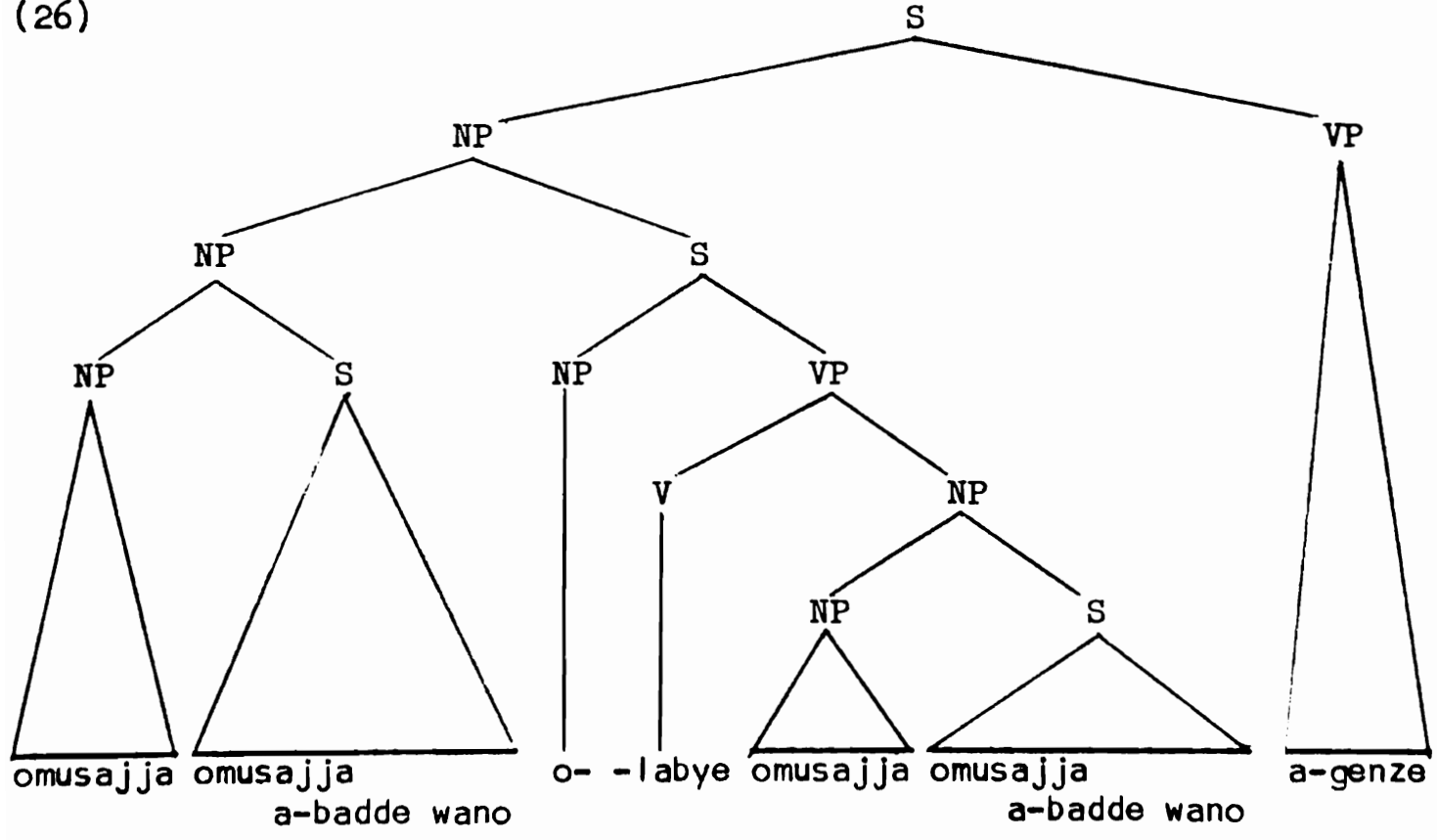

the man the man was here you saw the man the man was here left

The P-markers (25) and (26) above correctly characterize the semantic interpretation of stacked RRC's, namely, that the second (stacked) modifier does not modify the head noun alone, but rather the entire modified clause preceding it. 
3. Conjoined restrictive modifiers in Luganda

There are two major types of confoined RRC's construction in Luganda. Before we turn to examine them, however, notice first that subject head nouns may be ambiguous with respect to the feature [specific/generic]. We shall demonstrate this by using a construction with two stacked RRC's: (27) omusajja omulungi omunene mu-zira man good big (is) brave

Sentence (27) above may be assigned one of the following interpretations: (a) (specific): 'the big good man is brave'

(b) (generic): 'a/any big good man is brave'

Now, coming back to conjoined RRC's in Luganda, the first conjunction type involved that of simultaneous properties or events. With the specific lexical conjunction ate nga, it may be used only to conjoin RRC's which modify generic head nouns. ${ }^{2}$ The second type is the confunction of consecutive events or, alternatively, of a state and a consecutive event. It may be used only if the conjoined RRC's modify a specific (or referentially transparent) head noun.

a. Conjunction of simultaneous properties or events. Note the following:

$$
\begin{gathered}
\text { abasajja a-ba-kola ate nga ba-yimba ba-lungi } \\
\text { men who work and sing (are) good }
\end{gathered}
$$

'(any) men who work and also sing are good'

$$
\begin{aligned}
& \text { abasajja a-ba-lungi ate nga ba-nene ba-zira } \\
& \text { men who (are) good and (are) big (are) brave } \\
& \text { '(any) men who're good and also big are brave' } \\
& \text { 'good, big men are brave' }
\end{aligned}
$$

The generic nature of the head noun involved is also evident from the fact that it cannot take a Demonstrative modifier, so that $(30)$ is ungramatical:

2Under certain circumstances, with the use of the lexical confunction eera (or eera nga), it is possible to obtain structures in which the conjunction of simultaneous events/properties modifies a specific noun. (see section 4, examples (65), (66)). 
(30) *omusajja ono omulungi ate nga munene mu-zira
man this good and big (is) brave

though without the Demonstrative, (31) is grammatical:

(31) omusajja omulungi ate nga munene mu-zira man good and big brave

'a/any man who's good and also big is brave'

b. Conjunction of consecutive events. Observe the following:

(32) omusajja e ya-genze ne a-komawo mu-lungi man who left and returned (is) good

'the man who went and then came back is good'

'*any man who left and then came back is good'

The second, generic, interpretation is of course a correct English sentence, but is the wrong interpretation for (32), where a specific head noun is obligatory. The specific nature of the head noun is also evident from the fact that it may be modified by a Demonstrative, as in:

$$
\begin{aligned}
& \text { omusajja ono e ya-genze ne a-komawo mu-lungi } \\
& \text { man this who left and returned (is) good } \\
& \text { 'this man who left and then came back is good' }
\end{aligned}
$$

One can also demonstrate the consecutive nature of this confunction. Note first that the 'tense' is the second verbal in the conjunction must be the narrative (unmarked) tense; i.e., the stem -kola in (34) below is preceded only by the subject-agreement morpheme a-:

(34) omusajja e ya-genda ne a-kola mu-lungi $\operatorname{man}$ who left and work (is) good

'the man who left and then worked is good'

This is a rule of obligatory tense deletion, presumably under some conditions of tense identity, or perhaps conditions of tense sequence, i.e., that the tense in the second verbal indicates the same or a later time category than that in the first verbal. For this reason, all the alternatives in (35) below are ungrammatical, though semantically conforming to the sequentiality requirement: 
(35)

$$
\begin{aligned}
& \text { *omusajja e ya-genda ne }\left\{\frac{\frac{y a-k o l a}{y a-k o z e}}{\frac{a-k o z e}{\text { warked }}}\right\}_{\text {mu-l ungi }} \\
& \text { man who left good }
\end{aligned}
$$

By themselves, ya-genda 'left long ago', ya-kola 'worked long ago', ya-koze 'worked within 18-24 hours' and a-koze 'has just worked'. Thus, the violation responsible for the ungrammaticality of (35) is not a deep semantic one, but rather a violation of the obligatory, late (possibly even a second-lexicon) rule of equi-/sequi-tense deletion. This rule probably applies to sentence-conjunction as well, so that while the following, with an 'unmarked' tense in the second verbal, is grammatical:

$$
\begin{aligned}
& \text { omusajja ya-genda ne a-kola } \\
& \text { man left and work } \\
& \text { 'the man left and then (he) worked' }
\end{aligned}
$$

the following is just as ungrammatical as (35):

$$
\begin{gathered}
\text { *omusajja ya-genda ne }\left\{\frac{\frac{y a-k o l a}{\text { ya-koze }}}{\frac{a-k o z e}{\text { worked }}}\right\} \\
\operatorname{man} \text { left and }
\end{gathered}
$$

In addition, one could also demonstrate that the constraint requiring sequentiality (consecutiveness) is indeed a deep semantic constraint. This may be done by choosing two events which may occur only in one specific order, but not the other. Thus:

(38) omusajja gwe na-laba ne m-mu-lamusa a-genze

$$
\text { man whom I-saw and I-greet-him left }
$$

'the man whom I saw and greeted left'

but not:

(39) *omusajja gwe na-lamusa ne m-mu-laba a-genze

$$
\text { man whom I-greeted and I-see-him left }
$$

' the man whom I greeted and then saw left' 
There exists a stylistic variant, with somewhat less restricted distribution, for rendering the second (unmarked) verbal of the conjunction. It involves repeating that second verbal in its infinitival form (when contrasts exist, this variant seems to stress further the consecutive nature of the conjunction). In certain constructions this variant is obligatory, though in the following it is optional:

$$
\begin{aligned}
& \text { omusajja e ya-kola ne a-yimba ne oku-yimba a-genze } \\
& \text { man who worked and sing and to sing left } \\
& \text { 'the man who worked and then sang left' }
\end{aligned}
$$

(41) omusajja gwe na-laba ne m-mu-lamusa ne oku-mu-lamusa a-genze man whom I-saw and I-him-greet and to-him-greet left

'the man whom I saw and then greeted left'

Another interesting feature of this conjunction of consecutive events, is that it cannot be used to conjoin two adjectives, which in Luganda are all stative and thus may not be construed as events. So that the following is ungrammatical in Luganda:

$$
\begin{gathered}
\text { *omusajja o-mu-lungi ne mu-nene a-genze } \\
\operatorname{man} \text { who (is) good and big left }
\end{gathered}
$$

Sentence (42) may be made grammatical with a slight adjustment, but then it ceases to be a conjunction of modifiers to the same head noun, and becomes a conjunction of two non-coreferential noun phrases, the second of which uses an adjective as an anaphoric head:

$$
\begin{aligned}
& \text { omusajja omulungi ne o-mu-nene ba-genze } \\
& \text { man good and big-one left (pl. concord) } \\
& \text { 'the good man and the big (one) left' (good man } \neq \text { big one) }
\end{aligned}
$$

As to the level at which the constraint barring the conjunction of stative modifiers can be expressed, it seems clear that it could not be a surface structure constraint, since it holds true also for the conjunction of unreduced relative clauses containing the same adjectives (we here assume that modifying adjectives are indeed derived from those), so that the following is also ungrammatical: 
(45) *omusajja e yali omulungi ne ali (0)munene a-genze
$\operatorname{man}$ who is good and is big left

Thus, the constraint is in some sense a semantic constraint in Luganda. Sentence (45) above may again be slightly changed, to yield a grammatical sentence--in which the confunction is again of noun phrases (noncoreferential) rather than of modifiers to the same head. That is:

(46) omusajja e yali omulungi ne a yali omunene ba-genze $\operatorname{man}$ who is good and who is big left (pl.

'the man who's good and the (one) who's big left' concord)

(the man who's good $\neq$ the one who's big)

There are grounds to believe, however, that the semantic constraint on this conjunction type involved only the non-stativity of the second conjoined modifier. This is apparent from the fact that (45) may be changed into the grammatical (47) by substituting 'be' with 'become': (47) omusajja e yali omulungi ne a-fuka omu-bi a-genze ${ }^{3}$ man who was good and become bad left

'the man who was good and then became bad left'

As to universality of the seemingly semantic constraint on this type of conjunction, its validity is not readily apparent. Sentences such as:

(48) The man who was here today and there tomorrow ...

The man who was brave one day and cowardly the next...

seem to be perfectly natural and in no way semantically 'odd'. This opens an interesting question, one which we do not intend to fully answer here. It has been customary in recent years to assume that deep (semantic) structure is more universal than surface structure. Could this be

${ }^{3}$ There is probably a considerable difference between the lexical item 'be' in English and the copula $-1 i$ in Luganda. English 'be' is either ambiguous with respect to 'be' vs. 'become', or at least allows elliptic uses which correspond to non-stative interpretations (see Givon [forthcoming]). The Luganda copula carries only the meaning of the strictly-stative 'be'. 
also extended to the various constraints operating on deep versus lessthan-deep structures? The data presented above, as well as some more to follow, suggest that an extension of this kind is by no means guaranteed. That is, that some semantically definable constraints (and thus, presumably, deep structure constraint, within our frame of reference), may turn out to be of less than universal validity.

4. The stacking of conjoined modifiers

In the preceding two sections we have shown, separately, the two types of recursivity available for RRC's in Luganda: stacked RRC's and conjoined RRC's. We have suggested that a recursive rule such as (13), together with the sentence conjunction rule (4), can account for both types of recursivity. These rules predict, however, that at any 'stacked' node arising from the application of rule (13), conjunction may arise as a result of applying rule (4). That is, that structures such as both (49) and (50) below are possible (here one may also read interpretations' for 'structures', if one so wishes):

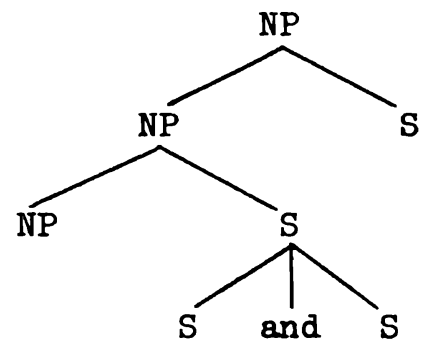

(50)

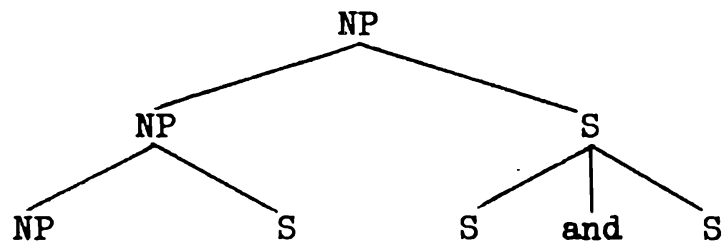

In the space below we will attempt to investigate these predictions, separately for the two conjunction types involved.

a. The stacking of consecutive-conjoined RRC's. In the case of this conjunction (with the lexical confunction ne), structures (or interpretations) such as both (49) and (50) are indeed obtained: 
(51) omusajja gwe na-laba e ya-koze a-genze (stacked with no conman whom I-saw who worked left junction)

'the man whom I saw who worked left'

(52) omusajja gwe na-laba e ya-koze ne a-yimba ne-okuyimba a-genze (as in $(50))$

man whom I-saw who worked and sing and to-sing left

'the man whom I saw who worked and later sang left'

(53) omusajja e ya-koze gwe na-laba a-genze (stacked with no conman who worked whom I-saw left junction)

'the man who worked whom I saw left'

(54) omusajja e yakoze ne a-yimba ne-okuyimba gwe na-laba a-genze (as in (49))

man who worked and sing and to-sing whom I-saw left

'the man who worked and later sang whom I saw left'

In structures (52) and (54) above, which involve conjunction as well as stacking, the presence of a confunction in no way interferes with the characteristic stacked interpretation obtained.

b. The stacking of simultaneous-confoined RRC's. At this point additional constraints begin to manifest their presence:

(55) omusajja omulungi omunene a-kola nnyo (stacked with no con$\operatorname{man}$ good big works hard junction)

'any good big man works hard'

(56) omusajja omulungi omunene ate nga mu-zira a-kola nnyo (as in (50)) man good big and brave works hard

'any good man who's big and brave works hard'

(57) omusajja omunene omulungl a-kola nnyo (stacked with no conjunction) man big good works hard

'any good big man works hard'

(58) *omusajja omunene ate nga muzira omulungi a-kola nnyo man beg and brave good works hard 
Further, on persistent examination, it turns out that the interpretation assigned to (56) above (i.e., assuming that it has some stacked structure in it), is also wrong and that, rather, the only interpretation assigned is a three-way confunction of all three restrictive modifiers;

that is:

(56') omusajja omulungi, omunene ate nga muzira a-kola nnyo

'any good, big and brave man works hard'

'any man who's good, big and brave works hard'

In other words, (56) is interpreted as arising from neither structure (49) nor $(50)$, but rather from:

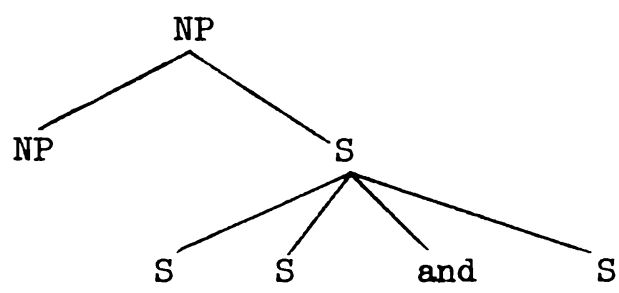

We are thus left with a curious constraint on (at least) the distribution of surface strings in the presence of the ate nga conjunction (of simultaneous properties/events). It may be formulated the following way:

(60) If a single confunction of the simultaneous type is found to conjoin two RRC's in a longer chain of RRC's, the entire chain may never be interpreted as having a stacked structure (as in (49) or (50) above), but will always be interpreted as a multiple conjunction of RRC's (i.e., as in (59)).

Given constraint (60) above, the ungrammaticality of (58) may simply arise from a (probably universal) restriction on surface conjunctions of the form:

(61) *A-and-B-C...

We have on purpose formulated constraint $(60)$ as a surface-structure constraint. By that we only mean that it applies at a level of less-thandeep structure. An alternative would be, of course, attempting to 
constrain the recursivity of rule (13) in some way; that is, regarding this constraint as a deep structure constraint. We feel this alternative is inappropriate, especially since constructions such as (49) and (50) seem in fact to be manifested in Luganda when the ne conjunction (consecutive) is involved. Rather, it may very well be that constraint (60) is in fact rooted in perceptual strategies, in the sense discussed by Bever and Langendoen [1970]. Thus, one may argue that the less-than-deep structure of (56) above:

(62) [NP [REL REL ate nga REL] ] np

is indeed ambiguous with respect to the constraints on deep structure, i.e. given our rules (13) and (4). So that, in principle, given (62), two alternative structural interpretations are available to the Luganda speaker:

(63) [ [NP REL $]_{n p}[\mathrm{REL} \text { ate nga REL] }]_{\mathrm{np}}$ (as in (50), stacked) (64) [NP [REL, REL ate nga REL] $]_{n p}$ (as in (59), non-stacked) At the surface (or 'less-than-deep') structure level, however, constraint (60) operates, so that the speaker in fact assigns only the non-stacked interpretation (64).

There are several pieces of data which suggest that constraint (60) is not a deep structure constraint. First, notice that if a different structural type of a relative clause is involved (i.e., if it is not the case that all three modifiers are of the same internal structure), a stacked interpretation may be obtained in spite of the presence of a conjunction. For this, we need to digress a little.

We have noted earlier that the conjunction ate nga may conjoin only modifiers of non-specific head nouns. However, there exists in Luganda a conjunction of simultaneous properties-events which may conjoin the modifiers of specific head nouns, the confunction eera. In the following example, the conjunction ate nga cannot be used (that is, the head noun must be specific) due to the presence of an object relative clause with a particular (non-generic) tense as well as a probably-referential 
pronoun. However, if eera is used instead, a structural interpretar tion such as (49) is readily obtained:

$$
\begin{aligned}
& \text { omusajja omunene eera mu-zira gwe na-laba a-kola nnyo } \\
& \text { man and brave whom I-saw works hard } \\
& \text { 'the big and brave man that I saw works hard' }
\end{aligned}
$$

Constraint $(60)$ is seemingly incorrect, then, since (65) seems to violate it. One may of course argue that it is possible to re-formulate (60) in terms of either the conjunction ate nga or, alternatively, the non-specificity of the head noun. There are reasons to believe, however, that it is not the semantic nature of the conjunction or the head noun that is involved in this particular constraint, but rather the interaction of universal perceptual strategies with respect to coordinate constructions. First, note that (66) below, which could have been, presumably, assigned both a stacked (as in (50)) and conjoined (as in (59)) interpretation, is assigned only a conjoined interpretation--in spite of the fact that the first RRC is not of the same structural type as the two conjoined ones:

$$
\begin{aligned}
& \text { omusajja gwe na-laba omunene eera mu-zira a-kola nnyo } \\
& \text { man whom I-saw big and brave works hard } \\
& \text { 'the man whom I saw, who is big and who is brave works hard' } \\
& \text { '* the man whom I saw who's big and brave works hard' }
\end{aligned}
$$

We would like to suggest that the fact that (65) is assigned a stacked interpretation while $(66)$ is not, is due to the interaction of three perceptual principles pertaining to the interpretation of coordinate structures :

(a) A principle by which structures of the same structural type are more likely to be interpreted as conjoined than structures of dissimilar structural type; ${ }^{4}$

\footnotetext{
${ }^{4}$ From notes of a lecture given by Thomas Bever at U.C.L.A. in May, 1970, we find: "In ' $x . . . y$ conjunction, Z...' ', in which $x, y, \ldots z$ are identical constituent types of type $T$, then the entire sequence is a conjoined phrase of the type T..." as an example of a perceptual strategy with respect to the assignment of conjoined interpretations.
} 
(b) Constraint (61) proscribing conjoined structures of the form A-andB-C • • : ;

(c) Constraint $(60)$, or at least the part of it which suggests that in the presence of one overt conjunction in a chain of modifiers, the entire chain is likely to be interpreted as conjoined.

We would further suggest that constraint $(60)$ be reformulated and principle (a) above incorporated into it, to then read:

(67) If a single conjunction of the simultaneous type is found in a chain of RRC's, and if all the RRC's in the chain are of the same structural type, then the entire chain may not be interpreted as involving a stacked structure (as in either (49) or (50)), but only as a multiple conjunction of the RRC's (as in (59)).

Let us now see how (67) and (61) can account for the facts of Luganda. We shall assume here that they are conjunctively ordered with (67) applying first:

Sentence (56):

The structures of the RRC's are identical and a conjunction is present; constraint (67) assigns a multiply-conjoined interpretation; constraint (61) does not apply.

Sentence (58):

The structures of the RRC's are identical and a conjunction is present; constraint (67) assigns a multiple-conjunction interpretation; constraint (61) blocks it as ill-formed; both possible interpretations are blocked, and the utterance is thus ungramatical.

Sentence (65):

The structures are not identical, so that constraint (67) does not automatically assign a multiply-conjoined structure; constraint (61), further, blocks a conjoined interpretation altogether; the only interpretation left is a stacked one, which is thus assigned. 
Sentence (66):

The structures are not identical, but a conjunction is present; constraint (67) does not block a stacked interpretation; but constraint (61) does not block a conjoined interpretation either; since the conjoined interpretation seems to win over the stacked one, another principle governing the relation between $(61)$ and $(67)$ is required, namely:

(68) If (67) and (61) allow both interpretations, the conjoined interpretation wins over the stacked.

Principle (68) can probably be incorporated as a modification of (67), though for the moment we shall refrain from so doing.

5. Other surface-structure constraints on RRC's

In the preceding section we have argued that some constraints on the distribution of stacked and conjoined modifiers in Luganda can be best understood as perceptually motivated constraints on less-than-deep structure. In this section we would like to show that perceptual principles as those invoked above, and in particular the principle of structural similarity with respect to conjoined structures, play an important role in constraining the output of RRC's in Luganda.

Note, first, that while one may stack restrictive adjectives in Luganda, one may not stack two subject-relative clauses in a row:

(69) omusajja omulungi omunene a-genze man good big left

'the big good man left'

(70) omusajja e ya-kola a-genze man who worked left

'the man who worked left'

(71) omusajja e ya-yimba a-genze

man who sang left

'the man who sang left'

but not: 
(72) "omusajja e ya-kola e ya-yimba a-genze man who worked who sang left

However, while stacking is blocked here, conjoining is not, and one may obtain the following:

(73) omusajja e ya-kola ne a-yimba a-genze

man who worked and sing left

'the man who worked and later sang left'

(74) omusajja (e) a-kola ate nga a-yimba mu-lungi man (who) works and sings good

'any man who works and also sings is good'

(75) omusajja a-kola eera a-yimba mu-lungi man works and sings good

'the man who works and also sings is good'

A similar restriction holds with respect to object relative clauses, which again cannot be stacked in a row--but only conjoined:

(76) omusajja gwe na-laba a-genze

man whom I-saw left

'the man whom I saw left'

(77) omusajja gwe na-lamusa a-genze man whom I-greeted left

'the man whom I greeted left'

but not stacked in a row:

(78) "omusajja gwe na-laba gwe na-lamusa a-genze

man whom I-saw whom I-greeted left

Though again, the conjunction of the same RRC's is permitted:

(79) omusajja gwe na-laba ne m-mu-lamusa a-genze

man whom I-saw and I-him-greet left

'the man whom I saw and then greeted left' 
Now, notice that if one of the RRC's in the chain is a subject relative clause, while the other is an object relative clause, stacking becomes permissible:

(80) omusajja e ya-kola gwe na-laba a-genze

man who worked whom I-saw left

'the man who worked whom I saw left'

(81) omusajja gwe na-laba e ya-kola a-genze man whom I-saw who worked left

'the man whom I saw who worked left'

A similar dissimilation of structure may be also achieved with reduced adjectives:

(82) omusajja e ya-kola omulungi a-genze man who worked good left

'the good man who worked left'

(83) omusajja omulungi e ya-kola a-genze man good who worked left

'the good man who worked left'

(84) omusajja gwe na-laba omulungi a-genze man whom I-saw good left

'the good man whom I saw left'

(85) omusajja omulungi gwe na-laba a-genze man good whom I-saw left

'the good man whom I saw left'

It seems, then, that the principle of structural similarity acts here again as an important, though probably not sole, determiner of the speaker's ability to interpret chains of RRC's as either stacked or conjoined. There is no apparent semantic reason for blocking sentences (72) and (78). Their interpretations in English are both grammatical ('the man who worked who sang left', 'the man whom I saw whom I greeted left'), at least for people who accept stacked interpretations. The fact that even for those people these interpretations are somewhat odd, is not at 
all surprising. It may very well be that the same perceptual mechanism which causes a construction to be 'fully ungrammatical' in one language, causes it to be 'only odd' in another. We shall return to this subject below.

Finally, we would like to illustrate that this constraint could not be a deep structure constraint. Notice that while it does not apply to modifying adjectives (presumably derived from fully reduced relative clauses), it does apply to relative clauses which carry the same semantic interpretation: 5

(86) omusajja omulungi omunene ya-li mu-zira man good big was brave

'the big good man was brave'

(87) *omusajja e ya-li omulungi e ya-li omunene ya-li mu-zira man who was good who was big was brave

\section{Conclusions}

a. Constraint on deep structures. We have shown that of the three main models available for describing the recursive, embedded structure of restrictive relative clauses, only one--the NP-S model (as in Ross [1967]) is capable for fully accounting for the facts of luganda (and, for that matter, of English). Neither the ART-S model (as in Chomsky [1965]), nor the conjoined model (as in Thompson [forthcoming]) can account for the strong surface distinction between stacked and conjoined RRC's in Luganda in quite as satisfactory a manner. In particular, these two models are ill-suited for describing stacked RRC's. We would thus like to conclude

5Within the framework of a theory which does not wish to derive adjectives from relative clauses, this would of course be an added argument against deriving the former from the latter. In our opinion, an argument of this sort does not carry much weight in this case, since the constraints in question may well turn out to be indeed perceptually motivated-and applying to less-than-deep structures. This makes their use for resolving arguments about deep structures highly questionable. 
that our recursive rule (13) and the recursive rule (4) (conjunction), are the only deep structure constraints needed for the grammar of restrictive relative clauses.

b. Constraints on less-than-deep structures. We have also shown, we believe, that in addition to the two deep structure constraints (recursive base rules) mentioned above, other constraints are also relevant for determining the surface distribution of RRC's. These constraints are complex and subtle, and we do not pretend to understand them fully. From the data presented above, however, it seems reasonably clear that many limitations on the distribution and interpretation of chains of RRC's as stacked or conjoined are explicable in terms of constraints on less-than-deep structures. It is also likely, we believe, that these constraints may turn out to be perceptually motivated, in the sense elaborated by Bever and Langendoen [1970]. It is likely, further, that constraints of this type may operate not at one point, but perhaps at several points of less-than-deep structure. The indications for this are not fully clear, but the question is still open. As to the universality of these constraints, it may well turn out that constraints on less-thandeep structures are as universal as those constraining deep structures. This should come as no surprise, of course, since if they are indeed motivated by perceptual strategies, one would hardly expect those to be of less than universal validity.

c. Some reflections about constraints on RRC's in English. Stockwell, Schachter and Partee [1969] claim that many speakers of English cannot assign a stacked--but only conjoined-interpretation to chains of RRC's. They claim that this may be a constraint on the deep structure grammar of these speakers. We would like to diverge sharply from this claim. Given the facts discussed above, we would like to suggest that while the grammar of RRC's in English is the same for all speakers-and includes a recursive rule such as (13) which allows for stacking, speakers may differ as to the degree to which perceptual strategies actually intervene and block certain structural interpretation of surface chains of RRC's. It is a fact, for example, that speakers who do not accept a stacked 
interpretation of relative clauses, accept more readily a stacked interpretation of preposed adjectives. This is extremely reminiscent of the facts of Luganda discussed at the end of Section 5, above. It also suggests that it is not a constraint on deep structures which blocks a stacked interpretation for these speakers, but rather a perceptually motivated constraint on less-than-deep structures.

It also seems that the constraints involving the principle of structural similarity in conjunction may be manifest in English in some fashion. For example, it seems that with structurally similar RRC's, the conjoined (88) and (89) are much more acceptable than the stacked (90):

(88) The man who worked and sang ...

(89) The man who worked and then sang . .

(90) ?The man who worked who sang . • .

On the other hand, given the structurally dissimilar RRC's below, the stacked (91) and (93) seem preferable to the conjoined (92) and (94):

(91) The man (whom) I saw who left . •

(92) ?The man (whom) I saw and who left...

(93) The man who left whom I saw ...

(94) ?The man who left and whom I saw ...

In short, it seems that perceptually motivated constraints of the kind we believe to exist in Luganda, may also exist in English. 


\section{REFERENCES}

Bever, Thomas, and D. Terence Langendoen. 1970. "The interaction of speech perception and grammatical structure in the evolution of language." Unpublished paper.

Chomsky, Noam. 1965. Aspects of the Theory of Syntax. Cambridge: MIT Press.

Givon, Talmy. Forthcoming. "Notes on the semantic structure of English adjectives." Language.

Perlmutter, David。 1968. "Deep and surface structure constraints in syntax." Massachusetts Institute of Technology doctoral dissertation.

Ross, John Robert. 1967. "Constraints on variables in syntax." Massachusetts Institute of Technology doctoral dissertation.

Thompson, Sandra Annear. Forthcoming. "The underlying structure of relative clauses," in Studies in Linguistic Semantics. Edited by Charles J. Fillmore and D. Terence Langendoen.

Stockwell, Robert P., Paul Schachter, and Barbara Partee. 1969. U.C.L.A. English Syntax Project: Integration of Transformational Theories on English Syntax. Los Angeles: U.C.L.A. Printing and Production. 


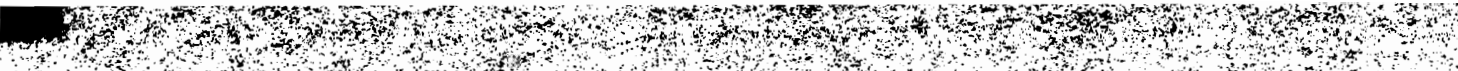
- 1 of

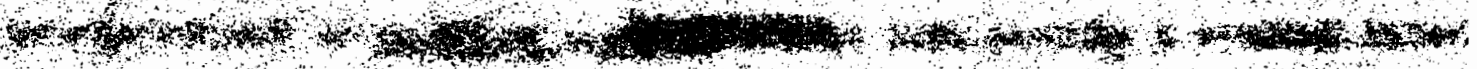

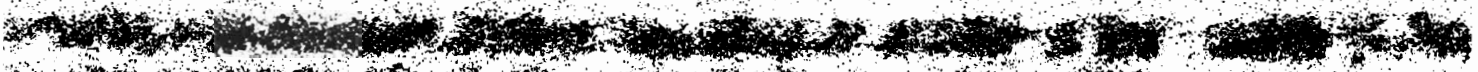

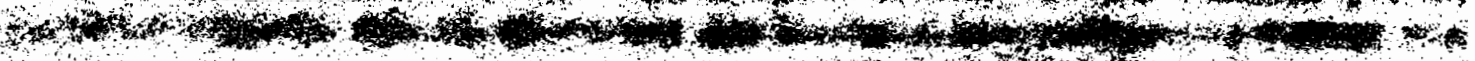

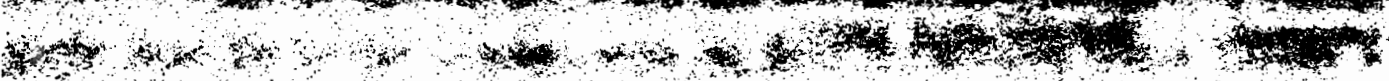

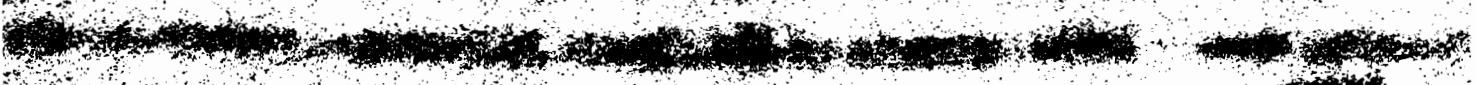

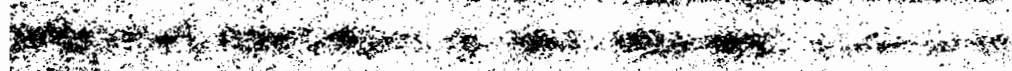

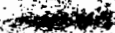

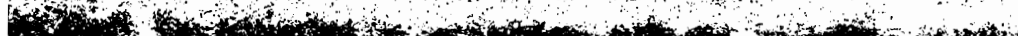

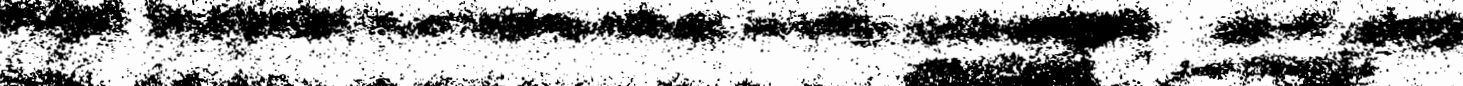
3. 1)

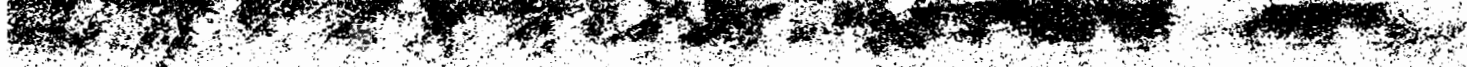

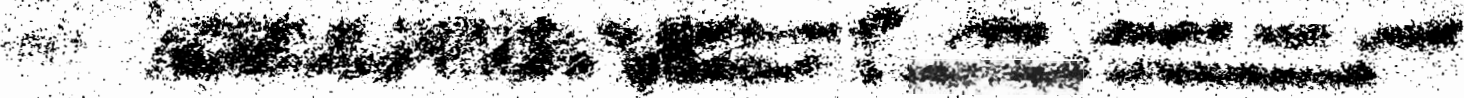

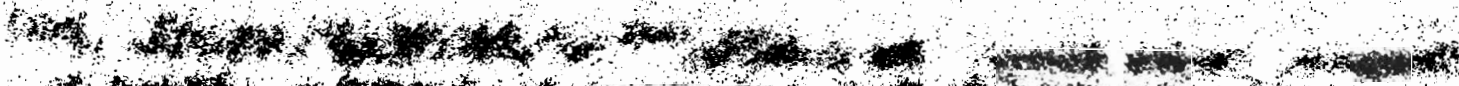

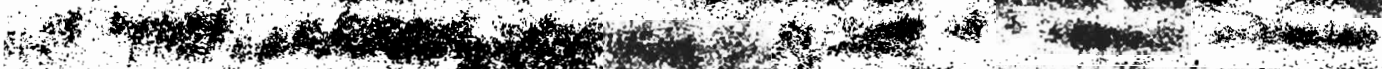
H.p.

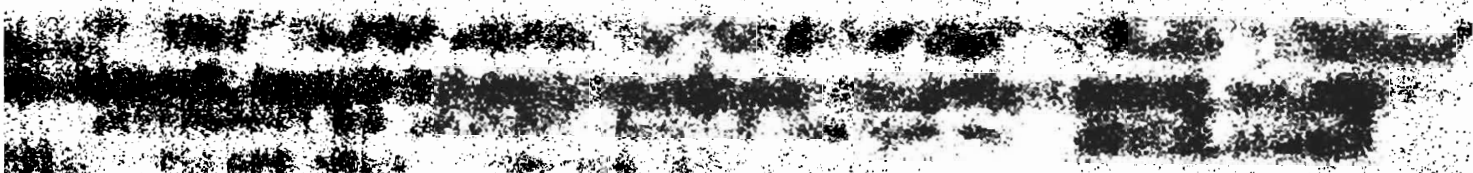

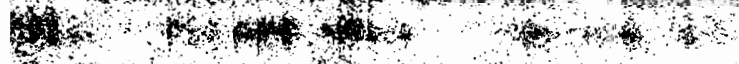

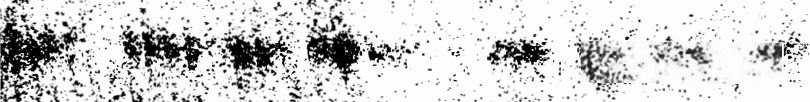

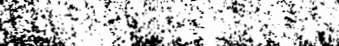

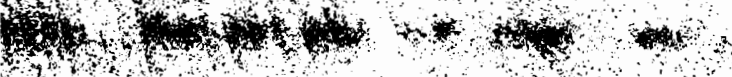

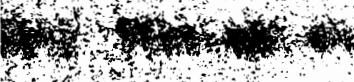

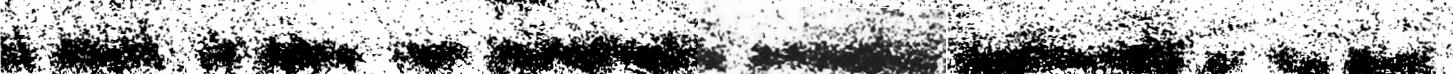

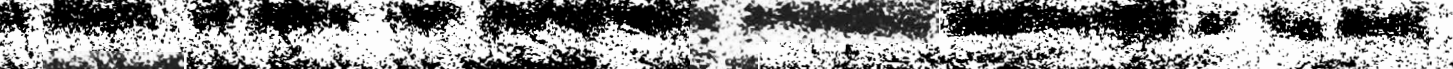

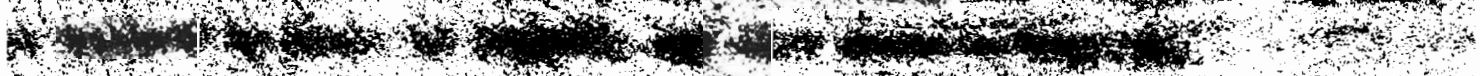

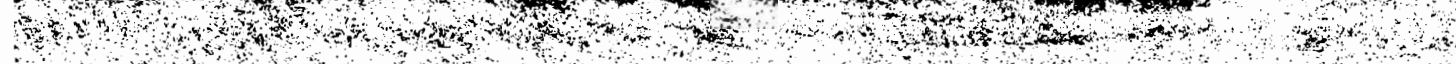

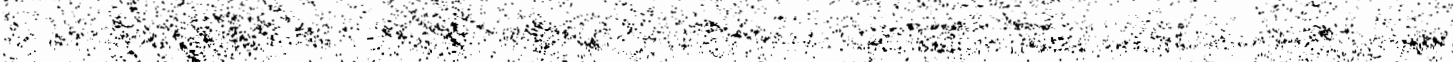

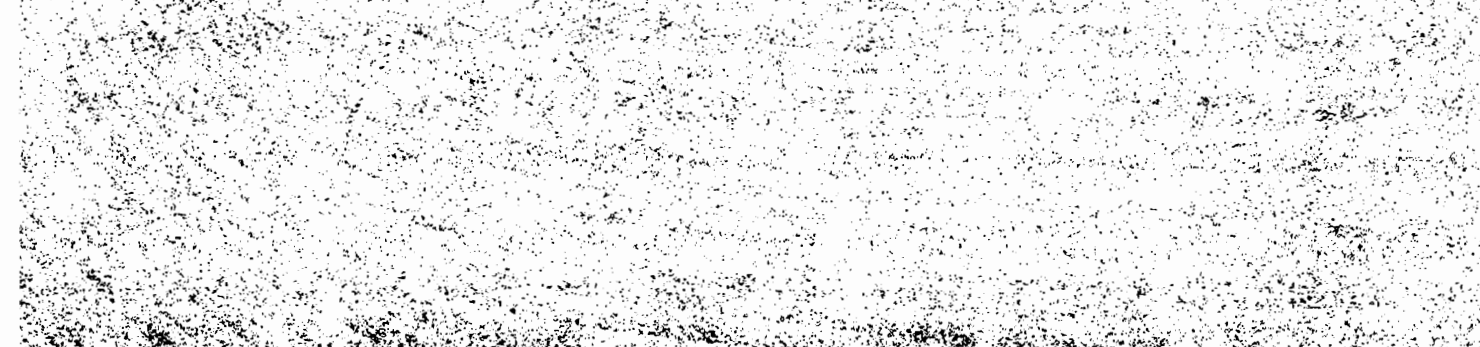

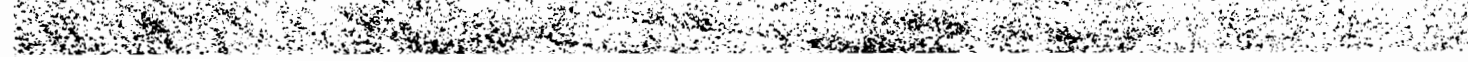




\section{NOUN CLASS LEVELLING IN BAMILEKE ${ }^{1}$}

\section{Larry M. Hyman, Erhard F. K. Voeltz and Georges Tchokokam Department of Linguistics \\ University of California, Los Angeles}

It has long been known that African noun class systems are not an isolated phenomenon in Bantu alone. Traces of noun classes have been observed in virtually all of the postulated sub-branches of Niger-Congo, with the possible exception of Mande. It is nonetheless true that a sizeable proportion of Niger-Congo languages exhibit the properties of a one-time universal system of noun classes (probably with prefixes and suffixes denoting class membership--see Welmers [forthcoming] for an exemplification of this position) that has by and large been reduced to nothing in Mande and to an insignificant role in much of Kwa. Somehow a complex noun class system was levelled, leaving groups of languages still undeniably related to those languages maintaining such a system (i.e. Bantu). How was this effected? What were the intermediate steps involved? In the Bamileke cluster of languages in Cameroon may lie a possible answer to these questions. Here we observe that in languages traditionally qualified as Semi-Bantu or Bantoid much of the noun class system they once shared with Bantu has been lost. In the Fe'fe' dialect (spoken in the vicinity of Bafang) there are strong indications that the remaining noun classes will survive no more than another generation or two.

In the following exposition we shall present data from $\mathrm{Fe}^{\prime}$ fe' dialect establishing a set of seven $\mathrm{sg} / \mathrm{pl}$ noun class pairings (genders). Some attention will be focused on three other Bamileke languages (Ngwe, Bangangté, Bandjoun), which we have not personally investigated, but about whose noun classes documentation is available from the literature.

IWe would like to thank the directors of the Nufi schools in the Bamileke region of Cameroon for helping and encouraging us on many occasions. 
This paper is divided into three sections. In the first, the criteria for distinguishing Bamileke noun classes are presented along with those groupings we have arrived at. In the second section we discuss the productivity of these noun classes. In the final section, Fe' $f e^{\prime}$ is considered in the broader context of comparative Benue-Congo. It is our contention that much of what we shall present actually occurred in some form or another in many of the languages of Kwa (Igbo, Yoruba, Nupe) and in Mande, resulting in the present absence of noun classes in these languages. Thus it is highly instructive to consider the status of Bamileke noun classes.

\section{Noun classes in Fe' fe'}

In Bantu languages the noun class membership of a specific noun is typically identified by its class prefix. In addition, complex processes of concord in a variety of situations help to establish the identity of a noun's class membership. In some Bamileke languages many of these concord properties are maintained. Thus, as Dunstan [1966] reports, noun class concord in Nowe is observed in possessives, adjectives, demonstratives, relatives, and a variety of other constructions. Nominals also generally consist of a class prefix plus a noun stem. On the basis of these phenomena it is possible to set up a system of noun classes in Ngwe. Other dialects, however, do not mark the identity of noun class membership as pervasively as in Ngwe. While Bangangté and Bandjoun seem somewhat intermediate [Voorhoeve 1968], the only context in which the full range of noun classes are differentiated in $\mathrm{Fe}^{\prime} \mathrm{fe}^{\prime}$ is in the observed concord of possessive pronouns. In most cases the original noun class prefix has been lost--or, if it once consisted of a nasal consonant plus a vowel, neutralized as a fully assimilated nasal prefix. We shall witness the remaining function of this nasal prefix in our discussion of classes $A$ and $F$ below.

We now present the noun classes of $\mathrm{Fe}^{\prime} \mathrm{fe}^{\prime}$ accompanied first by their respective possessive pronoun concord, and second by their respective noun class prefix, if any. These classes are exemplified in Table $l$. 


\section{Class}

A. sg.

pl.

B. sg.

pl.

C. $\mathrm{sg}$.

pl.

D. sg.

pl.

E. sg.

pl.

F. sg.

pl.

G. sg.

pl.

\section{Possessive Concord}

$0=$

b-

$m$

m-

z-

m-

$\phi=$

z-

$\varnothing=$

z-

$n=11=$

m-

$\phi=$

m-
Cless Prefix

$(\operatorname{mèn}) \emptyset-/ N-$

( pii) N-

N-

N-

$\varnothing$

N-

$\varnothing$

$\phi-$

$\mathrm{N}-$

N-

$\emptyset-/ N-$

N-

$\emptyset-$

N-

Table I

Fe'fe' Noun Classes

In the second and third columns a tone mark over a consonant (or $\emptyset$ ) denotes the tone of the immediately following vowel of the pronoun. [-] denotes mid, ['] lower-mid and ['] low. Elsewhere ['] denotes high tone. The tone is given only in the singular, since plural tone is predictable (and invariant). In addition to $A-G$ there are apparently four mass classes in which there is no $\mathrm{sg} / \mathrm{pl}$ alternation. Their concordial agreement is identical to parts of $A-G$ and are best seen as mass classes (i.e. as classes of things that do not readily lend themselves to being counted). We list these additional classes in Table 2. 
Table 2

$F e^{\prime} f e^{\prime}$ Mass Classes

\begin{tabular}{|c|c|c|}
\hline Class & Possessive Concord & Cless Prefix \\
\hline H. & $z-$ & $\phi-$ \\
\hline I. & $m-$ & $\mathrm{N}-$ \\
\hline J. & $\phi=$ & $\mathrm{N}-$ \\
\hline K. & $n=/ 1=$ & \\
\hline
\end{tabular}

Table 3

Exemplification of $\mathrm{Fe}^{\prime} \mathrm{fe}^{\prime}$ Noun Classes

Class Noun

A. sg. mènj̄ite 'woman'

pl. pūnjwiع 'women'

sg. SĒn 'friend'

pl. nsēn 'friends'

B. sg. nšuั

pl. nšù

sg. nə̀

pl. nà

C. sg.

$$
\text { pl. }
$$

sg.

pl.

D. sg.

pl.

sg.

pl.
'Priends'

'cane'

'canes'

'animal'

'animals' 2

'bone'

'bones'

'tree'

'trees'

'hoe'

'hoes'

'thing'

'things'
Possessive Concord

กjॅie $\emptyset$-æ̀ 'my wife'

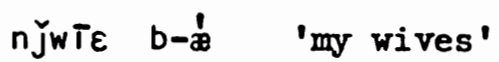

sह̄n $\emptyset$-æ 'my friend'

nsĒn b-æ̇ 'my friends'

nšì m-æ̀ 'my cane'

nšì $m-\infty$ 'my canes'

nว̀ m-æ̇ 'my animal'

nว̀ $m$-æ̇ 'my animals'

čwi z-̇ 'my bone'

กс̌wT $m-\dot{\nexists}$ 'my bones'

thw̄ z-í 'my tree'

$n$ thw w̄ $m-\dot{\Phi}$ 'my trees'

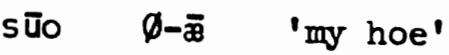

sర̄o z-⿱亠⿴囗十 'my hoes'

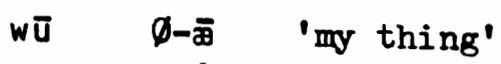

$z h \bar{w} \quad z-\dot{\theta}$ 'my things'

2The word for 'animal' is assumed to be derived from a nasal prefix before a noun stem with initial $/ \mathrm{n} /$. There is a nasal cluster simplification rule in Fe'fe': $N+N \rightarrow N$ in these cases. 


\begin{tabular}{|c|c|c|c|c|c|c|}
\hline Class & Noun & & Posse & ive Con & cord & \\
\hline E. $8 g$. & $m v \bar{u} \alpha$ & 'dog' & $m v \bar{w} \alpha$ & $\emptyset-\dot{x}$ & 'my & $\operatorname{dog}{ }^{\prime}$ \\
\hline pl. & $m v \bar{u} \alpha$ & 'dogs' & $m v \bar{u} \alpha$ & $z-\infty$ & 'my & dogs' \\
\hline sg. & mvhī & 'goat' & mvhT & $\phi-\dot{\circledast}$ & 'my & goat' \\
\hline pl. & mvhī & 'goats' & mvhT & $z-\dot{\prime}$ & 'my & goats' \\
\hline F. sg. & kwā' & 'ring' & kwā' & $\mathrm{n} / \mathrm{l}-\grave{æ}$ & 'my & ring' \\
\hline pl. & nkwā' & 'rings' & nkwā' & $m-\ddot{B}$ & 'my & rings' \\
\hline sg. & $m b \dot{a} ?$ & 'button' & $m b \grave{\alpha}^{?}$ & $n / 1-\dot{m}$ & 'my & button' \\
\hline pl. & $m b \dot{\alpha}^{?}$ & 'buttons' & $m b \dot{\alpha}^{?}$ & $m-\dot{x}$ & 'my & buttons' \\
\hline G. $s g$. & thus & 'head' & thū & $\emptyset-\bar{\nexists}$ & 'my & head' \\
\hline pl. & nthū & 'heads' & nthū & $m-\dot{\prime}$ & 'my & heads' \\
\hline sg. & khì & 'foot' & khù & 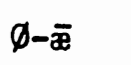 & 'my & foot' \\
\hline pl. & nkhù & ' feet' & nkhù & $m-\ddot{B}$ & 'my & feet' \\
\hline H. (mass) & zi? & 'sweat' & zi? & $z-\dot{\prime}$ & 'my & sweat' \\
\hline (mass) & lüa? & 'yams' & lìa? & $z-\dot{\infty}$ & 'my & yams' \\
\hline I. (mass) & nčĩ & 'saliva' & nčTe & $m-\dot{\theta}$ & 'my & saliva' \\
\hline (mass) & nzāt & 'feces' & nzāt & m-ǽ & 'my & feces' \\
\hline J. (mass) & mvên & 'grass' & mvên & $\phi-\dot{z}$ & 'my & grass' \\
\hline (mass) & nkèn & 'news' & nkèn & $\emptyset$ Ø-் & 'my & news' \\
\hline K. (mass) & pè & 'hate' & pè & $\mathrm{n} / 1-\dot{m}$ & 'my & hate' \\
\hline (mass) & $p \bar{e}$ & 'tarrot' & $p \bar{~}$ & $n / 1-\dot{m}$ & 'my & tarrot' \\
\hline
\end{tabular}

Classes A-K are exemplified in Table 3, above, using the pronoun $\rightarrow$ 'my' to illustrate possessive concord. ${ }^{3}$ Some of these classes contain a large number of nominals (e.g. C, E, I), while others have very few members. Note that some classes are distinguished primarily by possessive concord, while others are differentiated by taking into the consideration the

${ }^{3} \mathrm{All}$ citations are given in semi-phonemic form, differing in some detail from the orthography used by the Nufi schools in Cameroon. We do not wish to ignore the residue not accounted for in our analysis. Thus we cannot explain the tone in the singular pè? $1-\dot{t}$ (pl. mbe'? $m-\dot{t}$ 'my. house/houses'. 
pairing in which each class enters (the singulars of $A$ and $E$ or $D$ and $G$ are the same, though their respective plural differs). We shall return to this matter below. Note also for the moment that classes $A$ and $F$ (see Table 1 ) contain nominals differing in prefix. In the case of $F$, it is probable that we have a merger of two once distinct classes, one of which (as mbà? 'button') was characterized by a nasal prefix throughout, and one of which (as kwā? 'ring') was characterized by a nasal prefix only in the plural. In class $A$, we note the troubling fact from Table 2 that sEn 'friend' does not have a nasal prefix in the singular, while njwite 'wife' (and all other nouns of this class) do. (The optional prefixes mèn-/pür are discussed in Section 3.)

One final note is relevant to the noun classes we have just set up. There is a pair of kinship terms ('father' and 'mother') which although apparently belonging to class $E$ (though not impossibly to class $A$ ), exhibit some anomalous characteristics in the possessive construction. In the singular possessor pronouns, illustrated now with respect to 'dog',

\begin{tabular}{|c|c|c|c|}
\hline (1) & $m v \bar{w} \alpha$ & $\phi$-⿱亠凶禸 & 'my dog' \\
\hline & $m v \bar{w} \alpha$ & $\emptyset$-ò & 'your dog' \\
\hline
\end{tabular}

the following patterns are observed:

\begin{tabular}{|c|c|c|c|}
\hline$m b \overrightarrow{\alpha^{2}}$ & $+\phi-\overline{0}$ & $\rightarrow \quad[m b \bar{c} ? \overline{0}]$ & 'my father' \\
\hline$m b \overline{\alpha^{?}}$ & $+\phi-\bar{\theta}$ & [mbē?ē] & 'your father' \\
\hline$m b \bar{\alpha} ?$ & $+\phi-\bar{\alpha}$ & {$[m b \bar{\alpha} ? \bar{\alpha}]$} & 'his father' \\
\hline$m \bar{\alpha}$ & $+?-\overline{0}$ & [māvó] & 'my mother' \\
\hline $\mathrm{m} \bar{\alpha}$ & $+\phi-\bar{e}$ & [m巨ee ] & 'your mother' \\
\hline$m \bar{\alpha}$ & $+\phi-\bar{\alpha}$ & {$[m \bar{\alpha} \alpha]$} & 'his mother' \\
\hline
\end{tabular}

Thus, whereas the normal singular possessive pronouns are $\$$ 'my', 0 'your' and $i$ 'his, her, its', in these two cases only we find instead $\circ$ 'my', e 'your' and $\alpha$ 'his', not to mention the apparently suppletive form of 'my mother'. ${ }^{4}$ Our proposed explanation for these exceptional

"We might attempt to explain. [māv'] 'my mother' by positing a complex historical form: mā + vhì 'parity' +0 . This would also explain the anomalous lower-mid tone by the productive rule of downdrift after a low tone in $\mathrm{Fe}^{\prime} \mathrm{fe}$ '. 
kinship terms is given below. They are tentatively analyzed as belonging to class pairing $E$, since they take $z$ - concord in the plural. (We understand, however, that some speakers use plural concord b-, that which would classify these forms as class pairing $A_{\text {.) }}$

\section{Productivity of the noun classes}

We have seen in the above tables the only means by which we can successfully differentiate the noun classes of $\mathrm{Fe}^{\prime} \mathrm{fe}^{\prime}$. In this section we would like to present data that would seem to suggest that the present noun class system exists as such only as the result of an extensive levelling process. Much of what remains is also subject to levelling.

The first evidence of class merger is semantic. Only three of $\mathrm{Fe}^{\prime} \mathrm{fe}$ ' $\mathrm{sg} / \mathrm{pl}$ pairings are fairly homogeneous in this regard: class A (comprising a limited set of personal nouns), class $E$ (in which we find an abundance of animals) and class $G$ (body parts). This is not to say that there are no exceptions. Class $A$ is exceptionless as it admits no non-human nouns, but class $E$ contains some non-animals, while other classes contain a limited number of scattered personal nouns and animals. However, it is constructive to view $A$ and $E$ as forming a (basically animate) class together. We shall see the motivation for this below. Some class $E$ members are: ngāp 'chicken', mū̄a 'dog', nū 'snake', nj̄wie 'leopard', muht

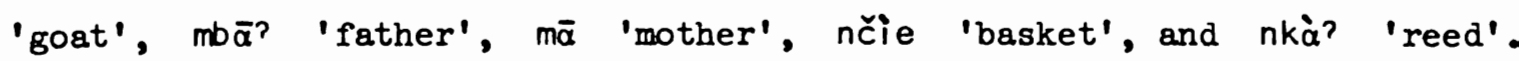
Among the members in class G are: vāk 'bone', tèn 'buttock', vü? 'hip', si 'face', thū 'head', pō 'hand', khù 'foot'. We have found extremely few non-body parts in this class. Many other body parts are to be found in class pairing $C$, although they form a minority in $C$ by virtue of the size of this class. Among these body parts are: Čwi 'bone', zòk 'knee', kúa 'penis', zāk 'eye', zāk 'hip', tغ̀?

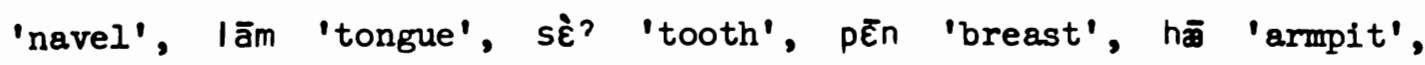
and yüa' 'cheek'. Finally-to complete those classes characterized by semantic unity--all of the mass classes consist of either mass nouns or abstract nouns, or both. Class I consists of the following elements: nzāt 'feces', nčTe 'saliva', ngwä? 'salt', nzi 'nose' (= snot), nòk 'hair', nkòp 'medicine' (=bark), nkwēn 'black-eyed peas', ndùa 'cloud', and nsisi 'urine', among others. It may not be possible in all cases to predict the noun class from the semantic nature of the noun, but 
it is clear that if a noun is placed in this class (I), it is conceived of as a mass--i.e. as something not to be differentiated by number. As a final illustration, we stated above that few non-body parts occur in class G. One example, hu' 'leaf', is to be found there. This noun is quite noteworthy in that it changes meaning depending upon its class membership. When it is in class $G$ its meaning is 'leaf'. When it is in class $H$ (a mass class), its meaning is 'medicine' (as from a leaf). One other example: $y \overline{\bar{e}}$ normally means 'ghost' when in its non-mass class (in which it is sole member, part of the residue referred to in footnote 2), but means 'breath' in mass class $\mathrm{H}$ again. However, as we shall now see, this semantic productivity is extremely limited, suggesting that different semantic properties were blurred as the various noun classes merged with one another.

We have been insisting that this noun class system is in the process of dying out. One clear indication of this observation is that unless $\mathrm{Mr}$. Tchokokam has heard the possessive concord of a noun, he is unsure and usually unable to assign it to a noun class. In this case, though his uncertainty is always reaffirmed, he will tend to assign new or unfamiliar lexical items to class C. For class $C$ is the generally productive class. All neologisms and borrowed words fit into this class. Thus we observe the following borrowings from Pidgin English:

$$
\begin{array}{lll}
\text { flāwà } & z-\not ̊ a & \text { 'my flower' } \\
\text { fâm } & z-\grave{1} & \text { 'my farm' }
\end{array}
$$

This observation would seem to confirm our view that $\mathrm{Fe}^{\prime} \mathrm{fe}^{\prime}$ noun classes have largely lost their initial semantic significance, with the few noted exceptions. If they hadn't, we would expect borrowings to fit into different classes according to their semantic content. Note however that although 'flower' and 'farm' are considered to be mass nouns (they have no plural), we ignore the possible debate over whether these should be assigned to $C$, as we have done, or to $H$, since we shall later collapse $H$ with the singular of $C$. The important factor in this process is that these words were not put into one of the other mass classes--notably class $I$, which is the most developed in terms of numbers. In adopting 
such words as they did, $\mathrm{Fe}^{\prime} \mathrm{fe}^{\prime}$ speakers point toward another tendency of their language: the decline of $\mathrm{sg} / \mathrm{pl}$ distinctions. We shall return to this issue below.

To summarize the discussion so far, the occurrences of noun class concord in $\mathrm{Fe}^{\prime} \mathrm{fe}^{\prime}$ have been reduced to one context. For this reason the Fe'fe' speaker is often unsure (or ignorant) of the noun class identity of a given noun. In most environments in which there was noun concord in Proto-Bamileke, there simply is a lack of any grammatical agreement whatsoever. Thus, consider in (7), the set of pre-posed possessive pronouns, whose function differs only slightly from the post-posed pronouns we have thus far been considering.

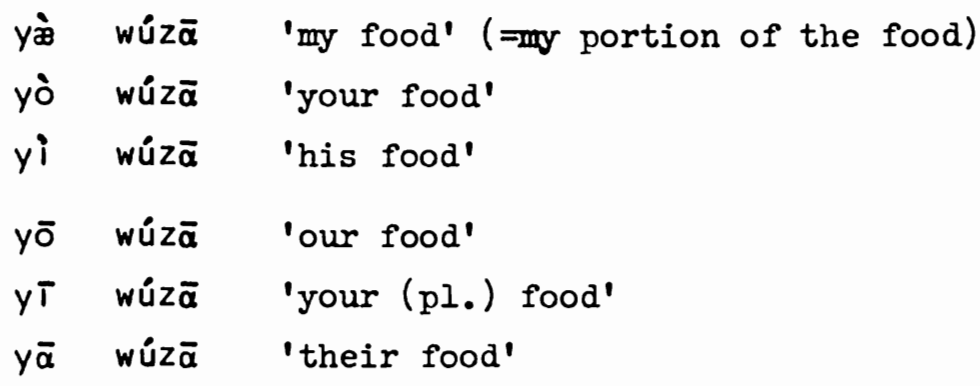

The pronouns in the first column are invariable. Not only do we always obtain $y-$, but also the tone is predictable: low for the singular set, mid for the plural person set. This should be compared with the postposed counterparts, for example: wúz̄̄ $\emptyset-\bar{\phi}$ 'my food' (class D). There are no plural pre-posed possessive pronouns, such that 'my dogs' can only be $m v \bar{w} \alpha z-\not$, and never *ż $m v \bar{w} \alpha$. The decline of $s g / p l$ distinctions is seen a second time.

In most cases we observe that one class has been generalized to replace all of the others. In anaphora, for instance, a complete gender (sg/pl pairing) has come to be used for all nouns, as we see in ( 8 ):

$$
\begin{aligned}
& \text { mó? thw 'the other tree' } \rightarrow \text { yi mō? 'the other one' } \\
& \text { mó? nthw 'the other trees' } \rightarrow \text { zi mō' 'the other ones' } \\
& \text { Cf.: yi be ' 'this one', zi be '- 'these ones' }
\end{aligned}
$$

Thus we see that the anaphoric pronouns are yi/zi for 'tree' (class C) as well as for nouns of all other classes, despite the clear resemblance 
of these markers to the possessive concord of class E (and 10! Bantu 9/10). This is not the only case where class $E$ has become general. In relative constructions we find that $y i$ is employed, though covering both singular and plural (a third instance of $\mathrm{sg} / \mathrm{pl}$ decline) as we see in (9):

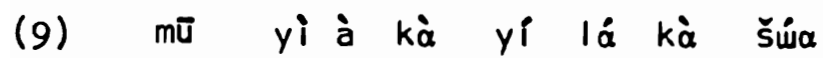
child $X$ he PAST see $Y$ PAST leave $(X+Y=$ rel markers $)$

'the child that he saw left' pū yì à kà yí lá kà šúa

'the children that he saw left'

BUT: *pū zì à kà yí lá kà šúa

In (4) we saw the concord in the singular possessor pronouns for 'dog' (class E). Let us complete that table with the plural set of possessive pronouns :

(10) mvw̄a y-ò: 'our dog'

$m v \bar{w} \alpha \quad y-i$ : 'your (pl.) dog'

$m v \bar{w} a \quad y-\grave{a}:$ 'their dog'

It seems reasonable to propose that the initial $y$ - that we find in the plural possessors originally comes from the singular of class E. In postnominal singular possessor pronouns ('my', 'your (sg.)', 'his'), we would claim, the concordial element fell, leaving it intact only in the above positions. (Compare the pre-nominal possessive pronouns in $(7)$, where we observe this $y$ - in all persons, which we now identify as the singular concord marker of class $\mathrm{E}$ which in this construction has been generalized to all nouns.) Having recognized this process, we are now in a position to explain the forms for 'father' and 'mother' in (5) above. Two processes are involved. First, Fe'fe' speakers chose, for whatever reason, to use plural possessive pronouns ('our', 'your ( $\mathrm{pl}$. )' and 'their') for the corresponding singular pronouns ('my', 'your', 'his') in the case of 'Pather' and 'mother'. One can imagine a cultural setting for such a move, perhaps politeness of some sort. These plural forms, then, came to be used indifferently for (semantic) singular and plural (e.g. 'my' and 'our'), as in (11): 
(11)

$m b \bar{a}^{2} \quad y-o ̀:$ 'our, my father'

$m b \bar{\alpha} ? \quad y-i$ : 'your $(\mathrm{sg} / \mathrm{pl})$ father'

mb $\bar{\alpha} ? \quad y-\grave{\alpha}:$ 'their, his father'

In present day $\mathrm{Fe}^{\prime} \mathrm{fe}^{\prime}$ these forms have only the plural interpretation. The second step was that at the time when initial concord consonants fell in the singular series of possessive pronouns, this $y$ - fell, creating once more a sg/pl person dichotomy in these exceptional pronouns. This rule of consonant drop (which would have had to apply to the semantic class of singular) left the way open for irregular vowel and tone assimilation to yield two identical vowels with mid tone in series. Let us take note in this explanation, that the form $y$-è: for second person plural is also heard and is perhaps more frequent than $y-i:$, though Mr. Tchokokam prefers the latter.

Thus, to summarize, it is important to recognize that although we have distinguished noun class pairings A-K on the basis of possessive concord, this concord is recoverable in the singular possessed noun only in the set of singular possessor pronouns. In other words, we can determine the class membership of a noun in the singular only by looking at what concordial prefix turns up in the frames: 'my $X$ ', 'your (sg.) $X$ ' and 'his $X '$ '. In other positions the concordial prefix is generalized to $y-$, though it maintains the tone of the singular set of pronominal possessors. Thus we observe the following:

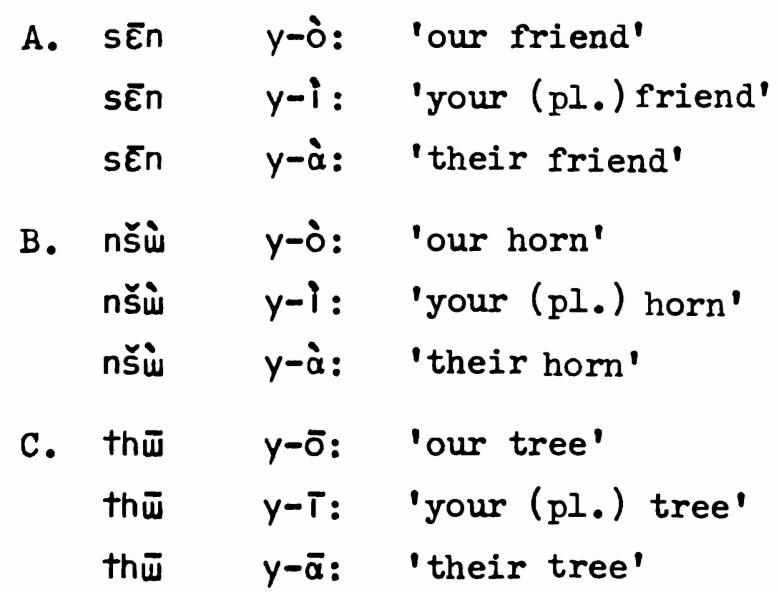




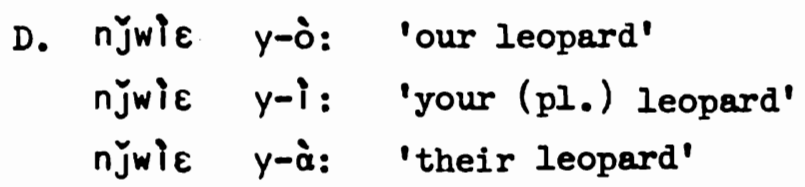

etc. (The tone of the plural possessor pronoun in class $C$ concord is mid, despite the fact that the singular pronouns receive lower-mid tone. This has to do with the complex tonemic system of $\mathrm{Fe}^{\prime} \mathrm{fe}^{\prime}$ and other Bamileke languages and does not seriously affect our statement that the plural pronouns receive a tone that correlates with the tone received by the singular series.) Thus we see that the actual marking of the possessive concord is even more limited than we have implied. Remembering that 'my tree' is thw $z-\dot{m}$, we should expect the form *thw $z-\bar{w}$ : 'our tree', but see from the above examples under $C$ that a crucial aspect of possessive concord has already been lost.

In the examples we saw in Table 3, we observed that when the possessed nominal is singular, at least, the tone of the possessive pronoun depends on the possessed noun's noun class. Thus, classes $A, B, E$ and $F$ are all characterized as low-tone classes, while $C, D$ and $G$ are best seen at this time as non-low-tone classes (see Table 1 ). We find a tonal demonstration of noun class membership in noun plus noun associative constructions, which although incomplete (given only two possibilities: low or non-low), provides some indication of the direction in which the language is shifting. In $\mathrm{Fe}^{\prime} \mathrm{fe}$ ' the nomen rectum follows the nomen regens, which in the case of classes $C, D$ and $G$ undergoes a tonal uplifting (low becomes mid, lower-mid becomes mid and mid becomes high), as now illustrated in the singular of these genders:

$$
\begin{aligned}
& \text { C. thū }+m \bar{u} \rightarrow \text { thú } m \bar{u} \quad \text { 'the child's tree' } \\
& \text { D. } w \bar{u}+m \bar{u} \rightarrow \text { } \rightarrow \text { } \quad m \bar{u} \text { 'the child's thing' } \\
& \text { G. khù }+m \bar{u} \rightarrow \text { khu } m \bar{u} \text { 'the child's foot' }
\end{aligned}
$$

In classes $A, B, E$ and $F$ there is no tonal change:

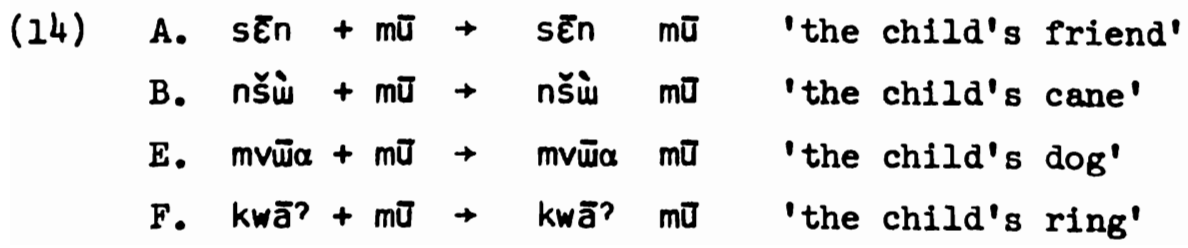


In the above examples we have seen two different situations arising out of the decline of the different noun classes. First it was said that in many constructions where concord once was obtained there simply is a lack of any sign whatsoever. Thus there is no subject-verb agreement, no concord in demonstratives or subject relative pronouns. In the second situation, we observe that the concord marker of one class (e.g. class E in anaphora) is extended to cover all classes. Thus it would appear that in reducing the functional load of the various noun class markers, Fe'fe' had two options: first, to supress concord marking of any type, or second, to adopt one invariant form for all noun classes. We have yet another possible option.

In object pronouns (where we assume an original full concord marking), instead of choosing one class to extend to all occasions, a new alignment of animate versus inanimate has been obtained. The full set of (invariant) direct object pronouns is the following:

$$
\begin{array}{lll}
\boxplus & \text { 'me' } & \text { yo 'us' } \\
\text { o 'you' } & \text { yi } & \text { 'you (pl.)' } \\
\text { i 'him, her' } & \text { ya 'them' }
\end{array}
$$

(Here tone depends on the tone of the verb form that precedes them.) We see from (15) that in the plural series it is once again (the singular of) class $E$ (class 9 of Bantu) that has won out. All of these pronouns are invariant, but also semantically animate. (The consonant that sometimes appears before the singular series properly belongs to the verb stem that precedes it.) Thus, in the sentence

$$
\begin{aligned}
& \text { à kà yínî (from } / y i n /+/ i / \text { ) } \\
& \text { he PAST see him } \\
& \text { 'he (recently) saw him/her' }
\end{aligned}
$$

the third person singular direct object can only refer to an animate being-that is, 'him', 'her', or 'it' (an animal). If one should wish to say 'he saw it' where 'it' is [-animate], it is necessary to use the paraphrase 'he saw that thing' (= the thing in question), 
(17) à k’a yi wū lá he PAST see thing that 'he (recently) saw that thing'

or, if the reference is clear enough, one can suppress the object altogether:

$$
\begin{aligned}
& \text { à kà yí } \\
& \text { he PAST see } \\
& \text { 'he (recently) saw (it)' }
\end{aligned}
$$

The same constraint holds for the third person plural 'them'. One says 'those things' or simply omits the pronoun.

This distinction exists in other aspects of the pronominal system in Fe'fe'. The third person pronouns 'his/her/its' and 'their' are limited to [tanimate]. The following set of subject pronouns is employed in the case of animates:

$$
\begin{array}{llll}
n(g \alpha) & \text { 'I' } & \text { pa } & \text { 'we' } \\
\circ & \text { 'you' } & \text { pen } & \text { 'you (pl.)' } \\
\text { a } & \text { 'he, she, it' } & \text { po 'they' }
\end{array}
$$

(Once again, tone is not constant. While po is generally high, the 0 others are usually low or rising.) Note that the plural pronouns appear to have a prefix identical to the plural of class A (Bantu class 2), which we have seen to be an animate (human) class (see footnote 5). While a 'he, she, it' and po 'they' are exclusively [tanimate], we find a separate pronoun $y \boldsymbol{x}$ 'it, they' used for inanimates. Its interesting distinguishing characteristic is that while there is a singular/plural distinction in animate subjects, this same $y \rightarrow$ is used for singular and plural, once again pointing toward the eventual obliteration of $\mathrm{sg} / \mathrm{pl}$ agreement in the language.

Thus we have seen three different situations arising out of one process: the levelling of noun classes in Fe'fe'. One interesting note relevant to the second situation (where one class displaces all others) is that where the singular of a class was generalized to all singulars 
(as we saw class $\mathrm{E}$ employed for all plural possessor pronouns possessing singular nouns), the corresponding plural (class E plural z- in this instance) has not become generalized in the corresponding possession of plural nouns. Instead, as we shall now see, the singular $y$ - is in the process of replacing all plural concords as well. Thus this process is not best seen as a regular one.

In this sub-section, we shall now argue that the overt singular/ plural distinction in concord is breaking down in Fe'fe'. We have already alluded to several instances where plural is no longer clearly distinguished from singular. For example, we have just observed that the inanimate subject pronoun $y \boxplus$ is not differentiated for number, while in other parts of the language such a distinction is still maintained. We have all but lost the ability to determine the number of a noun from its noun class prefix--while a prefixed $\mathrm{N}$ - marks the plural in classes $A, B$, $C, E, F$, and $G$, classes $B$ and $E$ exhibit a nasal prefix in the singular as well, while mass classes $I$ and $J$ also require a nasal prefix and have already failed to distinguish singular and plural (despite the logical possibility in many cases, e.g. ndùa 'cloud', class I). There are other indications of the imminent loss of this distinction, all from the behavior of possessive pronouns themselves. First, recent borrowed words, as we have noted, come into the language undifferentiated for number-we saw this in the case of 'flower' and 'farm'. Second, distinctions in plural possessor pronouns have been largely wiped out. While the tone of a possessor of a singular noun is predictable only from the individual noun class (some are low, others lower-mid and mid), the tones of pronouns possessing plural nouns have been completely regularized. The singular persons always have lower-mid tone, while the plural persons always have mid tone. We observe this in the following:

$\begin{array}{llllll}m v \bar{w} \alpha & z-\dot{\nexists} & \text { 'my dogs' } & m v \bar{w} \alpha & z-\bar{a}: & \text { 'our dogs' } \\ m v \bar{w} \alpha & z-\dot{0} & \text { 'your dogs' } & m v \bar{w} \alpha & z-T: & \text { 'your (pl.) dogs' } \\ m v \bar{w} \alpha & z-1 & \text { 'his/her dogs' } m v \bar{w} \alpha & z-\bar{\alpha}: & \text { 'their dogs' }\end{array}$

These tones are predictable in this way, despite the identity of the noun class of the possessed nominal. Thus there has already been a 
considerable amount of levelling underlying this simplification. This situation has its correlate in the noun plus noun associative construction examined in the singular in (13) and (14) above. In the singular it was seen that only in the case of some classes was there a tonal upstep in this construction. In the plural, however, all possessed nouns undergo such a tonal phenomenon. Thus, compare the uplifted tones in (21) to their singular counterparts in (13) and (14):

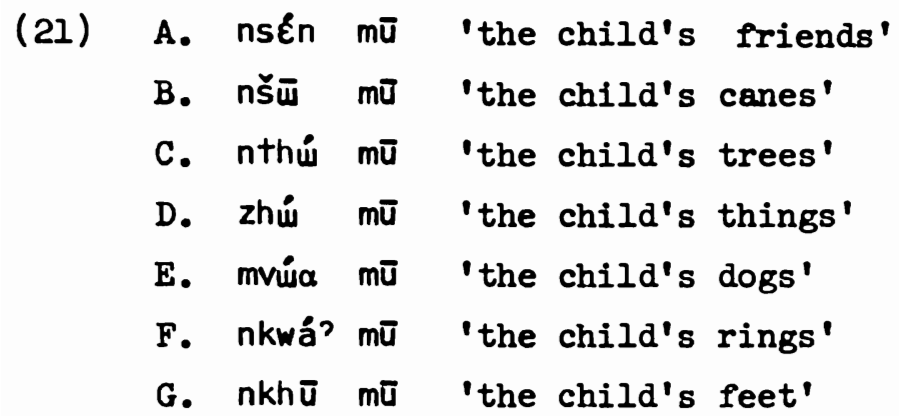

As the raising of this tone depends upon the non-low nature of possessive concord, this is not surprising. It is explained by the generalization illustrated in (20). The clearest indication, however, of the fate awaiting the plural in $\mathrm{Fe}^{\prime} \mathrm{fe}^{\prime}$ is that the widespread $\mathrm{y}$ - that we saw in the plural series of pronouns possessing singular nouns has now come to be used in plural persons possessing plural nouns as well. The following forms are rapidly replacing the forms in the second column of (20):

(22) mv"̄̄ $y$-ō: 'our dogs'

mvw̄a y-T: 'your (pl.) dogs'

mvī $\alpha \quad y-\bar{\alpha}: \quad$ 'their dogs'

This means that when this latter set is used, nouns in class $D$ are undeterminable for number as we see in (23),

(23) sūo z-ō: 'our hoes' $\rightarrow$ sūo $y-\overline{\text { : }}$

then, sūo $y-\bar{o}:=$ 'our hoe'/'our hoes'

while nouns in other classes can be interpreted as to singular or plural solely on the basis of tone. (súo $m \bar{u}$ is also ambiguously 'the child's hoe'/ 'the child's hoes'.) In addition, the functional load of the nasal 
plural prefix in $C$ and $G$ is increased-it alone tells you if the noun possessed is plural or not, as in (24):

$$
\begin{array}{r}
\text { C. nthw̄ m-ō: 'our trees' } \rightarrow \text { nthw̄ } y-\bar{o}: \\
\text { cf. thw̄ y-ठ: 'our tree' } \\
\text { nkhù m-ō: 'our feet' } \rightarrow \text { nkhù } y-\bar{o}: \\
\text { cf. khù } y-\bar{o}: \text { 'our foot' }
\end{array}
$$

But, Fe'fe' speakers fail in many cases to use the nasal prefix anyway. Nouns (such as unpaired body parts) that are not normally used in the plural have already become confused: the noun si 'face' has an etymological plural nst 'faces', but a Fe'fe' speaker may be unsure of whether 'our faces' is si y-ō: or nsi y-ō:. All of these observations point to the likelihood that the plural, as a morphologically marked category, is fading out--as it has done elsewhere in West Africa.

\section{Comparative Benue-Congo}

We are now in the position to consider the task of reconstructing proto noun classes. Our task can be seen to entail two objectives: first, to reconstruct the noun class system that the proto-language of Bantu and Bamileke (henceforth, Bantoid) had, and second, to reconstruct the individual noun stems and designate the noun class to which each stem originally belonged. The first objective requires several considerations. Our procedure should be first to reconstruct Proto-Bamileke, its noun classes and noun stems, and then to expand our efforts to encompass more and more ground, linguistically. Unfortunately it would be premature of us to present any more than a few observations at this time. The Bamileke languages have been grossly neglected by all but a very few scholars in the field and the information available is scanty and not always adequate in quality. Although the Bamileke languages differ markedly in phonetic detail, a deep phonology (internal reconstruction) of each dialect would (according to all indications) lead us to many common underlying forms. Thus we have not only been able to posit certain Proto-Bamileke roots despite limited information, but also have had some success in relating these posited forms to Proto-Bantu. (For further discussion and exemplification, see Hyman and Voeltz [forthcoming].) In addition to setting up 
the classes, we should want to isolate the semantic correlates associated with each class, if any. Also, we should want to provide the morphophonemic rules accounting for primary, secondary and tertiary concord, if applicable. Finally, we should provide the singular/plural pairings of these noun classes.

In this section we would like to reanalyze the noun classes we presented in section 1. We would like to do this while incorporating data from related languages. The forms of Ngwe, Bangangté and Bandjoun are from Voorhoeve [1968], although the Ngwe forms and correspondences to Bantu classes are attributed to Dunstan [1966]. The need for the Luganda forms (secondary concord in some instances) will become evident in a moment. The singular/plural pairings of the Bamileke forms correspond to those of the Bantu items. We now enlarge upon the table presented in Voorhoeve [1968] providing additional information from Comparative Bantu (from Guthrie [1967]), Luganda and Fe'fe':

\section{Table 4 \\ Comparative Noun Classes}

\begin{tabular}{|c|c|c|c|c|c|c|c|}
\hline CLASS & $\begin{array}{l}\text { Proto- } \\
\text { Bantu } \\
\end{array}$ & Luganda & Ngwe & Bndj. & Bngt. & $\begin{array}{l}F e^{\prime} f e^{\prime} \\
\text { P.C. } \\
\end{array}$ & $\begin{array}{l}F e^{\prime} f e^{\prime} \\
\text { N.P. } \\
\end{array}$ \\
\hline 1. & $\mathrm{mu}$ & $\mathrm{mu} / \mathrm{y} / \mathrm{e}$ & $g^{\circ}$ & $y^{\prime}$ & $(y)^{\circ}$ & $\emptyset^{\circ}$ & $(n \varepsilon ̀ n) \emptyset / N$ \\
\hline 2. A & ba & ba & $b^{\circ}$ & $p^{\prime}$ & $(c)^{\circ}$ & b & (pü) N \\
\hline 3. & mu & $\mathrm{mu} / \mathrm{gu}$ & $g^{\prime}$ & $y^{\circ}$ & $y^{\prime}$ & $\mathrm{m}^{\circ}$ & N \\
\hline 4. B. & $\mathrm{mi}$ & $\mathrm{mi} / \mathrm{gi}$ & $\mathrm{m}^{\circ}$ & $\mathrm{m}^{\circ}$ & $\mathrm{m}^{\circ}$ & $m$ & $\mathrm{~N}$ \\
\hline 5. & di & $1 \mathbf{i}$ & $d^{0}$ & ts & $c^{\circ}$ & $z^{\prime}$ & $\varnothing$ \\
\hline 6. C & ma & $\mathrm{ma} / \mathrm{ga}$ & $\mathrm{m}^{\circ}$ & $m^{\circ}$ & $\mathrm{m}^{\circ}$ & $m$ & N \\
\hline 7. & ki & ki & $z^{\prime}$ & $y^{0}$ & $y^{0}$ & $\emptyset^{-}$ & $\emptyset$ \\
\hline 8. D & $b i$ & $b i$ & $b^{\prime}$ & $p^{\prime}$ & $c^{\prime}$ & $z$ & $\emptyset$ \\
\hline 9. & $n i$ & $\mathrm{ni} / \mathrm{y} / \mathrm{e}$ & $z^{\circ}$ & $y^{\circ}$ & $y^{\bullet}$ & $\emptyset^{\circ}$ & $N$ \\
\hline 10. & ni & $\mathrm{ni} / \mathrm{zi}$ & $z^{\circ}$ & ts ${ }^{\circ}$ & $c^{\circ}$ & $z$ & $N$ \\
\hline 11. $F$ & $d u$ & Iu & & & & $1 / n^{\circ}$ & $\varnothing$ \\
\hline 15. G & ku & ku & & & & $\theta^{-}$ & $\emptyset$ \\
\hline
\end{tabular}


(The plurals of classes 11 and 15 are identical to class 6.) Thus we have reanalyzed the classes referred to as $A, B, C, D, E, F$ and $G$ as $1 / 2$, $3 / 4,5 / 6,7 / 8,9 / 10,11 / 6$ and $15 / 6$ respectively. Mass classes $H, I, J$ and $K$ are reanalyzed as 5,6,9 and 11 . The remainder of this paper will be devoted to validating the correspondences seen in Table 4.

Let us first evaluate the assignment of the more conservative Ngwe nominal system to the Bantu classes listed in Table 4, positing correspondence rules wherever possible. The Ngwe forms show very strong correspondences to the Bantu system. There is first of all the $d^{\circ}$ of class 5 corresponding to ${ }^{*} \mathrm{di}$ and the $z^{\prime}$ in Ngwe to the Luganda $z i$ of class 10. Ngwe class $3 \mathrm{~g}^{\prime}$ corresponds to secondary concord gu in Luganda. Classes 4 and 6 are realized as $\mathrm{m}^{\circ}$, corresponding to $\mathrm{mi}$ and $\mathrm{ma}$, respectively. In these cases (as opposed to class 3 ) the plural classes 4 and 6 have taken the basic noun prefixes for concord. Ngwe 2 and 8 , both of which are realized as $b^{\circ}$, furnish a clear correspondence with Bantu ba and bi, respectively. Thus we are able to provide a number of correspondence rules, seen in (25):

\begin{tabular}{|c|c|c|c|c|c|}
\hline RI & PB & ${ }^{*} \mathrm{mV}$ & : & Ngwe & $m / \ldots$ \\
\hline $\mathrm{R} 2$ & $\mathrm{~PB}$ & *bV & : & Ngwe & b /. \\
\hline & PB & ${ }^{*} \mathrm{di}$ & : & Ngwe & d /. \\
\hline & PB & ${ }^{*} \mathrm{gV}$ & : & Ngwe & $g /$ \\
\hline
\end{tabular}

(CRI is to be read, for example: 'Proto-Bantu *mV corresponds regularly to Ngwe $m$ in a given environment.') It is not clear that Guthrie's reconstructed form for class $10,{ }^{*} \mathrm{ni}$, is the correspondence for the Bamileke forms in Table 4. It is doubtful that $*_{n i}$ would correspond to z. Rather we recognize $P B * d i n i$ of which it is the *di (Cole's class $8 x$ ) that corresponds to Ngwe $z$ :

(27) CR5 PB *di : Ngwe $z / \ldots \ldots$

The nasal prefix of class 10 nouns is seen as deriving from the ${ }^{*} n i$ part of our reconstruction.

Most important about these rules is the fact that even within the noun class systems of languages which have lost most distinctions we can find 
regular correspondences. This fact raises serious questions regarding the status of Bamileke languages vis-à-vis Bantu, particularly in view of Guthrie's claim that it is sufficient to classify a language as Bantu if it shows regular correspondences in the noun class system and if it shows a sufficient number of correspondences with Common Bantu roots (see Tucker [1964:215] for the first discussion of these criteria). That these criteria, although arbitrary in some respect, can be satisfied for the Bamileke languages is certainly demonstrable [Hyman and Voeltz, forthcoming].

The case for the $\mathrm{Fe}^{\prime} \mathrm{fe}^{\prime}$ noun classes and their assignment to corresponding Bantu classes is perhaps a little less obvious. We have suggested a number of reasons for this above, namely, the large extent to which noun class distinctions in $\mathrm{Fe}^{\prime} \mathrm{fe}^{\prime}$ have been and are being levelled, leaving considerably less traces than in Ngre. Nevertheless we have assigned correspondence pairs to Bantu classes 1/2,3/4, 5/6, 7/8, 9/10, $11 / 6$ and 15/6. We will review the evidence presently.

As in Ngwe, PB *bV (e.g. class 2 *ba) corresponds to $b$ in $\mathrm{Fe}^{\prime} \mathrm{fe}^{\prime}$ (see discussion of class 8 below). We can therefore extend CR2 as follows : CR2' PB *bV : Ngwe b : Fe'fe' b / ..._...

(CR2' should properly be understood as correspondences between $\mathrm{PB}$ and Proto-Bamileke.) Also as in Ngwe, $\mathrm{PB}{ }^{*} \mathrm{mV}$ corresponds to $\mathrm{Fe}^{\prime} \mathrm{fe}^{\prime} \mathrm{m}$ : (29) CRI' $\mathrm{PB}{ }^{*} \mathrm{mV}$ : Ngwe $m$ : Fe'fe' $\mathrm{m} / \ldots \ldots$ Given CRI' and CR2' we have classified $A$ and $B$ as $1 / 2$ and $3 / 4$ respectively.

Where Ngwe has maintained a distinction between the behavior of super-closed $i(i)$ and $i(i)$, Fe'fe' has generalized on the behavior of $i$, allowing palatalization of $d$ to $z$ before *i and * $i$ (before or after their ultimate merger). Thus:

(30) $\quad \mathrm{CR}^{\prime}\left[\begin{array}{ll}\mathrm{PB} & * \mathrm{~d} ! \\ \mathrm{PB} & * \mathrm{di}\end{array}\right]:\left[\begin{array}{ll}\text { Ngwe } & z \\ \text { Ngwe } & \mathrm{d}\end{array}\right]: \quad \mathrm{Fe}^{\prime} \mathrm{fe}^{\prime} \quad \mathrm{z}\left[\begin{array}{l}1 \ldots \ldots \ldots \\ 1 \ldots \ldots\end{array}\right]$ 
Accordingly we can relate classes $C$ and $E$ to $5 / 6$ and $9 / 10$, respectively. Additionally we observe that the nouns of class $I$ are mass nouns, that their noun concord is a nasal, and that their concordial agreement is that of the plural of $\mathrm{C}$, and thus class 6 . Conversely, class $\mathrm{H}$ corresponds to the singular of $\mathrm{C}$, and thus class 5 .

What about the possessive concord in class 1 in Fe'fe'? According to $\mathrm{CRI}$ ' we would expect $m$. Notice, however, that class 1 and class 9 possessive concords are identical, namely $\phi^{\circ}$, pointing toward the possible (historical) relationship between classes 1 and 9. (We return to this question below.)

In addition to accounting for the concord markers, we must also be prepared to explain the presence or absence of nasal prefixes in the various classes. We may predict them on the basis of the Bantu noun class correspondences we have supported. Let us assume that the underlying form for the prefixes of classes 3,4 and 6 is $m$. This $m$ is realized as $/ \mathrm{m} /$ before a vowel (as in possessive concord), but is assimilated to the following consonant by the rule in (31):

(31) [+nasal] $\rightarrow$ [a position $] / \longrightarrow[$ a position $]$ $\mathrm{C}$

(In the case of would-be NN clusters, these are simplified to single nasal consonants.) Observe that this rule extends also to class 9 (and of course class 10, which differs solely by the addition of di) where a presumedly underlying /n/ is also assimilated to the following consonant.

Within the classes so far related to Bantu forms, there exist a number of problems. First, what is the source for the possessive concord in classes 1 and 9? Second, class 1 nouns normally have a nasal prefix, but there is at least one clear example lacking such a prefix (sEn 'friend'). Are we to recognize two genders, both of which have the same concords, but which are distinguished by the presence or absence of a nasal? We would have to sub-divide $11 / 10$ in the same way (see Table 1 ). Although this position would be consistent with our methodology, it is not clear to us how we might predict the concordial agreement in these 
classes other than assuming that they have the same cognates in Bantu, thus bringing us back to our first analysis. Finally, what is the source for the prefixes mèn- and pù in classes 1 and 2? It is not certain that these forms are cognate to any Bantu forms. If they cannot in fact be related by rule, this would lead to some interesting speculation: it has been argued [Givón forthcoming] that Bantu class $1 / 2$ is a Bantu innovation, by splitting class $9 / 10$ and assigning most [thuman] nouns to class 1/2. Is it possible then, that Bamileke experienced a parallel development? On the other hand the forms mèn- and pü- are quite close to their hypothetical counterparts *mu and *ba. (Bantu *b does in fact correspond to $\mathrm{Fe}^{\prime} \mathrm{fe}^{\prime}[\mathrm{p}$.) Does this then suggest that the creation of class $1 / 2$ preceded the Bantu-Bamileke split (as Givón concludes) and that $1 / 2$ has to be in fact reconstructed for what we term 'Bantoid'? All indications point in this direction. In Voorhoeve and de Wolf [1969], for example, the cognates of Bantu $1 / 2$ in Bantoid are the most frequently occurring classes. All the instances of nasal prefixes in nouns of classes 1 and 2 can be argued to be transfers from classes 9 and 10, retaining their original prefix $(n-)$, but adding the noun prefixes of $1 / 2$. The mèn/pì prefixes of $\mathrm{Fe}^{\prime} \mathrm{fe}^{\prime} \mathrm{l} / 2$ curiously resemble the sg/pl pair wèn/pù 'person/persons'. (In most dialects 'person' is mèn, so we needn't concern ourselves with this detail.) Thus we would have to conclude that some kind of compounding has taken place to create $1 / 2$ from $9 / 10$. This remarkable instance seems not too distant from the type of evidence one has longed for in the quest for deeper insight into Bantu noun class creation. At this point, we take note of the potential importance of $\mathrm{Fe}^{\prime} \mathrm{fe}^{\prime} \mathrm{l} / 2$ and refrain from further speculation.

Bamileke $7 / 8$ corresponds less obviously to Bantu *ki/*bi. The first piece of evidence for class 8 is that we find $b^{\circ}$ in Ngwe. Secondly, we find that class 8 is realized as $z i$ in some Bantu languages (e.g. Zulu) as it apparently is in $\mathrm{Fe}^{\prime} \mathrm{fe}^{\prime}$. We suggest that this $z$ has its source in *b!, where the super-closed ! has palatalized the *b $[\beta]$. We favor this over Cole's proposed class $8 x \mathrm{~d} i$, since we obtain $b$ in Ngwe and can motivate a change of the form, 
as we see in the correspondences:

$$
\text { PB *bina } 5 \text { 'to dance' : Fe'fe' } z \bar{\varepsilon} n \text { 'to dance' }
$$

(See Hyman and Voeltz [forthcoming] for further discussion.) Also keep in mind that $\mathrm{PB}{ }^{*} \mathrm{ba}$ is reflected as $\mathrm{b}^{6}$ in $\mathrm{Fe}^{\prime} \mathrm{fe}^{\prime}$. We can therefore . propose that Bantu ${ }^{*} b$ is cognate to $\mathrm{Fe}^{\prime} \mathrm{fe}^{\prime} \mathrm{b}$ before $\mathrm{a}$, and $z$ before !. Class 7, however, is not as clearly demonstrable. We note that $\mathrm{Fe}^{\prime} \mathrm{fe}^{\prime} 7$ is identical to what we are calling Fe'fe' 15. We are assuming that these are the correct cognates to the Bantu classes partially on the grounds that there are Bantu classes which group in the same manner, i.e. $7 / 8$ and 15/6. But we are also considering some more substantive evidence in this assignment. We see from Table 4 that both 7 and 15 are realized as $\emptyset^{-}$in $\mathrm{Fe}^{\prime} \mathrm{fe}^{\prime}$. We have noticed that Bantu prefixes containing nasals are reflected as nasals and that those containing voiced consonants in Bantu have reflexes in $b, d, z$ or $l$ (class 1l, as we shall see) in $\mathrm{Fe}^{\prime} \mathrm{fe}^{\prime}$. There are no cognates with Bantu prefixes which contain voiceless consonants. We therefore, by elimination, have the option of assigning those nouns taking $\emptyset^{-}$concord to Bantu 7 (*ki), 12 (*ka), $13(*+u)$ or 15 (*ku). In the case of those nouns taking class 8 plural, we feel that 13 is out on the grounds that it is basically a plural or mass class. We know of no Bantu language which has the plural class 8 and does not have as its singular counterpart class 7 . Class 12 is certainly a possibility, but again we are excluding it because of the absence, to our knowledge, of any Bantu language which pairs it with any class other than 13 or 14. Similarly, class 15, to the extent that it is not a mass class, pairs with 6 in Luganda and ChiBemba and a number of other languages. Furthermore, in Bamileke, it contains mostly body

5*bina is equivalent to the reconstructed form given by Carl Meinhof. 1932. Bantu-Phonology. Berlin. N.J. van Warmelo, translator.

${ }^{6}$ In $\mathrm{Fe}^{\prime} \mathrm{fe}^{\prime}$ underlying /b/ is realized as [p] as in the following rule: $b+p / \#$. That is, at the beginning or end of a word. 
parts, again paralleling the Luganda and ChiBemba class. By accepting $7 / 8$ and $15 / 6$ as such for $\mathrm{Fe}^{\prime} \mathrm{fe}^{\prime}$, we assume that at some stage 7 and 15 merged, perhaps after the loss of initial *k in both cases. One indication of this is the pair wü/zhw 'thing/things' in which the prefixes of $7 / 8$ irregularly remain before a stem consisting of a hypothetical $\bar{u} .{ }^{7}$ Most other Bamileke dialects exhibit a palatal consonant in the singular form, such as Bangangté yú, where we see that in addition to the loss of *k, the typically Bantu gliding rule $i \rightarrow y$ operates. We might explain the form wū for class 7 in Fe'fe' (where we expect $y \bar{u}$ ) by hypothesizing that 7 and 15 merged as 15 (where $*_{k}$ falls and $u \rightarrow w$ ). This solution does, of course, need further validation.

Finally, class 11 has no noun prefix, that which we would expect for a non-nasal cognate such as Bantu *du. It has $n$ alternating with 1 . The 1 can be related to $\mathrm{PB}$ *du by regular correspondence, while we note that [ 1$]$ and [ $n$ ] often occur as free variants in Bamileke [Hyman and Voeltz, forthcoming].

\section{Summary}

In the present paper we have shown that the seven genders which must be recognized for $\mathrm{Fe}^{\prime} \mathrm{fe}^{\prime}$ can be treated as twelve morphological agreement classes, all of which are cognate to Proto-Bantu forms. We have also seen cognate forms from Ngwe, Bangangté and Bandjoun from Table 4. Although it is somewhat premature to consider the implications of this study on the Proto-Bantoid noun class system, we would like to suggest that it is very unlikely 1 ) that Bantoid as a whole fully matches the inventory of classes of Proto-Bantu (i.e. Bantu may have innovated a number of classes after its separation from Bantoid); and 2) that no more than ten or twelve classes will ever be reconstructable for Bantoid.

\footnotetext{
7The [w] in 'things' is assumed to be the result of the rule: iu $\rightarrow$ w. This rule is discussed in Hyman and Voeltz [forthcoming].
} 
Cole, Desmond. 1967. "The prefix of Bantu noun class 10." African Studies $26: 119-37$.

Dunstan, Margaret A. 1966. "Tone and concord systems in Ngwe nominals." University of London, unpublished doctoral dissertation.

Givón, Talmy. Forthcoming. "Some historical changes in the noun class system of Bantu, their possible causes and wider implications," in Studies in African Languages and Linguistics. Proceedings of the Conference on African Languages and Linguistics, University of Illinois, Urbana, April 24-25, 1970.

Guthrie, Malcolm. 1967。 Comparative Bantu, vol. 1. Farnborough Heights: Gregg.

Hyman, Larry M. and Erhard F. K. Voeltz. Forthcoming. "The linguistic status of Bamileke", Studies in African Languages and Linguistics. Proceedings of the Conference on African Languages and Linguistics, University of Illinois, Urbana, April 24-25, 1970.

Tucker, Archibald. 1964. "Bantu philology." Mitterlungen des Instituts für Orientforschungen 10:207-15.

Voorhoeve, Jan. 1968. "Noun classes in Bamileke." Lingua 21:584-93.

Voorhoeve, Jan and Paul P. de Wolf. 1969. Benue-Congo noun class systems. Leiden: West African Linguistic Society.

Welmers, William E. Forthcoming. "The typology of the Proto-NigerKordofanian noun class system," in Studies in African Languages and Linguistics. Proceedings of the Conference on African Languages and Linguistics, University of Illinois, Urbana, April 24-25, 1970 。 


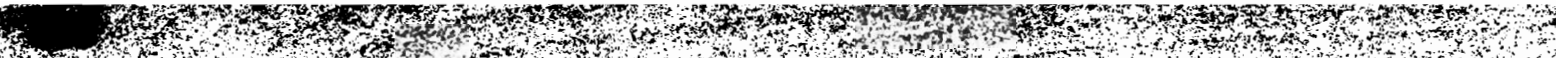
a $\gamma_{0}$

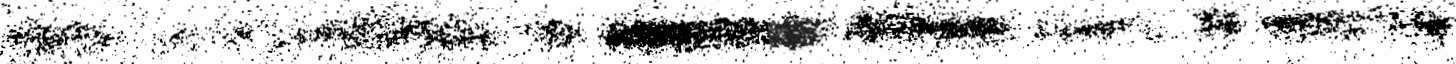

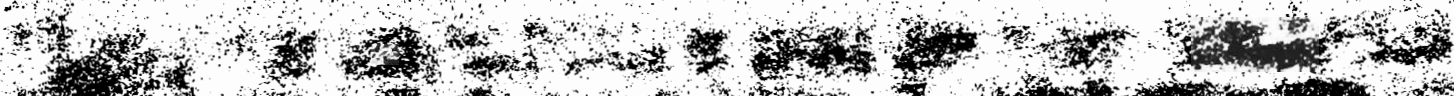

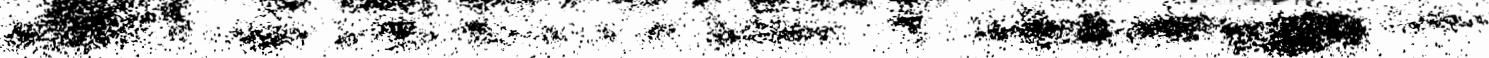

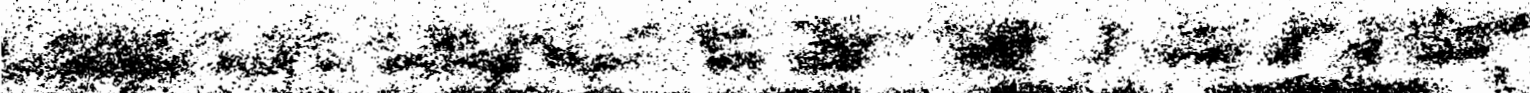

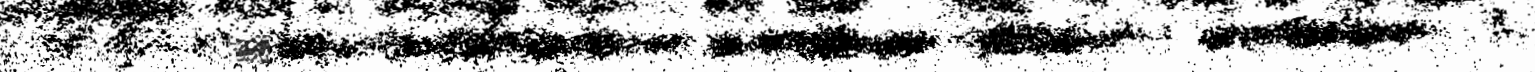

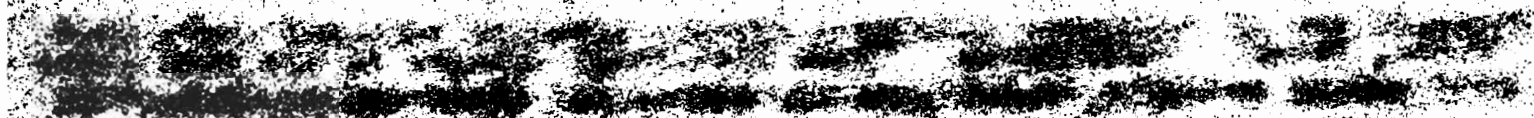

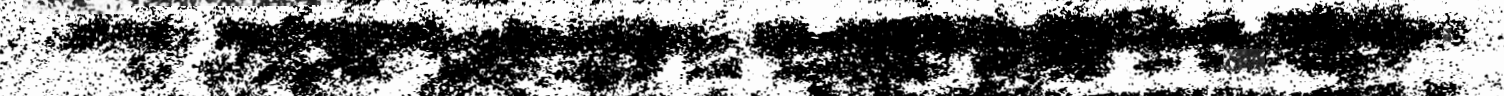

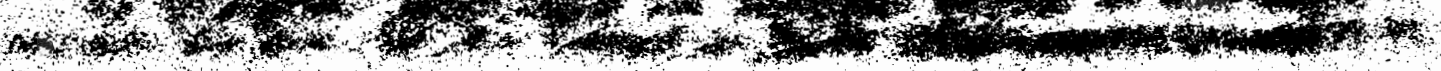

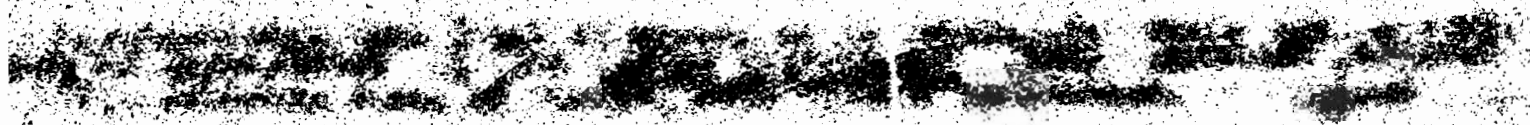

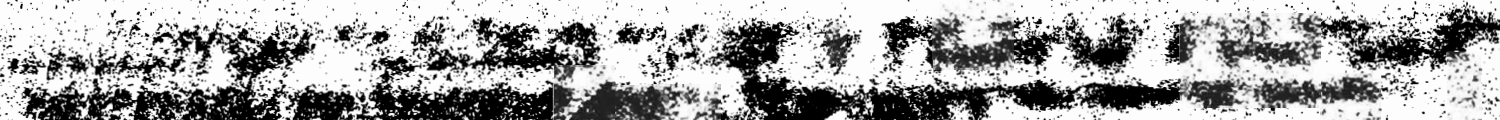

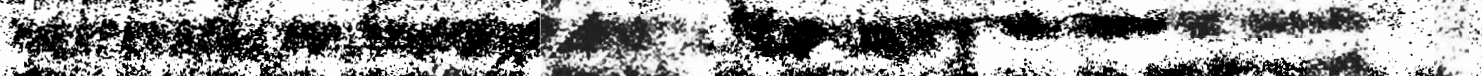
r.

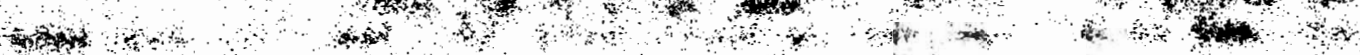

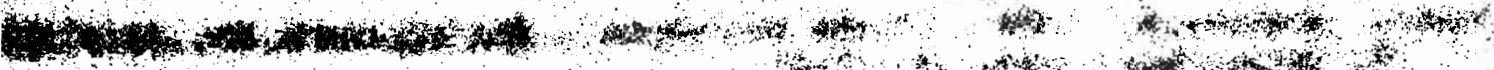

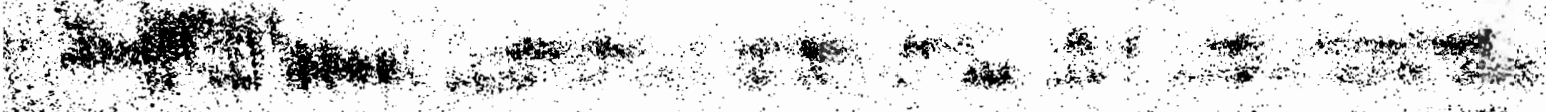

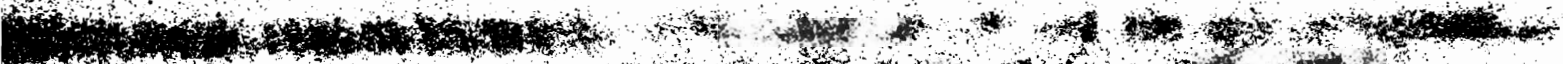
1
W

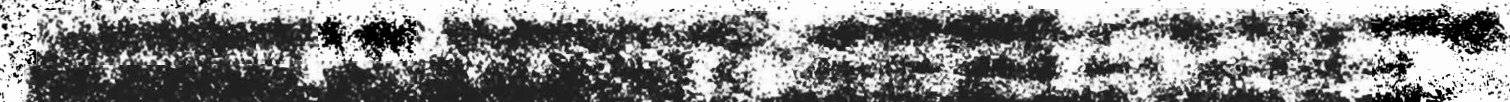

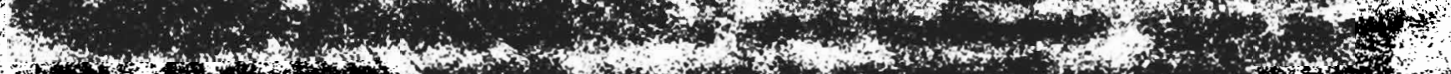

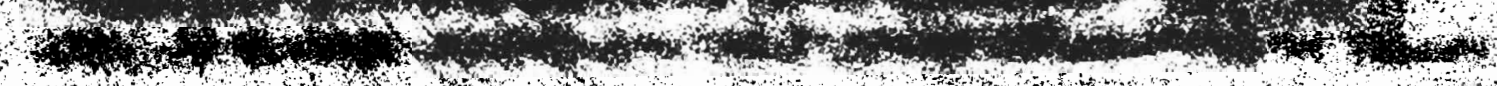

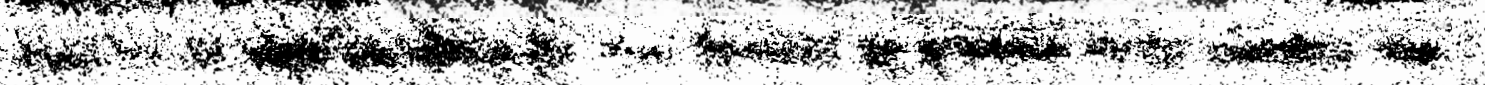

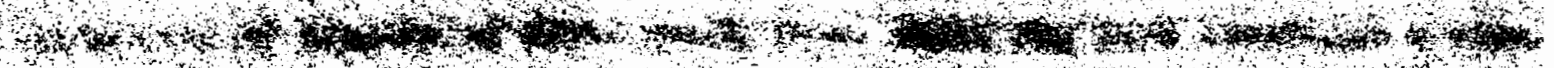

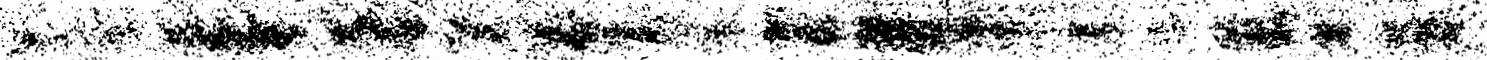

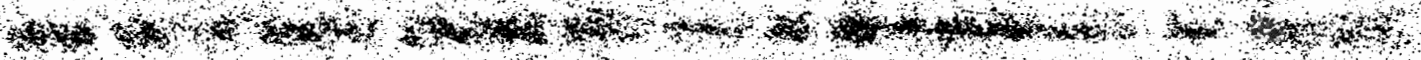

y

3.

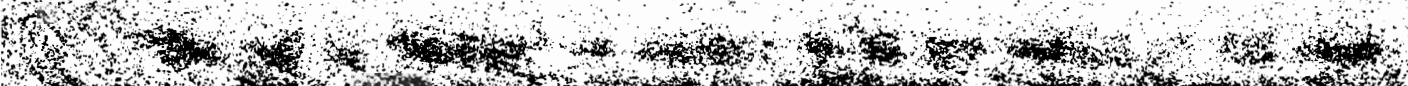
\begin{tabular}{l}
3 \\
\hline
\end{tabular} 
SONRAI CAUSATIVES AND PASSIVES: TRANSFORMATIONAL

VERSUS IEXICAL DERIVATIONS FOR PROPOSITIONAL HEADS ${ }^{1}$

\author{
Tim Shopen and Mamadou Konaré \\ Department of Linguistics \\ Indiana University
}

\title{
1. Sonrai verbs of the form STEM + NDI
}

Diré Sonrai has a number of verbs of the form STEM + NDI where the stem is itself a verb. Consider variations on the verb ja 'to eat':

(1) STEM WITHOUT SUFFIX

Musa na tasu di $\mathrm{NP}_{1} \mathrm{VNP}_{2}$
Mousa eat rice the
'Mousa ate the rice.'
STEM + NDI: THE DIRECT CAUSATIVE

(2) STEM + NDI: THE DIRECT CAUSATIVE

Ali jandi tasu di Musa se $\quad \mathrm{NP}_{3} \mathrm{~V}+$ ndi $\mathrm{NP}_{2} \mathrm{NP}_{1}$ se

Ali feed rice the Mousa to

'Ali fed the rice to Mousa.'

${ }^{1} A$ revised version of a paper prepared for the Conference on African Languages and Linguistics, University of Illinois, Urbana, April 24-25, 1970. Acknowledgements and thanks are due to a number of people. More than anyone, Charles Bird has been of great assistance in working out the ideas in this paper. We thank our colleague Fred Householder for reading and criticizing the preliminary version of this paper and offerring valuable information and suggestions. A lecture by Ray Jackendoff in December 1969 gave us important ideas on the form of lexical rules. Tim Shopen wishes to acknowledge a substantial debt to Dick Stanley, who, in several discussions in early 1969, helped him to formulate the idea of considering grammatical relations as a property of the lexical entries for propositional heads. Shopen had formulated that hypothesis in a working paper for the UCLA English Syntax project but had almost forgotten about it, and didn't think seriously about its consequences until the discussions with Stanley. We have heard indirectly rumors about work being done by Hugh Matthews along similar lines. Comments and criticisms from anyone who has been thinking about grammatical relations are invited. 
(3) STEM + NDI: THE INDIRECT CAUSATIVE
Ali nandi
tasu di Musa se
$\mathrm{NP}_{3} \mathrm{~V}+$ ndi $\mathrm{NP}_{2} \mathrm{NP}_{1}$ se

Ali cause-to-eat rice the Mousa to

'Ali had Mousa eat the rice.'

(4) STEM + NDI: THE PASSIVE

Tasu di nandi $\quad \mathrm{NP}_{2} \mathrm{~V}+$ ndi

rice the be-eaten

'The rice was eaten (by someone).'

In Sonrai there is no equivalent of the English by phrase, e.g. no way to say "The rice was eaten by Mousa", only "The rice was eaten". The existence of an AGENT is understood in (4), even though it cannot be expressed.

\section{Direct versus indirect causation}

The names we have given to the two causatives refer to the semantic role of the subjects of the sentences in which these verbs are used. Having indirect causatives expressed in simplex sentences is unusual although not unheard of in the languages of the world. ${ }^{2}$ The more usual situation is to have direct causation expressed in simplex sentences and indirect causation in complex sentences. ${ }^{3}$

${ }^{2} \mathrm{~L}$. Maran has informed us (personal communication) that Kachin, a Tibeto-Burman language, has a parallel process. There is a productive process of prefixation on verb stems that produces causative verbs some of which are ambiguous in just the way Sonrai causatives can be, e.g. [k' $\mathrm{k}^{\mathrm{hat}]}$ 'to fall' becomes [jok' rat] meaning either 'to drop' or 'to cause to fall'. Fred Householder reports that Turkic, Japanese and Korean have indirect causative verbs.

${ }^{3}$ English has no verb like nandi 'to cause to eat' with the combined meaning of indirect cause plus some additional element of meaning denoting the action that is caused. Indirect causation is typically expressed in complex sentences with matrix verbs like cause, make, force, have and persuade, where there are at least two propositional heads, the main clause verb and the subordinate clause verb. The verb cause can express indirect causation in a simplex, but a second propositional head has to be expressed or understood, e.g. with a nominalization as object, John caused the explosion; note the peculiarity of ?John caused the tree--explosion is a propositional head while tree isn't. 
The subject of a Direct Causative (DC) is the immediate or determinant cause. In Sonrai, as in English, feeding someone something entails rather than asserts that person's eating it. Corresponding to this is the fact that the only NP understood as AGENT in (2) is Ali, the causative subject. Musa, the one who gets fed, is GOAL. ${ }^{4}$ In the Indirect Causative (IC), on the other hand, the subject is the indirect or antecedent cause of the event. Causing someone to eat something asserts that he eats it: In (3) two AGENTs are understood, Ali, the causative subject, and Musa who initiates the eating. In fact, both $\mathrm{Ali}$ and Musa are

Cf. Hall [1965] on the indirectness of cause. George Lakoff (personal communication) reports that there are other kinds of cause besides the two defined in the direct/indirect dichotomy, probably four in all. A more abstract analysis of the semantic functions AGENT and INSTRUMENT would reveal them to share a feature of direct causation. What Gruber [1965] calls CAUSATIVE AGENT, PERMISSIVE AGENT and INSTRUMENT respectively could be analyzed with binary features as [+CAUSE, +RESPONSIBILITY], [-CAUSE, +RESPONSIBILITY] and [+CAUSE, -RESPONSIBILITY]; any verb or other propositional head with a CAUSATIVE AGENT or INSTRUMENT would be thereby "causative". When this paper was presented Getatchew Haile pointed out that -ndi in all its occurrences, including passive, is a marker for the presence of some kind of cause, direct or indirect, and could be called a causative marker. This would work except for instances of the passive (which we did not discuss in our presentation) where the generalization does not appear to hold, e.g. the passive of any stative verb like gunandi 'be seen' from guna 'to see' where in our analysis there is no association with a semantic function of cause, no AGENT or INSTRUMENT.

${ }^{4}$ We are indebted to Fillmore [1968] and Gruber [1965] for their many insights into the semantic primitives necessary to capture grammatical relations. We borrow terminology from both of them. The essential difference in our system is that we build the semantic representations into our lexical entries. Their systems involved doing the same thing twice. They put semantic labels on the nodes of the trees in the underlying representations and then built the same information into the lexical entries for verbs to insure proper lexical insertion. This obscured the syntactic properties of underlying representations. The correspondences between semantic functions and syntactic configurations in lexical items is a link between two different kinds of systems. The semantic system has different regularities from the syntactic, but an important part of the semantic system converges with the syntactic in lexical entries for propositional heads. The word is central to our view of language. 
causers, Ali an indirect one, and Musa a direct one.

The suppression of the AGENT function in 'to eat' which is essential to the meaning of 'to feed' should be captured in the rules for the derivation of direct causatives.

The difference between the two causatives is nicely illustrated by an example of a different sort. The following two sentences are not paraphrases of each other, (neere 'to sell', dey 'to buy', deyndi 'to cause to buy'):

(5) Ali neere bari di Musa se

Ali sell horse the Mousa to

'Ali sold the horse to Mousa'

(6) Ali deyndi bari di Musa se

Ali cause-to-buy horse the Mousa to

'Ali got Mousa to buy the horse'

In (5) Ali is AGENT and Musa is GOAL. In (6) both men are AGENT; moreover, in (6) a third person is understood, the one who sold the horse to Mousa. Ali in (6) cannot be understood as the salesman; the most likely explanation for this appears to be that $A l i$ is the AGENT of indirect causation and that this function is incompatible with direct participation in the transaction. 5

IC verb formation with $-n d i$ is much more productive than DC verb formation with -ndi. Most DC verbs are unanalyzable morphemes. Note that 'buy' and 'sell' are unrelated to each other, despite the fact that their meanings are so closely related. The verb cowndi 'to teach' is derived from cow 'to learn', fahamndi 'to explain' from faham 'to understand', hayndi 'to empregnate' (actually 'to give a baby to') from hay 'to give birth to', and wafakundi 'to reconcile' from wafaku 'to agree with'; however, these verbs are the exception rather than the rule. A list of all the DC verbs in -ndi that we have found

\footnotetext{
5 We owe these insights concerning the $D C$ verb neere 'to sell' and the IC verb deyndi 'to cause to buy' largely to Bob and Pat Terry.
} 
is located in the Appendix. Note that when -ndi is added to a stem which is a one place predicate to form a causative the result is a two place predicate (derey 'to get lost', dereyndi 'to lose'); when the stem is a two place predicate, the result is a three place predicate, at least most of the time (mow 'to hear', mowndi 'to translate, interpret'), but when the stem is a three place predicate, the causative can only be a three place predicate. We have an example of this with the IC verbs formed from the stems meaning 'buy' and 'sell'. With neerendi 'to cause to sell' we can get two objects [__ NP NP se ] and consistently ambiguous readings, e.g. 'Ali caused someone to sell the horse to Mousa', or 'Ali caused Mousa to sell the horse to someone'. There are only a limited number of syntactic slots available to verbs and if there are too many semantic functions, one of them has to be left out.

\section{Lexical entries for propositional heads}

We view grammatical relations as correspondences between deep structure configurations and semantic functions. These correspondences are defined in lexical entries for propositional heads. Consider the sentence:

$$
\begin{aligned}
& \text { Feneter di ba } \\
& \text { window the break } \\
& \text { 'The window broke' }
\end{aligned}
$$

This sentence describes a change of state for the object referred to in the subject NP. We will extend Gruber's notion [1965] and say that whatever undergoes a change of state is a THEME. The verb ba is the propositional head that provides us with the change of state meaning and with the information that the subject NP is to be interpreted as THEME. The deep-structure for (7) is:

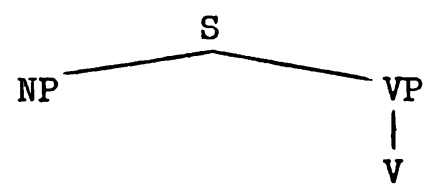

The lexical entry for the propositional head of (8) is: 


$$
\begin{aligned}
& \text { (a) (b) } \\
& \text { (c) }
\end{aligned}
$$

Under (c) in (9) we have the syntactic subcategorization of the verb: we include the subject $\mathrm{NP}$ because we want to represent all of the deep structure configuration for which the verb established grammatical relations. Under (d) is the semantic propositional structure that corresponds to the syntactic structure under $(c)$. As a first approximation of grammatical relations, it is useful to think of (d) as a template that fits over deep structure $(8)$ and gives the correct semantic interpretation. (e) represents the meaning of the verb.

Closely related to the intransitive sentence $(7)$ is the following transitive one:
Ali ba feneter di
Ali break window the
'Ali broke the window'

This is a causative sentence where the immediate cause of the event is an impact or direct application of force initiated by an AGENT (in the usual interpretation). We will call the AGENT the direct or determinant cause of the event in as much as he initiates the impact in some way. In this case the THEME is the NP which is the object of the verb, and the NP in subject position is the AGENT. Again, it is the lexical entry for the verb that provides the propositional structure corresponding to the syntactic configuration. The deep-structure configuration of (10) is:

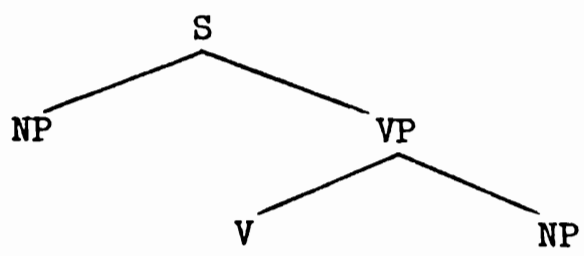

The lexical entry for the prepositional head of (10) is:
(12)
(a) (b)
(c)
(d)
(e)

$\mathrm{ba}+\mathrm{V},[\mathrm{NP}$ _NP ] [ AGENT_ THEME ], change of state caused by an impact... 
Under (d) we have what can be considered a template that fits over deep structure configuration (11) so that the two NPs are interpreted semantically as AGENT and THEME respectively.

There is no one-to-one correspondence between semantic functions and positions on a tree in a syntactically motivated deep structure. The correspondences vary from verb to verb. That this is the case for English has been made abundantly clear by Chomsky [1965:160-63], Fillmore [1966, 1968], and others. The situation is no different for Sonrai. Consider again ba 'to break' along with two other verbs, hina 'to cook' and na 'to eat'. All three can be used both transitively and intransitively. Transitively $\left(\mathrm{NP}_{1} \mathrm{VNP}_{2}\right)$ :

(13) Ali ba gorongo tondi di

Ali break chicken stone the

'Ali broke the egg'

(14) Ali hina gorongo tondi di

Ali cook chicken stone the

'Ali cooked the egg'

(15) Ali na gorongo tondi di

Ali eat chicken stone the

'Ali ate the egg'

On a significant level of abstraction, we can say that these three verbs have same gramatical relations in sentences such as these: [ NP_ _NP ] [ AGENT_ THEME ], as in parts (c) and (d) of (12). Their intransitive uses are different, however:

$\mathrm{NP}_{1} \mathrm{~V}$

(16) ?*Ali ba

Ali break

'Ali broke'

(18) Ali hina

Ali cook

'Ali cooked'
$\mathrm{NP}_{2} \cdot \mathrm{V}$

(17) Gorongo tondi di ba chicken stone the break 'The egg broke'

(19) Gorongo tondi di hina chicken stone the cook 'The egg cooked' 
$\mathrm{NP}_{1} \mathrm{~V}$

(20) Ali na

Ali eat

'Ali ate'
$\mathrm{NP}_{2} \mathrm{~V}$

(21) ?*Gorongo tondi di na

chicken stone the eat

'The egg ate'

Sentences (16) and (2l) are acceptable only when Ali is thought of as designating something brittle enough to break, in which case $\mathrm{Ali}$ could also occur in object position in a transitive sentence, or when, as in a folk tale perhaps, an egg is thought of as being capable of ingesting food in a manner similar to a fully-formed animal, in which case egg could occur in subject position in a transitive sentence. Syntactically these verbs are the same: They can all be inserted in deep structure configurations (8) or (11), but the sets of semantic templates assigned to these configurations, in particular to the intransitive configuration (8), are different:
(22) (a)
(b) (c)
(d)
(e)
$\mathrm{ba}+\mathrm{V}[\mathrm{NP}]$
[THEME
[AGENT THEME] impact...
change of state...
hina + V $[\mathrm{NP}$

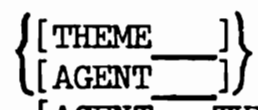
[NP
NP]
[AGWMT
THEMYE]
change of state...
$\mathrm{na}+\mathrm{V}[\mathrm{NP}$
NP NP]
[AGENT
[AGENT
] THEME ]
change of state...

Any grammar accounting for grammatical relations would have to indicate the difference between the above three verbs in the lexicon anyway, whatever other apparatus was proposed; our position is that the lexicon is the only part of the grammar where this distinction is appropriate.

4. Derivational morphology accounted for in the lexicon by word structure conditions

We will not content ourselves with simply listing lexical entries as in (22). There are many Sonrai verbs which like ba 'to break' and hina 'to cook', and unlike na 'to eat', can occur intransitively [NP__ ] with the semantic function [THEME as well as transitively 
[NP NP] with the semantic functions [AGENT THEME]. We call these object middle verbs in that they allow the same NP in subject position in intransitives as in object position in transitives. Some object middle verbs are:

$$
\begin{aligned}
& \text { kukur 'to burn', numey 'to wash', dumbu 'to sever', } \\
& \text { kayrey 'to shatter', morro 'to pulverize', ba 'to break', } \\
& \text { hina 'to cook', neere 'to sell', daabu 'to close', } \\
& \text { kufal 'to lock', fer 'to open', gami 'to mix', dibi 'to } \\
& \text { mix together', mun 'to spill', ton 'to fill', ko 'to dry', } \\
& \text { ben 'to finish', menne 'to melt' }
\end{aligned}
$$

The above verbs all share the following gramatical relations:

(c)

$$
[\mathrm{NP}
$$$$
\text { [NP }
$$

(d)

THEME

AGENT
THEME ]

The relationship between (i) and (ii) in (24) can be represented as Direct Causative Condition I:

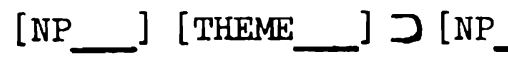
NP] [AGENT THEME ]

That is, if a propositional head can govern the grammatical relations on the left then it can also govern the grammatical relations on the right. It is a word structure (WS) condition for the part of lexical entries concerned with grammatical relations (cf. Stanley [1967] on morpheme structure conditions). A fuller treatment would have Direct Causative Condition II, concerned with causative sentences with instrumental subjects, etc. Condition (25) says nothing about morphological form: bun 'to die' and wi 'to kill', which are morphologically unrelated but semantically have the same propositional head. (25) could presumably apply to them equally well. There are few verbs, if any, which do not conform to (25), i.e. verbs which occur intransitively for which there is no transitive causative counterpart that shares their meaning. In the cases we have studied, causative verbs contain idiosyncratic accretions to the meaning of their intransitive non-causative counterparts, but not vice-versa. 
Including (25) in the grammar amounts to a claim about native speaker competence, and the way language is learned: When a child learns to produce intransitive sentences with the verbs in (23), or pairs of verbs like 'die' and 'kill', he relies on the general knowledge of grammatical relations represented by the WS condition (25), rather than learning each verb as a totally separate unit. ${ }^{6}$

There are cases where verbs to which WS condition (25) applies must, in transitive usage, have the causative suffix - ndi. We will examine variations on the verbs of motion kam 'to fall', goro 'to sit', jur 'to run' and fatta 'to go out':

$$
\begin{aligned}
& \text { Tu di kam } \\
& \text { pot the fall } \\
& \text { 'The pot fell' }
\end{aligned}
$$

(27) Garba kamndi tu di

Garba drop pot the

$$
\mathrm{NP}_{1} \mathrm{~V}
$$

'Garba dropped the pot'

(28) Usman goro

$\mathrm{NP}_{1} \mathrm{~V}$

Ousman sit down

'Ousman sat down'

Garba gorondi Usman

Garba sit down Ousman

$$
\begin{array}{lll}
\mathrm{NP}_{2} & \mathrm{~V} & \mathrm{NP}_{1}
\end{array}
$$

'Garba sat Ousman down'
(30) Bari di jur
$\mathrm{NP}_{1} \quad \mathrm{~V}$
horse the run
'The horse ran'

${ }^{6}$ There are important generalizations that could be made for universal grammar concerning grammatical relations. We have never heard of an SVO language which has transitive sentences [NP V NP] with the left-to-right order of semantic functions as [THEME verb AGENT] unless it is some kind of special sentence construction like the passive. The most common word order for intransitive sentences in SVO languages is [NP V]. Thus, the pattern of gramatical relations discussed here is very common: [THEME verb] for intransitive use of a given verb, and [AGENT verb THEME] for its transitive counterpart. 
(31)

Garba jurndi bari di $\mathrm{NP}_{2} \quad \mathrm{~V} \quad \mathrm{NP}_{1}$

Garba ride horse the

'Garba rode the horse'

Musi di fatta

cat the go out

'The cat went out'

(33) Garba fattandi musi di $\mathrm{NP}_{2} \quad \mathrm{~V} \quad \mathrm{NP}_{1}$

Garba take out cat the

'Garba took the cat out'

The morphological form of the verbs in the transitive sentences above can be described as the result of a lexical rule, the Verb Morphological Form Rule I: ${ }^{7}$

(34) $\mathrm{V}$ +ndi $=\mathrm{V}$

A unified lexical entry for kam and kamndi can be represented as follows :

(35) (a)<smiles>[V][Te][Te]</smiles>

(b)

(c) $+\mathrm{V}$ $[\mathrm{NP}$ NP] [AGENT (d)

[THEME___ ], THEME], physical motion caused by release from a grip, etc. ...

Given that there are a number of lexical items in Sonrai with the category label $+V$ which also have the internal structure $V+n d i$, the entries under part (a) of (35) can be considered less costly to the grammar. We are claiming that a child learning verbs such as kam, kamndi, and the others in (27)-(33), recognizes the internal structure of the morphemically complex verb and simplifies the learning by reference to the general principle of morphological form (34); furthermore, the formmeaning relationship in pairs of verbs such as kam/kamndi can be

7We got the formulation of this kind of rule, also the idea of separating the rules for morphological form from the generalizations concerning meaning in the content of lexical entries, from Ray Jackendoff in a lecture at Indiana University in December of 1969. 
captured as a statement of entailment between the rule of morphological form (34) (an MF rule) and rule (25) of Direct Causative Condition I (a GR condition):

(36) MF rule (34) つ GR condition (25)

The importance of this condition to the grammar corresponds to the number of items in the lexicon to which it applies. Although it characterizes a substantial subclass of verbs, it does not apply exhaustively to the language, $i . e$. not all verbs of the form $V+$ ndi are direct causatives. We will call such a statement a minor condition: It characterizes a subpart of the language but not the language as a whole. For this subpart we are saying in effect that the morphological form $V+n d i$ entails direct causative meaning.

It is our purpose to concentrate on the portion of meaning of sentences which is least idiosyncratic, the system of semantic functions that can be used to characterize the grammatical relations governed by all propositional heads. Even at that we have not been comprehensive. A more detailed account would take into consideration a number of facts we have passed over here. Note that for kamndi and gorondi, 'to drop' and 'to sit down (trans.)', the meaning involves physical contact between the subject and the object, and motion for the object; while for jurndi 'to ride' and fattandi 'to take out', the meaning involves not only these elements of meaning, but motion for the subject as well. In a fuller account of grammatical relations it could be argued that the subjects as well as the objects of the latter two verbs are THEME in propositions of motion, so that the subjects would be simultaneously AGEHT and THEFME.

There are subtleties which we have skipped about AGENT in kamndi 'to drop'. We have also passed over the fact that whereas the subject of kam 'to fall' is THEME, that of jur 'to run' and fatta 'to go out' may be AGENT as well as THEME, and that of goro 'to sit down (intrans.)' must be AGENT as well as THEME. These facts should not detract from the point that we intend to make here, which is that there are aspects of sentential meaning, closely related to aspects of form, which can be shown to be quite general and can be accounted for in the lexicon. 
It happens that each of the causative sentences, (27), (29), (31) and (33) are ambiguous. Given above are only the direct causative meanings. Each of them also has an indirect causative meaning:

(27') Garba kamndi tu di

Garba cause-to-fall pot the

'Garba caused the pot to fall'

(29') Garba gorondi Usman

Garba cause-to-sit Ousman

'Garba had Ousman sit down'

(31') Garba jurndi bari di

Garba cause-to-run horse the

'Garba made the horse run'

(33') Garba fattandi musi di

Garba cause-to-go-out cat the

'Garba made the cat go out'

To account for these meanings, we need another Grammatical Relations condition and another condition showing an implicational relationship between form and meaning.

We are making the following important distinction between DC and IC constructions (e.g. (27) versus (27')): Although they both are assigned a simplex tree (11) as their deep structure syntactic analysis, only DC constructions will be treated semantically as simplex propositions; IC will be treated as complex propositions. A simplex $S$ is everything dominated by an $S$ node without an intervening $S$. A simplex proposition is all the meaning governed by a propositional head without another one intervening. The lexical entries for the $\mathrm{V}+$ ndi verbs in sentences like (27') will contain the following gramatical relations:

(37) [NP_NP][AGENT IC [THEME_] ]
a $\quad \beta \quad \alpha$
B

The semantic representation [AGENT IC [THEME_] ] is to read: (37') 'AGENT cause indirectly [THEME to (STEM verb)]' 
(e.g. 27'), 'Garba caused the pot to fall' with kam+ndi from kam 'to fall'). The Greek letter indexes are to show the correspondences between NPs and semantic functions unequivocally. The head of the matrix proposition, in the outside set of brackets is a proverb IC meaning pretty much what the lexical item cause does in English, i.e. indirect cause, cf. the discussion in $\mathrm{Hall}$ [1965]; the head of the subordinate proposition is the stem of the $V$ +ndi verb.

As we will show in Section 5, not all of the co-occurrences of the stem verb in its independent occurrences are allowed in IC constructions; but in those that are allowed, the full meaning of the stem verb is preserved. The most compelling reason for the complex proposition analysis of IC constructions is that the subject of the IC verb $V+n d i$ is always interpreted as an indirect cause, while a direct cause may be associated with the part of the meaning governed by the stem verb, as in the cases discussed in Section 2, where there can be two AGENTs.

If complex structure is the appropriate semantic analysis for IC sentences, then one can ask why we do not assign a complex sentence deep structure to IC sentences for our syntactic analysis. In Section 6 we give arguments to show that the deep structure must be a simplex $S$.

We now see a case where we have different symmetries in our syntactic and semantic representations. This raises an important question in principle. Actually, left-to-right order in semantic representation has no value in our scheme except as an arbitrary convention for the purpose of exposition; hierarchy does have value, though, so the question of principle remains. Our position is that describing gramatical relations as correspondences between two systems of structure, one syntactic and one semantic and each with its own regularities, will allow simpler and more revealing descriptions of syntax and semantics respectively, which are, we think, properly defined as independent aspects of linguistic competence. By opting for such an approach, we also make a claim about a third aspect of competence, namely we attribute importance to the correspondences themselves, e.g. the Greek letter subscripts in (37), or, in more usual parlance, to the profections from syntactic onto semantic representations. Surely these correspondences are themselves systematic: 
we believe that they are and that interesting regularities in correspondences can be revealed in WS conditions on grammatical relations such as we are outlining here. The working out of detailed problems in the analysis of IC verbs here, and more particularly in Section 6, is offered in the way of empirical evidence for the validity of our position.

Two more conditions are necessary, the first, Indirect Causative Condition I:

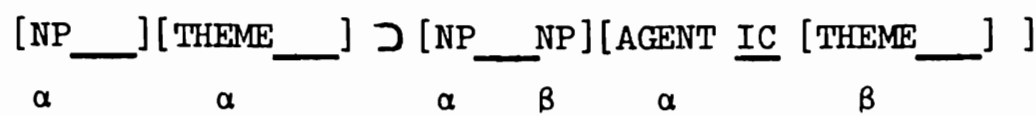

This condition accounts for pairs of sentences like (26) 'The pot fell' and (27') 'Garba caused the pot to fail'. In a comprehensive account, many other constructions would be accounted for by conditions of this kind. The formation of IC verbs $\mathrm{V}$ +ndi from already existent verb stems is pervasive but not fully productive (this matter will be discussed further in Section 6). Thus, (38) will have to be called a minor condition. However, it has greater importance for the gramar than other conceivable conditions of this kind, because there are so many lexical items to which it applies. Another condition is:

(39) GR Condition (38) つ MF Rule (34)

Condition (39) can be called a major condition, since it applies exhaustively in Sonrai: The only Sonrai verbs governing IC propositions like those above have the form $\mathrm{V}$ +ndi.

We are now prepared to display a unified lexical entry for the three related verbs kam 'to fall', kamndi 'to drop' (DC) and kamndi 'to cause to drop' (IC):

(40) (a)

kam

[ $]_{V}$ +ndi

[ $\left[{ }_{V}\right]$ +nd $i$ (b) (c) [NP__ ] [THEME

$+\mathrm{V} \quad[\mathrm{NP}$ NP] [AGENT

[NP NP] [AGENT IC [THEME (d)

THEME] caused by release from grip motion 
It should be reiterated that we are making generalizations about lexical items, and that in actual sentences it is the propositional head that is the repository of the native speaker's knowledge of grammatical relations: they are part of the meaning of this kind of word. An analysis of words is essential to the understanding of the deepest regularities of language. The WS conditions that we have formulated for gramatical relations and for form-meaning relationships in morphology are claims about linguistic competence, the way languages are learned and the way they change. We are saying that the primary elements involved are these generalizations and not lexical items as unrelated parts of a list. The ultimate arbitration of theoretical dispute over competing theories of grammatical relations should involve evidence from language learning and language change.

5. Lexicalist versus transformationalist hypotheses for derivational morphology

The distinction between lexical and transformational derivations of morphological items arises only in a theory that posits an abstract level of representation where lexical insertion takes place before the application of syntactic transformations. It is hard to imagine how in a theory in which all lexical insertion takes place after the cyclically ordered rules of syntax such a distinction would be possible or even desirable. We adhere to the notion of a syntactically-motivated deep structure where lexical insertion takes place, and we do so for two main reasons: first, we want such a level on which to make an abstract characterization about word order; and second, we want a level on which to define grammatical relations in the lexical entries for propositional heads. The two functions of deep structure coincide: the optimal point at which to specify grammatical relations for propositional heads is on the level at which syntactic co-occurrence restrictions are defined for them.

In our view there are two kinds of systematic sound-meaning correspondences: propositional meaning defined by lexical heads at the same level at which syntactic co-occurrence restrictions are specified, i.e. in deep structure before the application of syntactic transformations; and scope meaning, which depends on order after the application of syntactic 
we believe that they are and that interesting regularities in correspondences can be revealed in WS conditions on grammatical relations such as we are outlining here. The working out of detailed problems in the analysis of IC verbs here, and more particularly in Section 6, is offered in the way of empirical evidence for the validity of our position.

Two more conditions are necessary, the first, Indirect Causative Condition I:

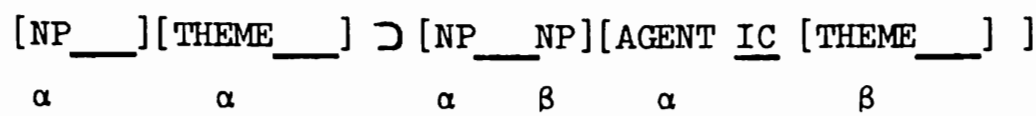

This condition accounts for pairs of sentences like (26) 'The pot fell' and (27') 'Garba caused the pot to fail'. In a comprehensive account, many other constructions would be accounted for by conditions of this kind. The formation of IC verbs $V+n d i$ from already existent verb stems is pervasive but not fully productive (this matter will be discussed further in Section 6). Thus, (38) will have to be called a minor condition. However, it has greater importance for the grammar than other conceivable conditions of this kind, because there are so many lexical items to which it applies. Another condition is:

(39) GR Condition (38) つ MF Rule (34)

Condition (39) can be called a major condition, since it applies exhaustively in Sonrai: The only Sonrai verbs governing IC propositions like those above have the form $\mathrm{V}+\mathrm{ndi}$.

We are now prepared to display a unified lexical entry for the three related verbs kam 'to fall', kamndi 'to drop' (DC) and kamndi 'to cause to drop' (IC):

(40) (a)

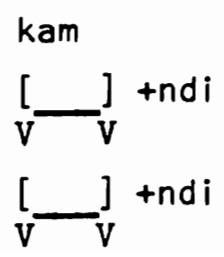

(b) (c) [NP_ ] [THEME $+\mathrm{V} \quad[\mathrm{NP}$ NP] [AGENT [NP NP] [AGENT IC [THEME physical motion

\section{(d)}

THEME ] caused by release from grip ]] 
'to break', etc. It is frequently the case semantic functions are changed in the derivation of these verbs, and sometimes in different ways for different items. For example, as we have said in the DC verb derived from kam 'to fall', kamndi 'to drop', the causative subject is stationary, while the $D C$ verb derived from jumbu 'to go down' is jumbundi 'to bring down' where the causative subject either moves with the object of the causative verb or is stationary at the terminal point of motion. In the latter case there is a level of meaning in which the causative subject would have to be represented as THEME or GOAL as well as AGENT, in the former the causative subject would be AGENT and SOURCE. No DC verb can have more than one AGENT: in DC verbs of the form STEM+NDI where the stem used without the affix is an agential verb, e.g. na 'to eat', goro 'to sit down', the semantic function AGENT is always suppressed for the stem, cf. Section 2. The effect DC verb formation has on grammatical relations can be seen to be even more extensive when a wider set of facts is considered. For example, agential verbs such as na 'to eat' can take an INSTRUMENT used by the AGENT, e.g. a fork, but in the derived DC verb, the only INSTRUMENT allowable is the one used by the causative AGENT-X's feeding $Y$ with a fork entails $Y$ 's eating, but not $Y^{\prime}$ 's eating with a fork. All this evidence concerning grammatical relations argues in our view for a lexical derivation of DC verbs. For supporting argument, we can point to the idiosyncratic nuances in the meaning of the DC verbs not predictable from either the meaning of the stems or the general meaning of direct causation, e.g. (35e), etc.

6. Why indirect causatives must be derived lexically

Among causative verbs of the form STEM+NDI, the most likely candidates for a transformational derivation are the IC verbs. The only IC verbs occurring as part of what appear to be simplex sentence constructions in surface structure are those of the form STEM+NDI. The only other way indirect causation can be expressed in Sonrai is in complex sentence constructions, e.g. with the verb gabi 'to force'. Usually, in the languages of the world, indirect causation is expressed only in complex sentences. One could hypothesize then that sentences such as (41) below are simplexes in surface structure only and that in their deep 
transformations, either cycle by cycle, or after all syntactic transformations have applied, cf. Chomsky [1969] on the notions of focus and presupposition, Jackendoff [1969] on coreference, scope of negatives, quantifiers and adverbs.

If such a point of view is correct, then it is easy to see one of the things that syntactic transformations should not be allowed to do: they should not be allowed to change the value of lexical items as propositional heads. 8 If the morphological item in question is a propositional head, and it is proposed that the morphological item be created by a syntactic transformation, then it would have to be the case that all the propositional properties of the derived item can be accounted for in the lexical entries present in the deep structures of the sentences in which it occurs. Conversely, if the derived item governs a new set of grammatical relations, then it has to itself be a lexical item inserted in deep structure.

An obvious example of a class of morphological items which cannot be derived transformationally in this view are the direct causatives, jandi 'to feed', cowndi 'to teach', neere 'to sell', the transitive ba

${ }^{8}$ In Chomsky [1968], the paper that inspired the title of this section, Chomsky gives a great deal of evidence to show that the meaning and cooccurrence restrictions for English deverbal nouns, e.g. criticism, are idiosyncratically related to the verbs from which they are derived so that the nouns should be lexical entries in their own right. He makes it clear that he expects cooccurrence restrictions between heads and their complements to be lexically defined, but does not go so far as to say that grammatical relations are also relevant to the problem. He treats grammatical relations as an open question in the theory, $c f$. Chomsky [1965:160-63; 1968: fnl5]; however, he does much to suggest that grammatical relations are relevant to the problem. For example, he points out the following data:

(a) John amused the children with his stories.

(b) *John's amusement of the children with his stories...

(c) John's amusement at the children's antics...

We would say that the verb amuse in its lexical entry allows for the imposition of the semantic function AGENT, while the noun amusement does not. This in itself would be a reason for having a lexical rather than a transformational derivation of amusement. 
structure (42) into the appropriate surface structure, a transformation involving seven elementary operations. ${ }^{9}$ More serious is the fact that this hypothesis makes the wrong predictions about what is gramatical. First, although hina can take an INSTRUMENT subject when used in a simplex sentence, the object of se after hinandi cannot be interpreted as IINSTRUMENT:

(44) Boosi kono hina gorongo tondi yo embers hot cook chicken stone pl.

'Hot embers cooked eggs'

${ }^{9}$ If the deep structure were (42), the embedding transformation would have to totally rebuild the tree:

(i) TRANSFORMATION FOR THE COMPLEX SENTTENCE HYPOTHESIS:

$$
\begin{aligned}
& \text { S.I. } \mathrm{X}-\left[_{\mathrm{VP}}-\mathrm{IDI}-\mathrm{C}_{\mathrm{S}}-\mathrm{NP}-\mathrm{v}-\mathrm{NP}-\mathrm{X}\right. \\
& \begin{array}{llllllll}
1 & 2 & 3 & 4 & 5 & 6 & 7 & 8
\end{array} \\
& \text { S.C. } 1,2,6+3, \varnothing, 2>7, \emptyset, 2>\mathrm{PP}>5+\text { POST }>\text { se }, 8 \\
& \text { (a) Attach a copy of } 6 \text { as left sistes of } 3 \text {. } \\
& \text { (b) Attach a copy of } 7 \text { as left sister of } 4 \\
& \text { (c) Attach PP as right sister of } 4 \\
& \text { (d) Attach a copy of } 5 \text { as left daughter of the PP in (c) } \\
& \text { (e) Attach POST as the right daughter of the PP in (c) } \\
& \text { (f) Attach se as daughter of the POST in (e) } \\
& \text { (g) Erase } 4 \text { and everything under it }
\end{aligned}
$$

Several of these operations become unnecessary under the Revised Complex Sentence Hypothesis (47), but another transformation must be added for Equi-NP deletion. Any hope of limiting the power of transformations when rules of this kind are allowed is completely lost. The forms that these transformations can create can occur freely in subordinate as well as main clauses. The promising work by Emonds [1969] on a structure-preserving theory of transformational grammar makes the claim for English that transformations can do least to rearrange the structure of deep structure trees in embedded position. Our preliminary investigation of Sonrai syntax leads us to believe that this principle is appropriate for Sonrai too. For example, there is a preposing emphasis construction that moves phrase nodes from the right of the verb and places them in front of the sentence. This rule operates freely only in main clauses. 
structure they are complex sentences with a matrix verb NDI 'to cause'. We will call this the Complex Sentence Hypothesis for IC verbs of the form STEM+NDI (see hinandi 'to cause to cook' from hina 'to cook'):

(41) Garba hinandi gorongo tondi yo Ali se

Garba cause-to-cook chicken stone pl. Ali to

'Garba had Ali cook eggs'

The Complex Sentence Hypothesis would assign to (4l) the deep structure:

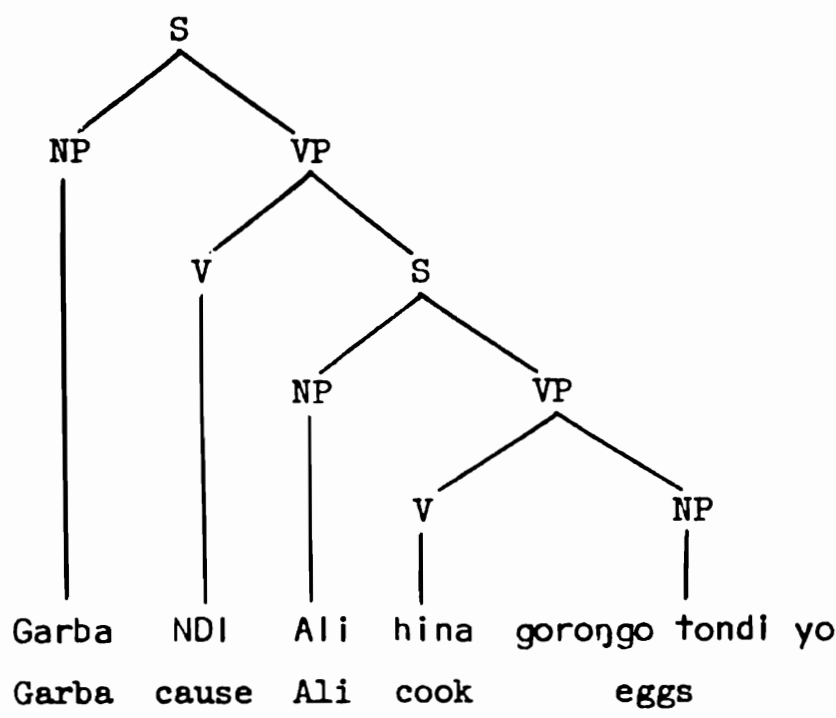

The deep structure (42) would be converted into a simplex sentence by an obligatory transformation. In the meanwhile semantic interpretation for the propositional content of the sentence could be carried out in deep structure, with grammatical relations defined in the lexical entries for the two verbs NDI 'to cause' and hina 'to cook', that is THEME is extended to apply to entities that are caused, where cause is a kind of change of state, and we obtain:
(43)
(a) (b)
(c)
(d)
(e)
$\mathrm{NDI}+\mathrm{V}\left[\mathrm{NP} \_\mathrm{S}\right]$ [AGENT_ THEME] indirect causation ...
hina $+\mathrm{V} \quad[\mathrm{NP}$ NP ] [AGENT THEME]... change of state...

The first problem with the Complex Sentence Hypothesis is the sheer complexity of the transformation that would be required to convert deep 
If the Complex Sentence Hypothesis were right, there would be nothing syntactically ill-formed about (46), for clause-by-clause it is a grammatical sentence. Instead of positing the unlikely constraint of a selection between the main clause verb and the subject of the embedded sentence, the only way to account for the ungramaticality of (45) is to revise the Complex Sentence Hypothesis as follows, e.g. for sentence (41):

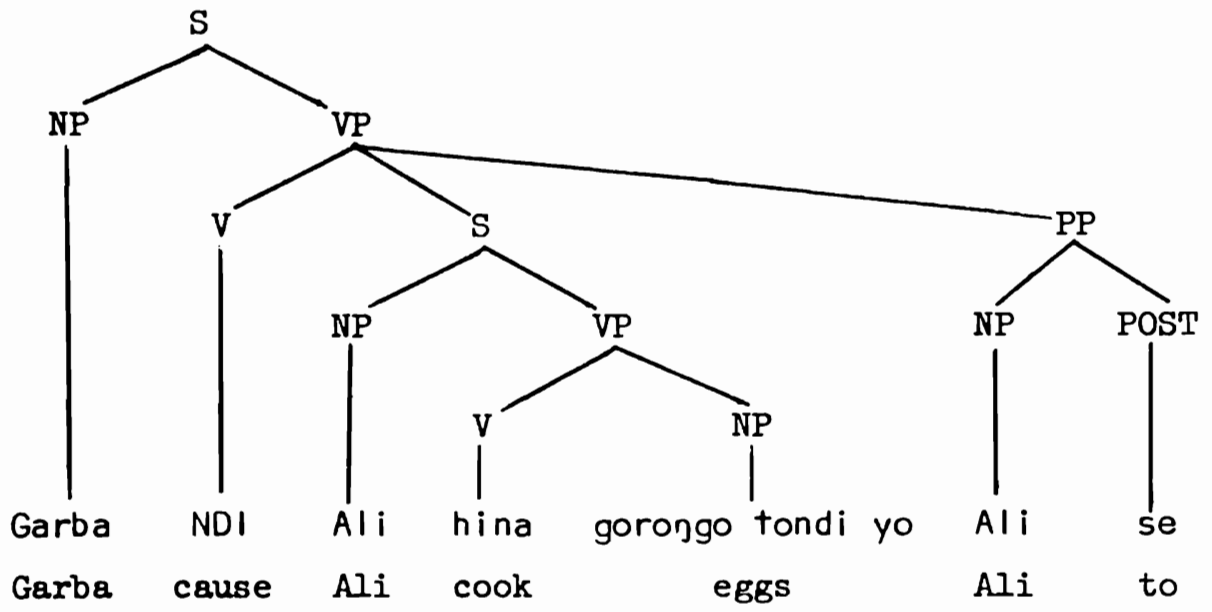

Now instead of having the subject of the embedded sentence raised into the main clause by the embedding transformation, we could say that there is a rule of equi-NP deletion that deletes the subject of the embedded sentence on identity with the object of se in the main clause. All the objects of se must be interpreted as animate. If instead of Ali, we had boosi kono 'hot embers' as the embedded subject, this same NP would have to be the object of the postposition se and the main clause. The structural description for equi-NP deletion and embedding could be met, but boosi kono 'hot embers' in the main clause would be incompatible with the presuppositions of se (under normal circumstances). Thus, the ungramaticality of (45) would be accounted for. But it turns out that troubles are just beginning for the Complex Sentence Hypothesis. Sentence (4I) had the form [Garba V NP [Ali se]]; it is also possible to get [Garba V [Ali se] NP] and [Garba V Ali NP] as paraphrases. This suggests that there might be a Sonrai rule of "Dative Shift" with a sentence 
*Garba hinandi gorongo tondi yo boosi kono se

Garba cause-to-cook chicken stone pl. embers hot to

'Garba caused the hot embers to cook the eggs'

Sentence (45) is grammatical only in the fanciful situation where the embers are personified and thought of as AGENT.

The problem is how to block the embedding transformation posited for the Complex Sentence Hypothesis from operating on what would have to be the deep structure for (45):

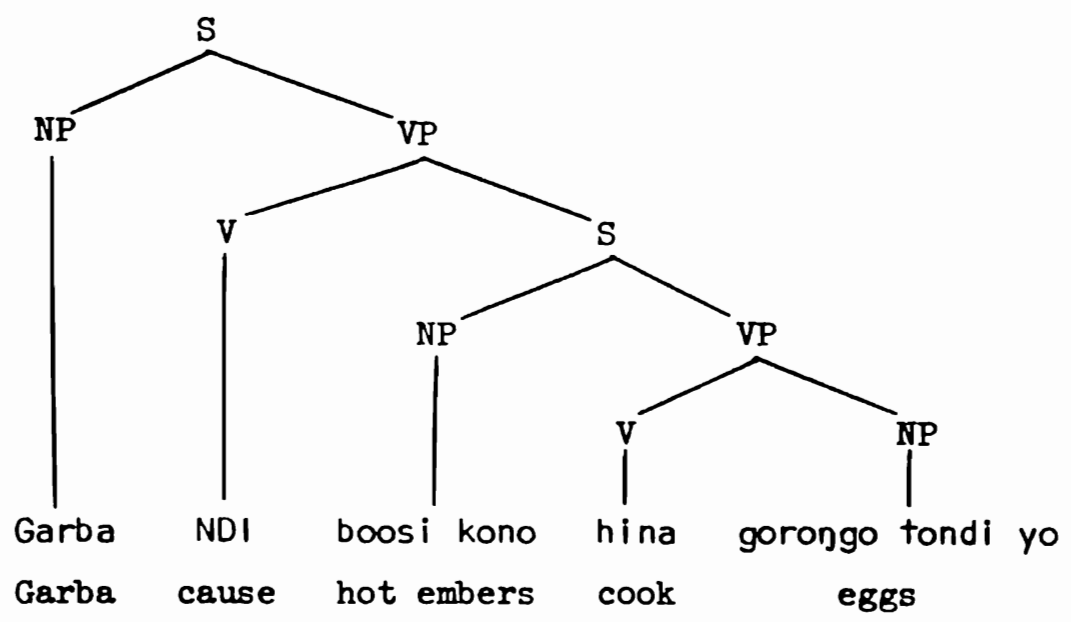

The formulation of transformation (i) becomes much more complicated when a fuller range of examples is examined. The [NP se] phrase can occur only when the causative verb has a double object; this is a general constraint on double object verbs. Some of the same causative verbs that take double objects will also take single objects.
(ii) Garba hinandi
mo di Ali se

Garba cause-to-cook the rice Ali

(iii) Garba hinandi mo di (*se)

'Garba is having someone cook the rice.'

(iv) Garba hinandi Ali (*se)

'Garba is having Ali cook.'

Generating sentences (iii) and (iv) correcting is a very complicated problem for either the Complex Sentence Hypothesis (42) or the Revised Complex Sentence Hypothesis (47). An algorithm can be found but it doesn't look like a rule of language. 
(50)

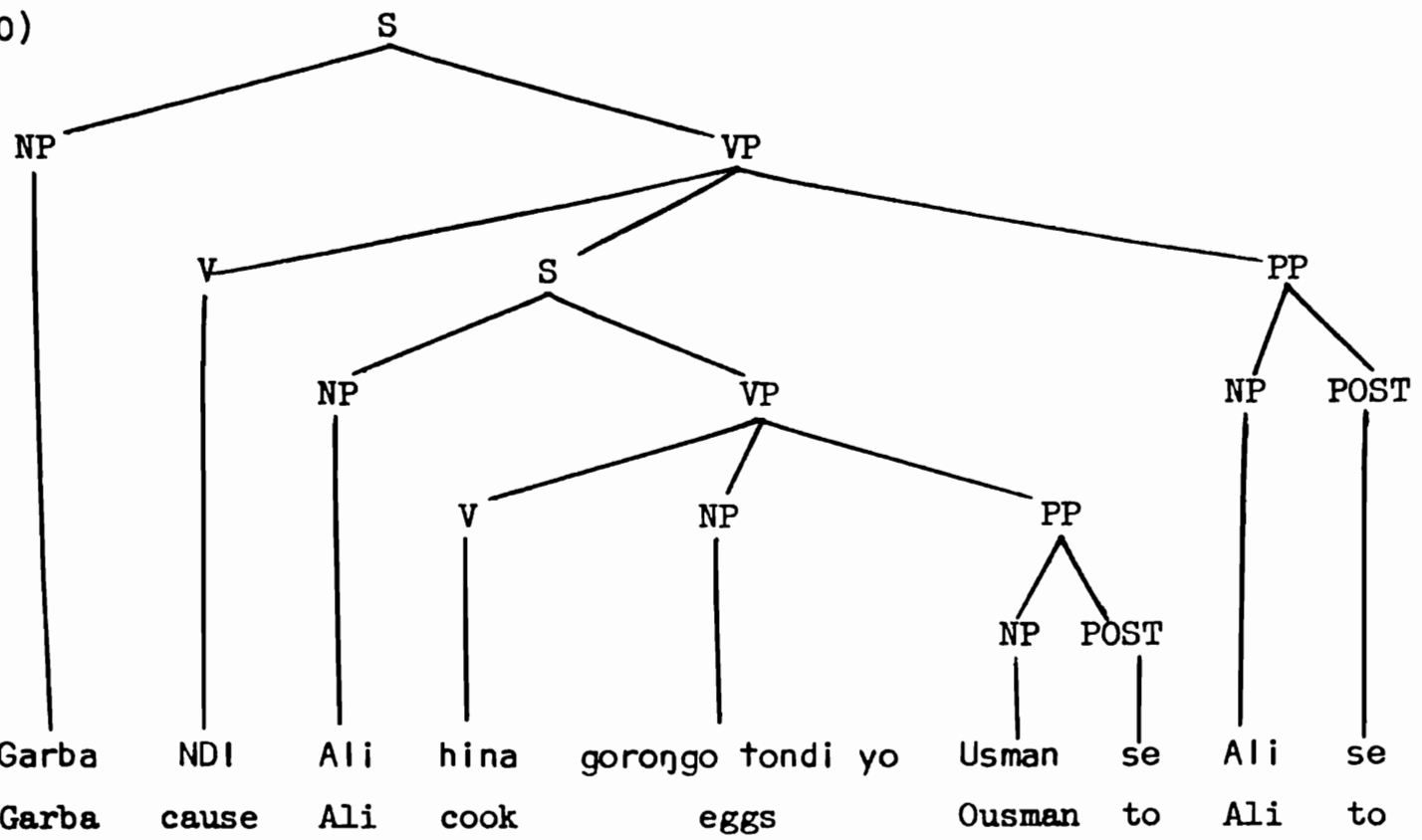

The embedding rule would raise the embedded PP into the main clause and then the hypothetical dative shift rule would have to obligatorily move the main clause PP next to the verb and delete the se to ensure output of the grammatical (48') instead of the ungrammatical (4I'). Making an otherwise optional rule obligatory just in case a certain kind of embedding transformation has operated is a highly dubious solution, and one which in fact throws the Complex Sentence Hypothesis into doubt. The logically conceivable range of sentences under the Complex Sentence Hypothesis would include one with two benefactives, one for the main clause and one for the embedded sentence. Sentence (4I) is actually ambiguous.

(41) Garba hinandi gorongo tondi di yo Ali se Garba cause-to-cook chicken stone the pl. Ali to

a. 'Garba had Ali cook the eggs'

b. 'Garba had someone cook the eggs for Ali'

We leave aside the question of what the deep structure would be for the second interpretation of (41) (further reason to doubt the Complex Sentence Hypothesis). Imagine the sentence for the following situation: 'Ali cooks the eggs for Ousman and Garba causes this to happen for Kalil'. 
such as (41) as input, and then shift of the postpositional phrase with optional deletion of the se. This rule would apply to most if not all sentences with double object verbs occurring in the environment (a) $\left[\mathrm{NP}_{1}-\mathrm{NP}_{2}\left[\mathrm{NP}_{3}\right.\right.$ se]] giving (b) $\left[\mathrm{NP}_{1} \_\left[\mathrm{NP}_{3} \text { se }\right] \mathrm{NP}_{2}\right]$ or (c) $\left[\mathrm{NP}_{1} \mathrm{NP}_{3} \mathrm{NP}_{2}\right]$ as output. The (c) variant for (41) would be as follows:

(48) Garba hinandl Ali gorongo tondi yo

Garba cause-to-cook Ali chicken stone pl. 'Garba had Ali cook eggs'

Now the dilemma: sentence (48), but not (41) can be extended by another [NP se] phrase, which must have a benefactive meaning.

(48') Garba hinandi Ali gorongo tondi yo Usman se

Garba cause-to-cook Ali chicken stone pl. Ousman to

'Garba had Ali cook eggs for Ousman'

(41') *Garba hinandi gorongo tondi yo Ali se Usman se

Garba cause-to-cook chicken stone pl. Ali to Ousman to

'Garba had Ali cook the eggs for Ousman'

For one of the possible interpretations of (48'), the Complex Sentence Hypothesis would have to posit (49) as an embedded sentence in the deep structure (50); the latter giving the deep structure of (48'):

(49) Ali hina gorongo tondi di yo Usman se

Ali cook chicken stone the pl. Ousman to

'Ali cooked the eggs for Ousman' 
if the environment is [ $\mathrm{V} \mathrm{NP}$ _ ] and the verb is a single object verb, they can have only a benefactive meaning; whereas if the verb is double object, as is hinandi, then their meaning is usually ambiguous between benefactive and something else. Our analysis takes note of the fact that benefactives are an optional semantic function with a wide range of sentences, that se always has a meaning best glossed by 'to' and that its object is always a [tanimate] goal for some kind of abstract motion. What the GOAL may receive may be simply an object, or the meaning associated with benefactives, or in the case of IC verbs like hinandi the predication of the semantic function associated with the deep structure subject of the stem of the IC verb, i.e. for hina 'to cook' as in hinandi, AGENT; for mow 'to hear' as in mowndi, GOAL. The evidence that we have summarized here briefly leads us to believe that there is no Dative Shift Rule and that VPs of the form [V NP NP ... ] can be generated in deep structure, where the PS rule for VP is as follows: $\left(53^{\prime}\right) \mathrm{VP} \rightarrow \mathrm{V}(\mathrm{NP})(\mathrm{NP})(\mathrm{PP}) *(\mathrm{~s})$

Some general co-occurrence restriction (a semantic one?) would prevent more than one se per VP in a simplex sentence in deep structure.

If one did away with the Dative Shift Rule within the framework of the Complex Sentence Hypothesis, then new measures would have to be taken to bar the generation of the ungramatical *(54) (cf. (44) and *(45)):

$$
\begin{aligned}
& \text { *Garba hinandi boosi kono gorongo tondi di yo } \\
& \text { Garba cause-to-cook embers hot chicken stone the pl. } \\
& \text { 'Garba caused the hot embers to cook the eggs' }
\end{aligned}
$$

The ungrammaticality of (45) and (54) are representative. All IC verbs on the form STEM+NDI are constrained in the same way: if the event that is caused indirectly itself has a direct cause, that direct cause must be AGENT and not INSTRUMENT. The co-occurrence restrictions for the complements of STFMANDI IC verbs altogether the cases involving both IHSTRUMEINT and BENEFACTIVE appear unmanageable with the framework of a Complex Sentence Hypothesis. Such a hypothesis means positing 
The deep structure for this sentence would be as follows:

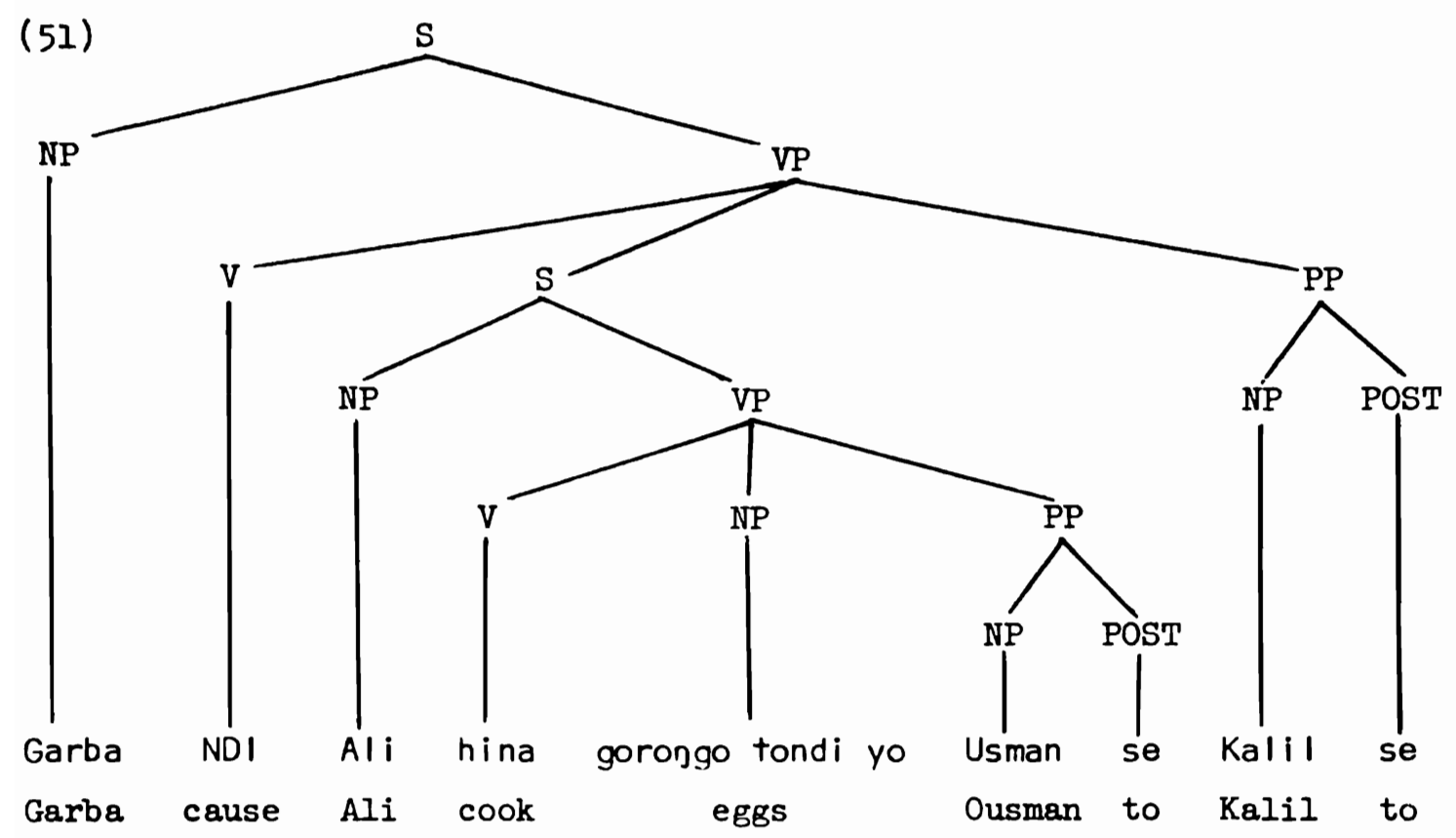

There is no gramatical output for such a deep structure, e.g. (52), (53), etc. are ungrammatical:

(52) *Garba hinandi gorongo tondi yo Ali se Usman se Kalil se Garba cause-to-cook chicken stone pl. Ali to Ousman to Kalil to 'Garba had Ali cook eggs for Ousman for Kalil'

*Garba hinandi Ali gorongo tondi yo Usman se Kalil se Garba cause-to-cook Ali chicken stone pl. Ousman to Kalil to 'Garba had Ali cook eggs for Ousman for Kalil'

A blocking transformation designed just to block deep structures such as (51) would be needed, or else a principle of semantic interpretation. The problem with the latter is that more than one se can occur in complex sentences in Sonrai. It is only in simplex sentences that only one se and only one benefactive is allowed. We would be left with the principle that surface structure simplexes can have only one se and only one benefactive and need a principled way of incorporating that in our grammar in order to block sentences like (52) and (53).

The general situation for [NP se] phrases is that they can occur in the environment [V NP_ ] or [V NP NP__] and in those environments only; 
cause to eat', numeyndi 'to cause to wash' and dumbundi 'to cause to sever'. Others cannot, e.g. hinandi 'to cause to cook', neerendi 'to cause to sell', kufalndi 'to cause to lock up'. Such idiosyncracy can be accounted for only in lexical entries for the IC verbs themselves.

The final argument against the Complex Sentence Hypothesis concerns verbs of the form [STEM+NDI]+NDI, where the inside -NDI is usually a DC suffix, sometimes an IC suffix, but never a passive suffix; the outside -NDI can be a passive suffix or an IC suffix, never a DC suffix:

(55) [STEM+NDI]+NDI: [DC or IC] + PASSIVE

Tasu di nandindi Musa se (Ambiguous)

rice the ... Mousa to

Passive of DC: 'The rice was fed to Mousa (by someone)'

Passive of IC: 'The rice was caused to be the object of Mousa's eating (by someone)'

(56) [STEM+NDI]+NDI: [DC, perhaps IC ]+IC

Garba nandindi tasu di Musa se (Ambiguous)

Garba ... rice the Mousa to

IC of DC: 'Garba had someone feed the rice to Mousa'

IC of IC: ''Garba had someone have Ali eat the rice'

Sentences like these can and do occur, although Sonrai speakers do their best to avoid them. 10 They seem awkward, not because of their meaning, but because of their form, about as awkward as two -ing

${ }^{10} \mathrm{~A}$ nice example of a natural use of double -ndi was supplied to us by Susan Higgins:

(i) A go sendu boro ma berndindi ka

it's hard person SUBJUNCTIVE be honored CONJ

kaynandindi han fo

be reprimanded day one

'It is hard to be congratulated and reprimanded both on the same day.'

Berndindi is the pessive of berndi 'to honor', which is the DC of beri 'to be big'; kaynandindi is the passive of 'to reprimand, to insult' kaynandi, which comes from kayna 'to be small'. 
two sentences each having a main verb with its own lexical entry. The lexical entry for the matrix verb, the hypothetical NDI 'to cause' can be anything we want to make it since it is an abstraction created only for the purpose of deriving STEM+NDI IC verbs, but the lexical entry for the stem verb, the one in the embedded sentence, would have to account for what we know about the use of that verb in all contexts. What we have shown is that when we allow the full generation of sentences in embedded sentence allowed by the lexical entry for the stem verb we get deep structures that require transformational machinery to filter bad co-occurrences out and rearrange constituents in poorly motivated ways.

By using transformations to account for the possible co-occurrence of grammatical relations with the verb stems, we would be violating the theoretical criterion we have posited as checks on the power of transformations. We would be allowing transformations in effect to change the value of verbs as propositional heads.

If on the other hand we treat the co-occurrence restrictions after STEM+NDI IC verbs as applying within a simplex sentence in deep structure with a single lexical entry for one main verb, the situation becomes much more manageable.

There are several aspects in which IC verbs are idiosyncratic and the idiosyncracies themselves mitigate against the Complex Sentence Hypothesis. First, there are idiosyncracies concerning which stems can and cannot take -ndi to form IC verbs, e.g. koosu 'to slaughter' is related to koosundi 'cause to slaughter', but wi 'kill' has no corresponding IC verb *windi ('to cause to kill'); similarly, dumbu 'to sever' is related to dumbundi 'to cause to sever', but kayrey 'to shatter' has no corresponding IC verb, *kayreyndi ('to cause to shatter').

Another idiosyncracy is the syntactic co-occurrence restrictions on IC verbs; there are differences that cannot be explained by reference to lexical entries of the stems. It appears rather that syntactic cooccurrence restrictions are a property of the IC verbs themselves. We will cite one instance here. Some IC verbs can be used intransitivelyelliptically, with their objects understood. For example, gandi 'to 
we have ordered morphological processes, with causative formation and passive formation strictly ordered, although WS conditions can make comparable generalizations; in case passives were proved to be lexical, it would be even more implausible to consider causatives as products of syntactic transformations. 11

We conclude by saying the IC verbs, like DC verbs, are lexical items, produced by lexical rules. The deep structure configuration for sentences such as (4I) with hinandi 'to cause to cook' is the same as that for (5) with neere 'to sell', i.e. with the simplex sentence in (58) below representing the deep structure for 'Garba had Ali cook eggs' :

(58)

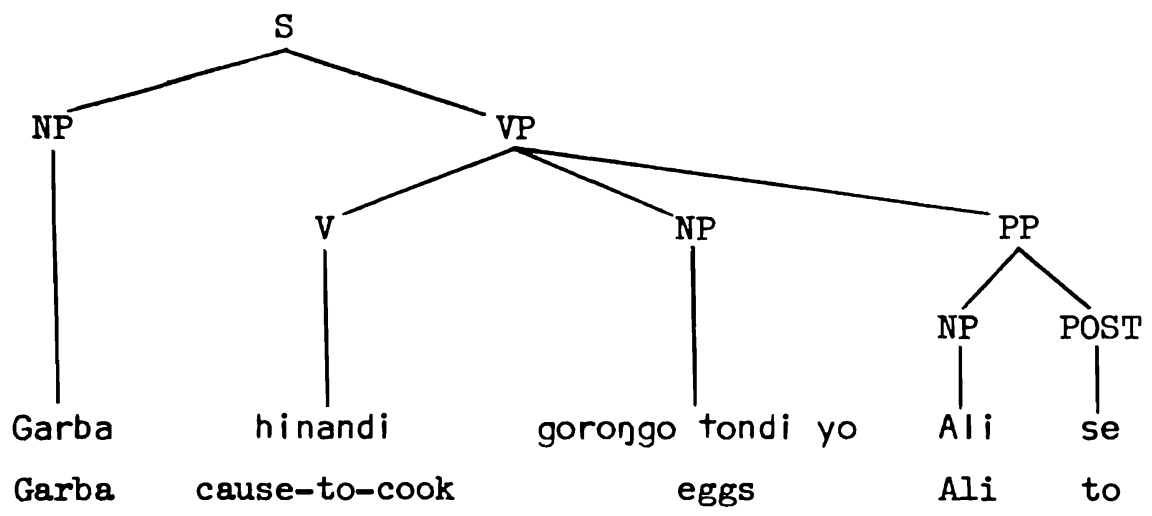

The simplex sentence in (59) will then represent the deep structure for 'Ali sold the pot to Mousa':

(59)

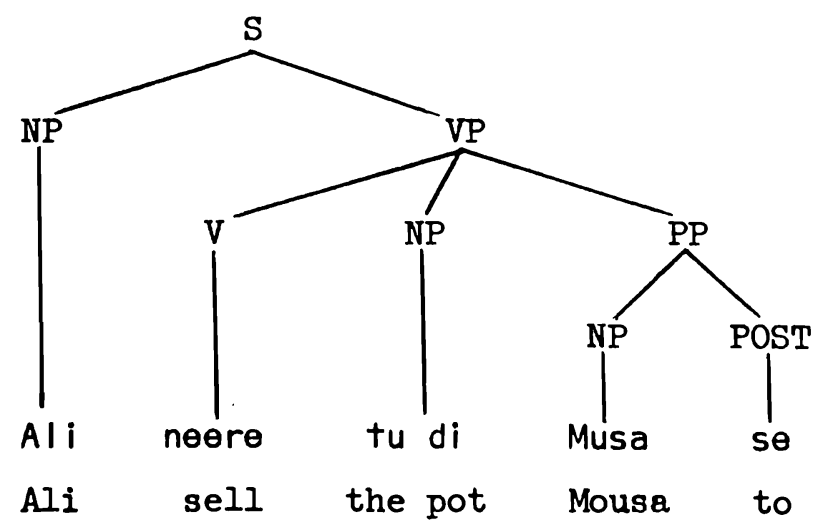

${ }^{11}$ Fred Householder informs us that in Turkish, too, where passive and causative verbs are formed by suffixation, the causative suffix can never follow the passive, only be followed by it; moreover, Turkish can have two causative suffixes in a row followed by a passive, just as in Sonrai, e.g. (57). 
suffixes in a row in an English sentence like "I began stopping working at 7 o'clock." Even three -ndi suffixes seem marginally acceptable, e.g.

(57)

$[[$ STEM+NDI ]+NDI ]+NDI: $[[D C]+I C]+$ PASSIVE

Tasu di nandindindi Musa se

rice the be-caused-to-be-the-object-of-feeding Mousa to

'The rice was caused to be the object of (someone's) feeding to Mousa (by someone)'

What is crucial in the instances with more than one -ndi is that there are no cases where - ndi is added to a passive form. In the Complex Sentence Hypothesis it would, after the first cycle, be possible to have a sentence such as (4) as the embedded clause under NDI 'to cause' as main verb, that is the passive 'The rice was eaten'. Then a sentence of the form of (56) ought to allow an interpretation appropriate for the causative of a passive 'Garba had the rice eaten by $A l i$ ' or 'Garba had the rice eaten for Ali'. But such an interpretation is not possible. Some third person is understood as the one who feeds Ali, or the one who causes $\mathrm{Ali}$ to eat, an interpretation possible only when there is a double causative construction.

Whatever the status of the passive is, this is strong evidence against the Complex Sentence Hypothesis. We assume that -ndi is added by a process of suffixation, i.e. at the end. If the passive is formed by a syntactic transformation, the hypothetical embedding rule for causative formation would have to be constrained by a very unnatural condition, i.e. the rule will not apply if passive has applied on the lower cycle. If the passive is formed by syntactic transformation and sentences like (43) and (45) are simplexes in deep structure, then the data receives the most natural explanation: passive can be involved in multiple -ndi verbs only when it adds the last -ndi to the verb. The penultimate -ndi or the ante-penultimate one can only be causative, since causatives are formed in the lexicon before lexical insertion, and before syntactic transformations begin. If the passive is formed lexically as well, then we might have evidence for saying that 
transformationally: they pass the two tests that we have described. Passivization does not change node labels and it does not change the value of lexical items as propositional heads.

The passive could be characterized as an elliptical variant of the active. For every passive of the form $\left[\mathrm{NP}_{2} \mathrm{~V}+\mathrm{ndi}\right]$ there is always a corresponding active of the form $\left[\mathrm{NP}_{1} \mathrm{~V} \mathrm{NP}_{2}\right]$. The passive has the same meaning as the active except that there can be no $\mathrm{NP}_{1}$ expressed; however, whatever semantic function would be associated with $\mathrm{NP}_{1}$ in the corresponding active sentence is understood in the passive sentence. Consider the following paradigm of examples with ba 'to break'. A similar paradigm could be presented for any of the object middle verbs cited in

(23). ACTIVE sentences are:

(61) Garba ba feneter di $\mathrm{NP}_{1} \mathrm{~V} \mathrm{NP}_{2}$

Garba break window the

'Garba broke the window'

(62) Garba ba feneter di nda tondi di Garba break window the and stone the $\mathrm{NP}_{1} \quad \mathrm{~V}_{2} \quad \mathrm{nda} \quad \mathrm{NP}_{3}$

'Garba broke the window with the stone

(63) Tondi di ba feneter di $\mathrm{NP}_{3} \mathrm{~V} \mathrm{NP} 2$ stone the break window the 'The stone broke the window'

(64) *Tondi di ba feneter di nda tu di stone the break window the and pot the *NP $3 \mathrm{VNP}_{2}$ nda $\mathrm{NP}_{3}$ (only one INSTRUMENT *'The stone broke the window with the pot' per sentence)

(65) Feneter di ba window the break

'The window broke'

while PASSIVE ones are:

(66) Feneter di bandi (Ambiguous) $\quad \mathrm{NP}_{2} \mathrm{~V}+n d i$ window the be-broken

'The window was broken (by someone or by something); NB: (66) corresponds to $(64)$ or (63) in its semantic functions, and not to $(65)$. 
The difference in semantic interpretation as far as gramatical relations is concerned is accounted for by the lexical entries for the main verbs :

\begin{tabular}{|c|c|c|c|c|c|c|c|}
\hline$(60) \quad(a)$ & (b) & & (c) & & (d) & -. & \\
\hline neere & $+V$ & {$\left[\begin{array}{c}\mathrm{NP} \\
\alpha\end{array}\right.$} & $\begin{array}{cc}N P & N P \\
B & \gamma\end{array}$ & se ] [ AGENT & $\begin{array}{cc}\text { THEME } & \text { GOAL] } \\
\beta & Y\end{array}$ & & \\
\hline [hina] +ndi & $+V$ & {$\left[\begin{array}{c}\mathrm{NP} \\
\alpha\end{array}\right.$} & $\begin{array}{cc}N P & N P \\
B & \gamma\end{array}$ & $\begin{array}{c}\text { se }][\text { AGENT } \\
\alpha\end{array}$ & 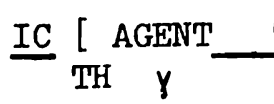 & $=\underset{B}{\text { THEME ] TH }}$ & $\begin{array}{c}\text { GOAL] } \\
\gamma\end{array}$ \\
\hline
\end{tabular}

For the IC verb hinandi 'to cause to cook', there is abstract motion of the THEME (TH) of the main clause to the GOAL (Ali in 58); this THEME is itself the proposition governed by the STEM verb.

\section{Passives in Sonrai}

It is not an open and shut case that passives should be derived by syntactic transformations. It is of course possible to provide algorithms for generating passives by either syntactic transformation or lexical transformation; what is important is the justification for the choice.

We will once again approach the question by asking what syntactic transformations should not be allowed to do, given a commitment to a deep structure level where lexical insertion takes place. The strongest universal claim that could be derived from the work of Chomsky [1968] and Jackendoff [1969] on the lexicalist versus transformationalist hypotheses is that transformations should not be allowed to change node labels. For English, Chomsky gave arguments against allowing transformations to change verbs into nouns and Jackendoff gave arguments against allowing transformations to change adjectives into adverbs. But none of the processes we have been discussing would violate that constraint, i.e. neither DC formation, nor IC formation nor Passive formation change node labels; we are dealing with verb-to-verb derivation mules.

We have proposed a still stronger claim: transformations should not be allowed to change the value of lexical items as propositional heads. This is a principle that will apply whether or not a derivational process changes node labels. We have shown why this principle is of central importance to grammatical theory, and have proceeded to apply it to the causative data to argue that causatives cannot be derived transformationally. Passives, in contrast to the causatives, however, could be derived 
As a description of a natural disaster, this sentence is not paraphrasable by either of the following two:

(69) Boro fo kukur subu di kul

someone burn grass the all

'Someone burned all the grass'

(70) Haya fo kukur subu di kul

something burn grass the all

'Something burned all the grass'

It is equally important, on the other hand, to keep in mind that sentence (55) is not paraphrasable by the following active intransitive sentence :

(71) Subu di kul kukur grass the all burn

'All the grass burned'

In this last sentence the burning is understood to be a spontaneous event, cf. (65), whereas in (68) the semantic function AGENT or INSTRUMENT is understood as the direct cause of the event. But if having a deleted by someone or by something in English is dubious, it is even more so in Sonrai. In English it would be a case of partial neutralization; in Sonrai it would be a case of absolute neutralization; the AGENT or INSTRUMENT corresponding to deep structure subject position are never expressed in passives. The Sonrai data lends theoretical support to the treatment of agentless passives in Chomsky [1965] and Fmonds [1969] in which no lexical material is inserted for the deep structure subjects of agentless passives. Following Chomsky and Emonds in this respect, we could propose (72) as the deep structure for (68), (73) as the rule that creates passives, and (74) as the output, i.e. where the triangle symbol means 'lexically empty'. This analysis follows closely that of Emonds [1969] for agentless passives in English: 12

${ }^{12}$ In our formulation, were we to adopt a theory that required empty phrase nodes as receptacles for the contents of full ones to be moved 
window the be-broken and stone the

'The window was broken (by someone) with a stone' (cf. (62))

With verbs like na 'to eat', nin 'to drink', mow 'to hear', guna 'to see', hay 'to give birth to', jow 'to take', lenje 'to carry', kar 'to beat', garey 'to chase away', verbs which take only animate subjects in the active voice, an animate being is understood though not expressed in the passive. With cow 'to learn' and warra 'to throw', which take only human subjects in the active voice, there is always a person understood but not expressed in the passive. Thus one of the main arguments in support of the passive in Chomsky [1957], the one concerning selectional restrictions, applies to Sonrai as well, with the interesting twist that we are talking about a part of the meaning which is always understood in active-passive sentence pairs, but which is syntactically manifested only in the active.

The above evidence shows that grammatical relations and selectional restrictions in passives are identical to those in a subset of the possible active sentences in which the same verb occurs. That subset of active sentences is definable syntactically: those sentences that have NPs in object position. This makes it appear quite plausible that passive formation takes place after deep structure and after lexical insertion.

How the passive is best defined in Sonrai is an interesting problem in itself. Recall that in Katz-Postal [1964] agentless passives are generated with an underlying someone or something in deep structure subject position which is deleted after being moved into the by phrase. But this is a dubious procedure even for English: 'Germany was defeated' (from [Emonds 1969]) is certainly not paraphrasable by either 'Germany was defeated by someone', or 'Germany was defeated by something'. Similar sentences exist in Sonrai, e.g. from kukur 'to burn' (an object middle verb like ba 'to break'):

(68) Subu di kul kukurndi

grass the all be-burned

'All the grass was burned' 


$$
\begin{array}{lllllll}
\mathrm{x}, & {\left[\begin{array}{lll}
\mathrm{N} \\
1
\end{array}\right.} & \mathrm{NP} & \mathrm{NP} & \mathrm{x}, \mathrm{v}, \mathrm{NP}, \mathrm{x} \\
3 & 4 & 5 & 6 \Rightarrow 1, \emptyset, 5,3, \mathrm{v}>4+\mathrm{ndi}, 6
\end{array}
$$

Condition: 2 and 5 are clause mates

The application of (73) to the deep structure (72) will then result in: (74)

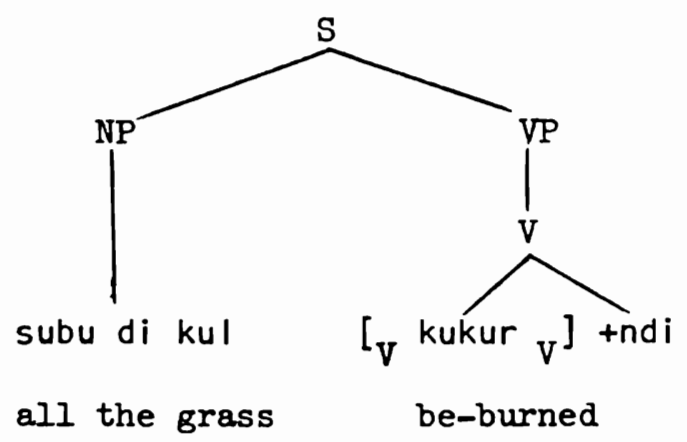

The semantic interpretation for (68) can be accounted for by the theory of grammatical relations that we have proposed. Gramatical relations are read from the lexical entries for propositional heads, on deep structure trees. Below is the lexical entry for kukur 'to burn'. Either line $(i)$ or $(i i)$ could be selected for the semantic interpretation since the semantic configuration corresponds to transitive configuration, cf. deep structure (72):
(75)
(a) (b)
(c)
(d)
(e)

(i) kukur, $+\mathrm{V},[\mathrm{NP}$ NP (nda NP)] [AGENT THEME( INSTRUMENT) ], change of

$\left[\mathrm{NP} \_\mathrm{NP}\right]$
[ INSTRUMENT THEME ] state...

Since deep structure (72) has a configuration corresponding to lines (i) and (ii) of the lexical entry for kukur one of the two templates from those two lines must be imposed for semantic interpretation, and thus either AGENT or INSTRUMENT must be interpreted, even though there is no syntactic manifestation of it on the surface.

This analysis, to make an analogy to work in phonology by Kisseberth, makes the passive look like part of a syntactic conspiracy to insure having a subject for sentences in surface structures. In current theory it would be possible to claim that the subject NP is the one obligatory NP node generated by the PS rules. An empty NP node with no lexical 
(72)

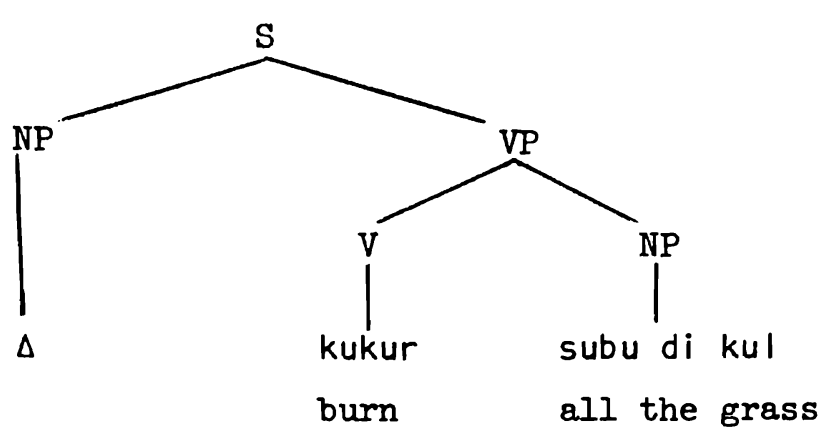

one could then describe object raising in Sonrai as:

into, we still would not need to leave empty nodes behind after movement transformations have applied. In the preliminary version of Chapters I and II of his thesis, Emonds needs the device of empty nodes left behind after a movement transformation for his formulation of the full English passive and the process of there insertion, but we have no comparable cases in Sonrai. Emonds has stipulated that empty nodes can be deleted in surface structure provided that they have been filled at some point during the derivation. But this formalism, part of a system designed to constrain the power of transformations, will in fact allow power in transformational grammars which probably no one would want to say within the domain of natural language. A reductio ad absurdum involves a hypothetical transformational process not very different from the Complex Sentence Hypothesis we have tried to argue against for Sonrai indirect causatives: imagine a deep structure complex sentence with nested embeddings 500 clauses deep where only the last clause down is lexically filled; then imagine a transformation that moves all lexical material from a subordinate clause into its matrix; this transformation operates cyclically empty phrase nodes as it goes; on the first cycle the 500th clause is emptied of lexical material and all the phrase nodes of the 499th clause are properly filled, the 500th clause remains a set of empty phrase nodes, and so on, on up the tree. After the last cycle the topmost clause is lexically filled and the 499 other clauses are nothing but empty phrase nodes. All the empty phrase nodes can be deleted because they have been filled at some point in the derivation; what happens to the $S$ nodes is not clear to us (they are called phrase nodes too), but it would not be inconsistent for them to be deleted too. So in the end only a simplex sentence would be left. All sentences could have infinite structural ambiguity with this grammar: the sentence in question could have had 501 clauses instead of 500 , etc. As an alternative to Emonds' formalism, we are working on a structurepreserving constraint based on lexical entries for propositional heads (cf. Shopen [forthcoming]). 
Kalil ka farikoy

$\begin{array}{lll}\mathrm{NP}_{1} & \mathrm{~V} & \mathrm{NP}_{2}\end{array}$

Kalil became farmer

'Kalil became a farmer'

\section{(78) Farikoy kandi}

$\mathrm{NP}_{2} \quad \mathrm{~V}+$ ndi

farmer be-became

'A farmer was become'

Even if it were established that passivization changed meaning, perhaps that the -ndi added to verbs to form passives carried meaning with it, it could still be argued that passive is a legitimate transformation, since it does not violate either of the criteria that we have suggested: it does not change node labels, and, although it changes meaning, it doesn't change the part of meaning which concerns the function of lexical entries as propositional heads--it does not change grammatical relations.

We cannot end our discussion without pointing out what could be gained if passives were derived lexically. Let us point out first that not so much would be lost as one might think.

True, adding passive forms to the lexicon increases the number of lexical entries. But we have already shown that on independent grounds there is a need for word structure conditions concerning grammatical relations in order to account for systematic aspects of linguistic competence, cf. our discussion of WS conditions to account for the systematic relation between causative and non-causative verbs. A Passive WS condition could show the systematic relation between active and passive verb forms. A paradoxical situation exists here with respect to cost to the grammar: the more productive passive-formation is, the more material would be added to the lexicon, but at the same time the more generality and the more importance a Passive WS condition would have. Although passive-formation is very productive it is also very simple and regular in its form-meaning relation to active sentence formation. Thus, we could say that the language learner learns passiveformation largely in terms of the Passive WS condition, and the long list of items added to the lexicon would seem to have very little cost. 
material would have no value in surface structure, since there would be no way to give it a phonological interpretation. If subjects are obligatory elements in surface stmucture sentences of most kinds, they have to be lexically filled. The creation of passives helps bring this about. The existence of empty nodes in deep structure could be claimed to have independent motivation for just such a construction as the Sonrai passive, since it supplies the appropriate configuration for deep structure semantic interpretation.

While we are much in agreement with Emonds' proposal for a structure preserving constraint on transformations in its general conception, we find no need for the device of empty nodes. The lexical entries for propositional heads already carry sufficient information about ideal tree structure to themselves apply the structure-preserving constraint. There is no space here to discuss the alternate approach in detail, (cf. Shopen [forthcoming]), but we feel that a better transformational solution to the Sonrai passive would involve the generation of an elliptical deep structure tree, i.e. with no subject. The lexical entry for the propositional head would allow for semantic interpretation of the elliptical structure supplying the semantic function for the missing NP. The same lexical entry would allow the object Raising transformation to apply moving object NP into subject position, since the lexical entry for all verbs allows subject NPs. Thus, alternatively, the deep structure for (68) will be given not as (72), but rather as:

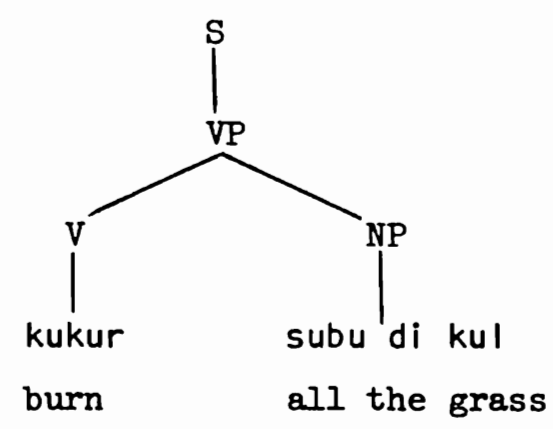

It appears that the passive transformation changes meaning. One evidence of this is that there is something semantically incompatible about the passive and the meaning of certain verbs that occur in the context [NP_NP] in the active voice, cf. English: 
heads never govern meaning or co-occurrence restrictions beyond the simplex sentence; indeed, they can govern less than the simplex $S$, as when sentence adverbs are involved, or when the propositional head is the head noun of an NP in a simplex and not the head of the $S$ as a whole. In stating the passive transformationally it is necessary to constrain it to simplexes, but no WS condition of the kind we are discussing can have a scope greater than the simplex S, so no such constraint need ever be stated.

Talmy Givón has pointed out to us that it is doubtful that any syntactic transformation must be ordered before the passive in any language. This is the case for Sonrai: as far as we know, there is no syntactic transformation that precedes the passive. Thus, we have also argued against a Sonrai Dative Shift transformation (see Section 6), which, if it existed, would have to be ordered before the passive. This doesn't in itself provide a proof of the location of the passive rule in the grammar, but it does leave the way open for putting it in the lexicon.

Passives are not strictly regular from a syntactic point of view, e.g. (77) and (78), and the idiosyncracies could be more easily captured with a lexical analysis.

A major benefit from a lexical analysis of passives is that a major class of expressions could be generated in a much less complicated fashion: infinitives. Infinitives on surface structure are typically subjectless clauses preceded by a subordinating conjunction; in many languages it is also the case that there are certain auxiliary verb or adverbial elements that cannot occur in infinitives. Infinitives are analyzed as Conjunction $S$ in many cases only because there are passive infinitives and it is believed that there must be a full $s$ for the passive to be derived transformationally. If passives were lexical, however, infinitives could be simply Conjunction VP in deep structure.

All of this gives a perspective of a grammar in which greater importance is given to lexical entries for propositional heads and the transformational machinery is less complicated. Transformations would then be confined to essentially one function: the permutation of words. 
Given that the relation to items already in the lexicon is regular, it seems that the longer the list of items added to the lexicon, the less the cost!

Let us say that an elliptical semantic function is one which is understood though not expressed and that it can be represented as an obligatory part of the semantic template of a propositional head which is not manifested syntactically. Thus, with $(74)$ as the deep structure for (68), 'All the grass was burned', the possible interpretations of the sentence could be accounted for by the following continuation of lexical entry (75) for kukur 'to burn':

(b)

(c)

(d)

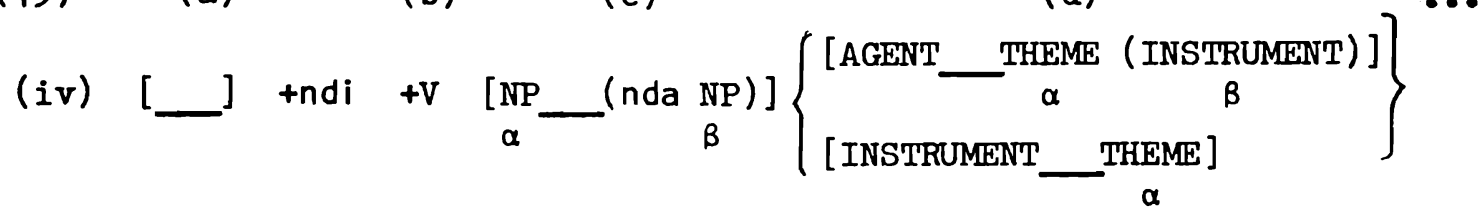

Then WS conditions of the following form would also be appropriate (where $X, Y$ and $Z$ are variable constants): first, the Passive Condition:

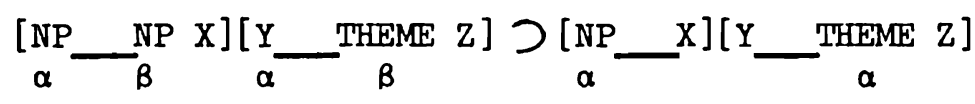

then, a more general condition:

(81) GR Condition (80) つ MF Rule (34)

GR Condition (80) says that if a lexical entry allows insertion in a deep structure environment with an object NP, then it will also allow the passive. Condition $(81)$ says passives have the form V+ndi.

It might be said that $(80)$ and $(81)$ together have the same effect as the passive transformation, that we are proposing WS conditions that give the grammar the same power as transformations, that our theory is a notational variant of generative semantic theory with prelexical transformations. The change in indexing in (80) amounts to a permutation. There is, however, a crucial difference in domain. These conditions concern grammatical relations in lexical entries for propositional heads, and not trees of potentially infinite expansion. The maximum possible domain is the simplex sentence since it can be shown that propositional 


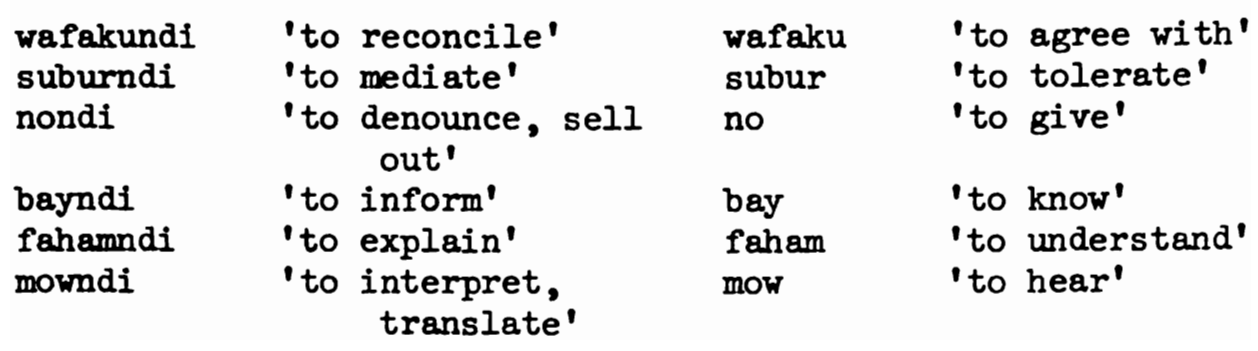




\section{APPENDIX: Direct causative verbs ending in -ndi}

A. From intransitive stems:

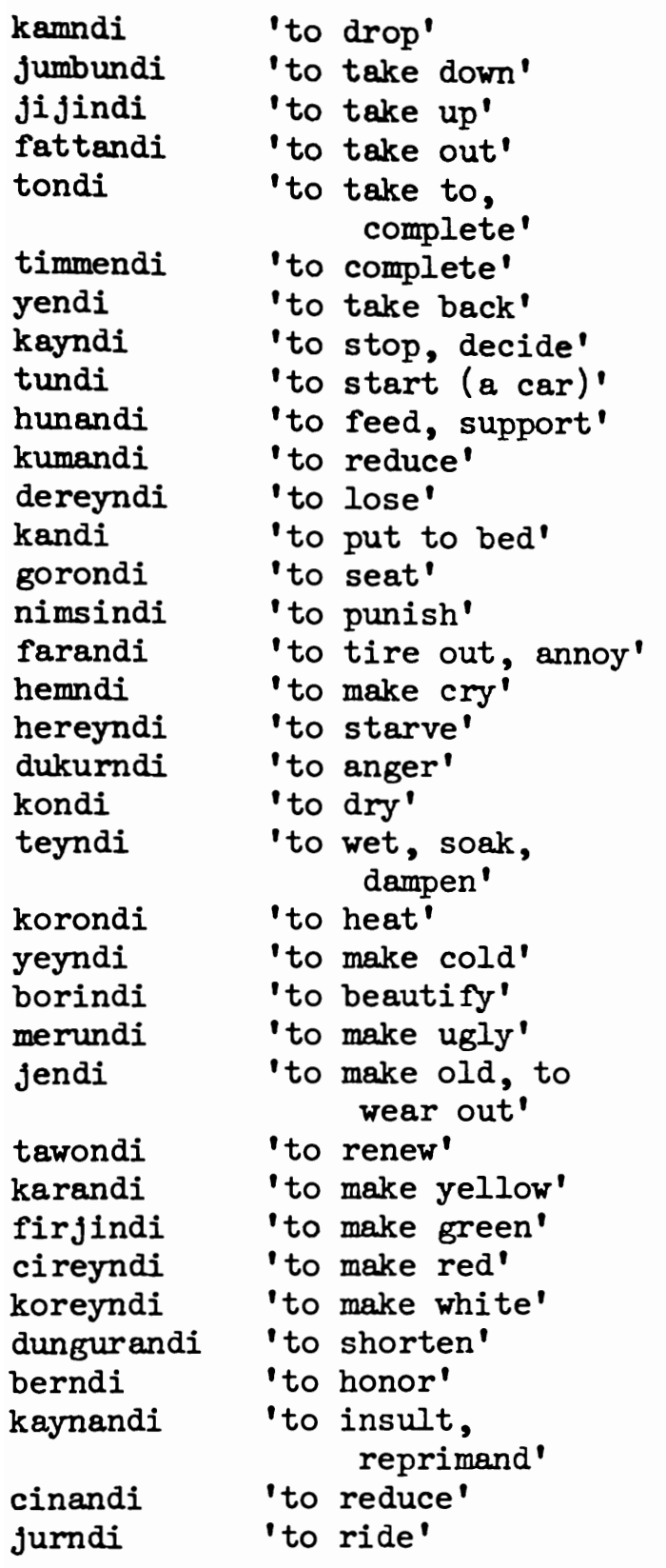

$\begin{array}{ll}\text { kam } & \text { 'to fall' } \\ \text { jumbu } & \text { 'to go down' } \\ \text { jiji } & \text { 'to go up' } \\ \text { fatta } & \text { 'to go out' } \\ \text { to } & \text { 'to arrive' } \\ \text { timme } & \text { 'to be complete' } \\ \text { ye } & \text { 'to go back' } \\ \text { kay } & \text { 'to stop' } \\ \text { tun } & \text { 'to get up' } \\ \text { huna } & \text { 'to live' } \\ \text { kuma } & \text { 'to be lacking' } \\ \text { derey } & \text { 'to get lost' } \\ \text { kani } & \text { 'to lie down' } \\ \text { goro } & \text { 'to sit down' } \\ \text { nimsi } & \text { 'to be regretful' } \\ \text { fara } & \text { 'to get tired' } \\ \text { hem } & \text { 'to cry' } \\ \text { herey } & \text { 'to be hungry' } \\ \text { dukur } & \text { 'to be angry' } \\ \text { ko } & \text { 'to dry' } \\ \text { tey } & \text { 'to be wet' } \\ \text { koron } & \text { 'to be hot' } \\ \text { yey } & \text { 'to be cold' } \\ \text { bori } & \text { 'to be beautiful' } \\ \text { meru } & \text { 'to be ugly' } \\ \text { jen } & \text { 'to be old' } \\ \text { tawo } & \text { 'to be new' } \\ \text { kara } & \text { 'to be yellow' } \\ \text { firji } & \text { 'to be green' } \\ \text { cirey } & \text { 'to be red' } \\ \text { korey } & \text { 'to be white' } \\ \text { dungura } & \text { 'to be short' } \\ \text { beri/ber } & \text { 'to be big' } \\ \text { kayna } & \text { 'to be small' } \\ \text { cina } & \text { 'to run' } \\ \text { jur } & \end{array}$

B. From transitive stems:

$\begin{array}{llll}\text { nandi } & \text { 'to feed' } & \text { na } & \text { 'to eat' } \\ \text { nindi } & \text { 'to feed (liquid)' } & \text { nin } & \text { 'to drink' } \\ \text { hayndi } & \text { 'to empregnate' } & \text { hay } & \text { 'to give birth to' } \\ \text { cowndi } & \text { 'to teach' } & \text { cow } & \text { 'to learn, study, read' }\end{array}$


Gruber, Jeffrey S. 1965. "Studies in lexical relations". Massachusetts Institute of Technology doctoral dissertation. Reproduced by the Indiana University Linguistics Club.

Hall, Barbara C. 1965. "Subject and object in modern English". Massachusetts Institute of Technology doctoral dissertation.

Katz, Jerrold J., and Paul M. Postal. 1964. An integrated theory of linguistic descriptions. MIT Research Monograph 26. Cambridge: MIT Press.

Lakoff, George. 1965. On the nature of syntactic irregularity. Mathematical Linguistics and Automatic Translation, Report SF-16. Aiken Computational Laboratory of Harvard University.

Prost, R. P. A. 1956. La langue Sonay et ses dialectes. Mémoires de l'Institute Français d'Afrique Noire, 47. Dakar: IFAN.

Shopen, Tim. Forthcoming. "A generative account of ellipsis".

Stanley, Richard. 1967.. "Redundancy rules in phonology". Language 43:393-436. 
REFERENCES

Chomsky, Noam. 1957. Syntactic structures. The Hague: Mouton.

Chomsky, Noam. 1965. Aspects of the theory of syntax. Cambridge: MIT Press.

Chomsky, Noam. 1968. "Remarks on nominalization". Reproduced by the Indiana University Linguistics Club. Forthcoming in Readings in English transformational grammar. Edited by Roderick A. Jacobs and Peter A. Rosenbaum. Waltham: Blaisdell.

Chomsky, Noam. 1969. "Deep structure, surface structure, and semantic interpretation". Reproduced by the Indiana University Linguistics Club. Forthcoming in Studies in general and Oriental linguistics: Commemorative volume for Dr. Shiro Hattori. Edited by Jakobson and Kawamote. Tokyo: TEC Corporation. Also forthcoming in Semantics: An interdisciplinary reader in philosophy, linguistics, anthropology, and psychology. Edited by Danny D. Steinberg and Leon Jakobovits. London: Cambridge University Press.

Emonds, Joseph. 1969. "Constraints on transformations". Preliminary draft of chapters 1 and 2 of Massachusetts Institute of Technology doctoral dissertation. Reproduced by the Indiana University Linguistics Club.

Fillmore, Charles J. 1966. "Toward a modern theory of case", Project on Linguistic Analysis Report 13:1-24. The Ohio State University Research Foundation. Reprinted 1969, with slight revision, in Modern studies in English: Readings in transformational grammar. Edited by David A. Reibel and Sanford A. Schane, pp. 361-75. Englewood Cliffs: Prentice-Hall, Inc。

Fillmore, Charles J. 1968. "The case for case", in Universals in linguistic theory. Edited by Emmon Bach and Robert T. Harms, pp. 1-88. New York: Holt, Rinehart and Winston。

Ireenberg, Joseph $\mathrm{H}$. 1963a. The languages of Africa, Part 2 of International Journal of American Linguistics 29.1. Also published as Publication 25 of the Indiana University Research Center in Anthropology, Folklore, and Linguistics. Bloomington: Indiana University; The Hague: Mouton。

ireenberg, Joseph H. 1963b. "Some universals of gramar with particular reference to the order of meaningful elements", in Universals of language. Edited by Joseph H. Greenberg, pp. 58-90。 Cambridge: MIT Press。 